NBER WORKING PAPER SERIES

\title{
SIMULATING ENDOGENOUS GLOBAL AUTOMATION
}

\author{
Seth G. Benzell \\ Laurence J. Kotlikoff \\ Guillermo LaGarda \\ Victor Yifan Ye \\ Working Paper 29220 \\ http://www.nber.org/papers/w29220 \\ NATIONAL BUREAU OF ECONOMIC RESEARCH \\ 1050 Massachusetts Avenue \\ Cambridge, MA 02138 \\ September 2021
}

We thank the Alfred P. Sloan Foundation, the Gaidar Institute, and Boston University for research support. We also thank Daniel Rock, Pascual Restrepo, and Sarah Bana for very helpful comments and providing key data. Andrey Zubarev, Kristina Nesterova, and Rodrigo Razo provided crucial analytical assistance. And we thank Ulrich Muller, James Stock, and Mark Watson for providing critical region-specific productivity-growth estimates. The views expressed herein are those of the authors and do not necessarily reflect the views of the National Bureau of Economic Research or the Inter-American Development Bank.

NBER working papers are circulated for discussion and comment purposes. They have not been peer-reviewed or been subject to the review by the NBER Board of Directors that accompanies official NBER publications.

(C) 2021 by Seth G. Benzell, Laurence J. Kotlikoff, Guillermo LaGarda, and Victor Yifan Ye. All rights reserved. Short sections of text, not to exceed two paragraphs, may be quoted without explicit permission provided that full credit, including $(\odot)$ notice, is given to the source. 
Simulating Endogenous Global Automation

Seth G. Benzell, Laurence J. Kotlikoff, Guillermo LaGarda, and Victor Yifan Ye

NBER Working Paper No. 29220

September 2021

JEL No. E1,E23,F43,O31,O33,O4,O41

\begin{abstract}
This paper develops a 17-region, 3-skill group, overlapping generations, computable general equilibrium model to evaluate the global consequences of automation. Automation, modeled as capital- and high-skill biased technological change, is endogenous with regions adopting new technologies when profitable. Our approach captures and quantifies key macro implications of a range of foundational models of automation. In our baseline scenario, automation has a moderate effect on regional outputs and a small effect on world interest rates. However, it has a major impact on inequality, both wage inequality within regions and per capita GDP inequality across regions. We examine two policy responses to technological change -- mandating use of the advanced technology and providing universal basic income to share gains from automation. The former policy can raise a region's output, but at a welfare cost. The latter policy can transform automation into a win-win for all generations in a region.

Seth G. Benzell

Massachusetts Institute of Technology

Initiative on the Digital Economy

100 Main Street

Cambridge, MA 02142

sbenzell@mit.edu

Laurence J. Kotlikoff

Department of Economics

Boston University

270 Bay State Road

Boston, MA 02215

and NBER

Guillermo LaGarda

Inter-American Development Bank

1300 New York Avenue NW

Washington, DC 20577

and Boston University,

the Global Governance Initiative

culagui@gmail.com

Victor Yifan Ye

Boston University

270 Bay State Road

Boston, MA 02215

victor@yifanye.com
\end{abstract}

kotlikoff@gmail.com 


\section{Introduction}

Advancements in robotics, machine learning, and high-performance computing are revolutionizing production technologies in virtually all industries and altering the distribution of economic rewards, both within and across countries. Cross-country studies record a decline in labor's income share as well an increase in wage inequality associated with reductions in middle-class jobs (Autor, 2015). Karabarbounis and Neiman (2014) report a downward trend in labor's share in over 70 percent of countries with at least 15 years of data. As for the U.S., its labor share fell by 4.3 percentage points between 1980 and 2017. During the same interval, the share of wages of top quintile U.S. workers rose from 48.5 to 59.1 percent (Census, 2019). Acemoglu and Restrepo (2020) and Acemoglu and Restrepo (2019, 2018b) connect these trends to automation and skill-biased technological change.

This paper develops a large-scale computable general equilibrium model of endogenous global automation to study automation's impact on the evolution of economic power and inter- and intraregional inequality. The model lets us predict the economic consequences of different technological scenarios and evaluate policy responses. It quantifies the importance of previously theorized impacts of automation - it's potential to increase income inequality, induce cross-country divergence, raise interest rates, and even reduce output in some regions.

The model features 101 overlapping generations located in 17 regions. These regions, which contain over 150 countries, account for 99 percent of the world's population and 98 percent of the world's GDP. Agents comprise three skill groups - high, middle, and low - that are more or less abundant depending on the region. The model has 464 demographic, fiscal, preference, and technology parameters, each of which is precisely calibrated using UN, IMF, and other macro data as well as micro findings from Acemoglu et al. (2020), Altig et al. (2020), Auerbach et al. (2016).

We examine several scenarios for the endogenous evolution of global technological change. Endogenous references the choice of firms to adopt the latest available, region-specific technology as it emerges. The rate of U.S. innovation is extrapolated from past changes in U.S. factor-shares. Foreign regions' frontiers advance, in our baseline scenario, at the same percentage pace as in the U.S.

In our baseline simulation, the U.S. and other economically advanced regions adopt frontier technologies immediately as they emerge. Other regions adopt later or not at all. Many factors, such as tax policies, demographics, and technological parameters, contribute to this decision by altering factor-price paths. In line with Zeira's (1998a) seminal contribution, countries with higher initial capital shares are more likely to automate, increasing cross-country inequality. Since factor prices are determined in the economy's dynamic general equilibrium, a decision by one region to automate will impact automation decisions in all other regions.

We calibrate initial factor-input shares and population skill-group shares based on IMF (2019a) data on the global distribution of capital and (Alvaredo et al., 2020) data on country-specific income inequality. Our calibration implies important technological differences across regions. For example, in our base year, 2017, the calibrated shares of capital for the U.S. and China are 34.1 and 38.3 percent, respectively. We also calibrate region-specific total factor productivity (TFP) growth to Müller et al. (2019)'s long-term growth projections.

In our baseline simulation, which projects innovations through 2050 consistent with post-1980 U.S. input share shifts, the U.S. overall labor share falls from 65.9 to 63.1 percent. The Chinese overall labor share falls from 61.7 to 59.1 percent. The U.S. high-skilled share rises from 22.0 to 26.4 percent and from 20.6 to 24.8 percent in China. Middle-skilled labor shares remain roughly fixed in both regions. In contrast, the U.S. low-skilled labor share falls from 22.0 to 16.1 percent and the Chinese low-skilled labor shares falls from 20.6 to 15.1 percent. 
Comparing our baseline transition to a future without automation identifies winners and losers. Western Europe, Japan, Canada, the UK, and the U.S. experience the largest percentage increases in GDP. Compared to no-automation, output in 2050 is, respectively, 12.9, 12.7, 12.1, 10.0, and 5.1 percent larger. China defers automating until 2027. Automation makes slow- or non-automating regions, including India, Brazil, and Sub-Saharan Africa, worse off. This reflects the flow of capital from non-automating to automating regions. Mexico, for example, produces 3.6 percent less output in 2050 due to a 9.2 percent decline in the amount of capital that can profitably operate in that region.

We also consider alternate scenarios where access to new technologies is restricted to the U.S., where automation technologies reduce labor input-shares of all skill groups proportionally, and where technological change is more rapid than historical experience. In virtually all cases, automation benefits the U.S. and raises the welfare of middle- and high-skilled American workers. As indicated, relative to no automation, U.S. GDP in 2050 increases by 5.1 percent in our baseline scenario. This figure is 8.3 percent if the new technology is exclusive to the U.S., 6.1 percent if the new technology is not skill-biased, and 11.9 percent if global technological change occurs at twice the historical rate.

As suggested by stylized models (e.g. Benzell et al. 2016; Sachs et al. 2015a; Acemoglu and Restrepo 2018a; Peretto and Seater 2013), automation increases the world interest rate. However, this effect is relatively modest in our model and does not significantly deter countries from automating. Absent automation, the global interest rate falls from 6.0 percent in 2017 to 2.8 in 2050. In our baseline scenario, the 2050 interest rate decreases by less - to 3.2 percent. Two fundamental trends contribute to a global savings glut (Eichengreen, 2015). The first is population aging in developed and many emerging regions that raises global wealth per worker. The second is the high saving rate of Chinese and Indian households coupled with their rising share of world GDP.

Wage inequality increases dramatically in our baseline scenario. In the U.S, for example, the high-skilled wage increases by 28.8 percent between 2017 and 2050. The low-skilled wage falls by 22.8 percent. In 2050, 92.5 percent of the world's high-skilled workers are better off due to automation. But 85.7 percent of low-skilled workers and 71.5 percent of all workers are worse off. In the same year and relative to no-automation, the world's average worker is 0.9 percent worse off in terms of lifetime welfare, measured as a compensating differential.

Our paper's final section considers policy responses. One example is mandating automation in regions that would not otherwise automate. Such 'forced industrialization' policies (see, for example, Preobrazhensky 1926; Erlich 1950) have been pursued historically by the Soviet Union and other countries. In India, but no other region, forced adoption raises output by up to 1.5 percent although it lowers welfare of all low- and middle-skilled Indian generations. There are two sources of India's GDP increase. First, the policy reduces wages, increasing Indians' labor supply. Second, the adoption of the more capital intensive technology leads to capital on-shoring. However, the new technology remains inefficient. If the mandate is rescinded, firms revert to their 2017 technology and inputs revert to their baseline levels.

We also simulate adopting a universal basic income (UBI) per Friedman (1966) to offset automationinduced U.S. wage inequality. A UBI policy costing, depending on the year, 3.9 to 5.1 percent of U.S. GDP can make automation Pareto-improving for all U.S. generations. This transfer equals, in 2020, 23.6 percent of the low-skilled annual wage in 2050. Our policy entails 20 years of debt financing and, subsequently, a 5 to 14 percentage-point increase in average income tax rates depending on the year and skill-level of the worker. This policy leaves low-skilled Americans indifferent between the baseline and no-automation scenarios at a cost of roughly halving the gain to high-skilled workers. Alternative financing schemes, entailing consumption, corporate income, or capital income taxation are either less efficient or rule out a Pareto improvement. 


\section{Background}

Concern with technological change is longstanding. The historical record stretches from Prometheus, who was bound and tortured for giving ancient Greeks fire, to the followers of 'King Ludd,' who were hanged for smashing English textile machines, to Marx (1867), who ardently proclaimed technology's economic threat to the proletariat. To quote Marx,

"Within the capitalist system all methods for raising the social productivity of labour are put into effect at the cost of the individual worker; all means for the development of production undergo a dialectical inversion so that they become means of domination and exploitation of the producers; ...they alienate from him the intellectual potentialities of the labour process in the same proportion as science is incorporated in it as an independent power..."

Marx's views resonated for a reason. As recently documented by (Katz and Margo, 2014), early industrialization redistributed to the elite at the expense of middle-skilled, craft-workers. Keynes (1930) also raised concerns with automation, although he believed automation's cost to workers was transitory.

"We are being afflicted with a new disease of which some readers may not yet have heard the name, but of which they will hear a great deal in the years to come - namely, technological unemployment. This means unemployment due to our discovery of means of economizing the use of labor outrunning the pace at which we can find new uses for labor."

Today, the world faces new concerns about new technologies displacing labor across a wide range of tasks. McAfee and Brynjolfsson (2017) note how advances in machine learning are overcoming Polanyi's Paradox, an alleged critical barrier to automation. Polanyi observed that most human behaviors, such as driving a car or recognizing a face, harness tacit or intuitive knowledge which cannot be expressed mathematically, making it impossible for an expert system to replicate. However, neural networks are overcoming this barrier by training machines how to act in ways that don't require explicit algorithms.

The advance of machine vision technologies is particularly impressive. In the well known 'ImageNet' image-classification contest, the 2012 top performer had a 15 percent error rate. In 2017, the top twenty contestants had less than a 5 percent error rate (Wikipedia contributors, 2021). Estimates of how widely new technologies may impact employment are daunting. Frey and Osborne (2013), in a controversial article, estimate that 47 percent of the U.S. work force is at risk of automation. Recent estimates find that almost all occupations include some tasks conducive to automation (Brynjolfsson et al., 2018b).

These prognostications must be taken seriously given the dramatic shifts in factor shares in recent decades documented by Karabarbounis and Neiman (2014). In their study of 59 countries, they report 42 with declining labor shares. There is strong evidence that the decline in the labor share in developed countries is connected to technological changes. Autor et al. (2020) claims that innovations, especially in information and communication technologies, are making the U.S. economy more 'winner take all' and thereby reducing labor's share. Acemoglu and Restrepo (2020) and Acemoglu et al. (2020) show that robot adoptions by U.S. counties and French firms also led to decreases in labor's income share. Goos et al. (2011) offer supporting evidence for Europe. 


\subsection{Stylized Models of Automation}

Our study builds on a number of stylized macro models of technical change. Zeira (1998b)'s paper considers the introduction of labor-substituting technology, showing that countries with high labor costs and low interest rates will adopt such technology, i.e., automate, more rapidly than others. Countries that adopt grow faster, making automation a potential source of international growth disparities. This force for international inequality plays an important role in our model's baseline scenario.

Zuleta (2008), Peretto and Seater (2013), and Acemoglu and Restrepo (2018c) build on Zeira (1998b). Zuleta (2008) evaluates an economy's decision to invest in automation technology rather than traditional capital. He shows that countries will use either the most or least capital-intensive technology available - never an interior option. Zuleta (2008) further demonstrates that, in the absence of productivity growth, automation is necessary to maintain long-term growth in per capita output. Economies in his model either converge to AK growth, in which output grows at a constant rate, or stop growing on a per capita basis. The reason automation enables long-term per capita growth is that capital per-capita is an elastic factor that can be increased, but labor per-capita is limited in the absence of improvements in workers skills (which plausibly cannot continue indefinitely). The larger labor's input share in the production function, the more this asymptotically scarce factor of production lowers asymptotic output.

Peretto and Seater (2013) more fully develops the micro foundations of Zuleta (2008), showing conditions under which firms will invest in automation technologies under imperfect competition. Acemoglu and Restrepo (2018a) endogenize the choice of technology in which to invest. In their setup, scientists endogenously decide whether to automate existing labor tasks or invent new ones for humans to perform. This decision depends on prevailing factor prices. When wages are high and interest rates are low, it makes more sense to automate. When the opposite holds, scientists invent new jobs to take advantage of the relatively abundant labor. Thus, technological change has a self-correcting mechanism preventing complete automation. However, depending on parameters, the response to automation-inducing shocks can take a very long time to raise wages.

An important point of these papers is that, when profitable, firms will invest to reduce, if not eliminate their dependence on labor. Automation is profitable when capital is abundant and cheap and when labor is scarce and expensive. The result is generally not less aggregate employment, as these models assume that workers are willing to work for lower pay. There is, though, a rise in capital's income share. This explains our choice to model automation as the adoption of technologies that are more capital-intensive and, in our baseline scenario, more high-skilled labor intensive.

Another critical factor in all of these papers is that the interest rate determines whether and to what extent a region gains from automation. The interest rate is, in turn, determined by the rate of saving. In Zeira (1998b) the rate of saving is constant, and in Acemoglu and Restrepo (2018a) the rate of saving is pinned down by a representative agent's Euler condition. Both of these saving rules tend to guarantee automation has positive social effects, because they keep the rate of investment constant (or even increase it) after an increase in automation technology.

Our life cycle model's saving behavior is different. Workers save to finance their retirements whereas retirees dissave, i.e., spend down their accumulated assets. Hence, the path of national saving is a complex function of the path of factor incomes and demographics. Automation may, therefore, lower the total saving rate and have an offsetting negative effect. Benzell et al. (2015b) and Sachs et al. (2015b) illustrate the important interaction of saving and automation. In their models, the adoption of new automation technologies redistributes from young savers to old spenders. This can 
reduce the economy's long-run supply of capital and, potentially, lower long-run output and welfare. In other words, automation can be immiserating.

In our calibrated model, we find this theorized negative effect of automation to be relatively unimportant. While automation does lower wages (which Benzell and Brynjolfsson (2019) shows to be a general, short-run prediction of a broad class of automation models) this effect is not large enough to dramatically redistribute between young savers and old consumers. Indeed automation in our baseline scenario leads to higher levels of capital accumulation over time.

\subsection{Previous Computable General Equilibrium Models}

Our model is, to our knowledge, the first large-scale, multi-region, global OLG model of automation. Dawid (2006) surveys the use, through 2006, of CGE models for understanding technological change, emphasizing the deployment of such models to understand microeconomic and industry level dynamics in R\&D, innovation, spillovers, and firm-size distribution - none of which are directly relate to this investigation. In the years since, there have been a handful of papers simulating technological change, but these have been narrow applications to specific industries such as agriculture (Dietrich et al., 2014) and residential heating (Knobloch et al., 2021). Our model descends from Auerbach and Kotlikoff (1981), Auerbach and Kotlikoff (1983) Judd (1985), Auerbach and Kotlikoff (1987), Fullerton and Rogers (1996), Altig et al. (2001), Auerbach et al. (1989), Fehr et al. (2003), Fehr et al. (2013a), Fehr et al. (2013b), and Benzell et al. (2015a). This is a long literature that expands the original AuerbachKotlikoff model to include demographic change, multiple skill groups, multiple goods, multiple regions, an energy sector, and other key features. Our model's closest antecedent is the Global Gaidar Model (GGM), presented in Benzell et al. (2020) and (Benzell and Lagarda, 2017), which simulates a variety of corporate and business cash-flow tax reform policies. Similar versions of this model have also been used to investigate the impact of fossil fuel rents on fiscal transitions and to simulate long-term U.S. fiscal sustainability (Nelson and Phillips, 2019).

Compared to Benzell et al. (2020), we make four advances. First, we develop an auto-calibration algorithm that accommodates a major increase in the complexity of CGE models. Instead of manually adjusting the model's parameters to match target data, the cost of which grows exponentially with the number of parameters, our approach, described in section 3.3.3, permit rapidly calibrating very large numbers of parameters. Absent this feature, our model would be too complex to calibrate.

Second, we calibrate region-specific production technologies, modeled as Cobb-Douglas functions with region-specific coefficients. We utilize region-specific capital stock data from the IMF Investment and Capital Stock Database (ICSD; IMF 2019a) and adjust the capital-use intensivity of each region's representative firm to match the ratio of capital to GDP in each region. This captures the fact that countries have different mixes of industries and technologies and, therefore, should not be modeled with the same production function.

Third, we use recent U.S. microeconomic data in Auerbach et al. (2016) and Altig et al. (2020) to calibrate our model's initial U.S. age-skill asset distribution, the progressivity of the U.S. tax system, and the skill distribution of U.S. Social Security benefits. We assume the model's other regions have the same initial age/skill asset distribution as the U.S., the U.S. degree of tax progressivity, and the U.S. skill distribution of state pensions.

Fourth, we use micro estimates in Acemoglu et al. (2020) and other assumptions to calibrate factor-specific productivities. These productivities, in turn, tell us how output changes in response to changes in factor shares given factor prices. Determining these productivities is critical to ensure that the analysis of technological change arising from changes in factor shares is invariant to the scaling 
of inputs and outputs. Controlling for scaling is not important in standard analyses of technological change, which involve only changes in TFP.

\section{Model}

Our model has seventeen regions, each with three distinct sectors: a household sector whose agents work, save, and consume, a government, which taxes, transfers, and spends, and a business sector, which hires labor, rents capital and produces a single output that can be consumed or invested. Regions also receive fossil fuel rents that accrue to both private investors and governments. The seventeen regions are listed in table $1 .{ }^{1}$

\begin{tabular}{l|l|l|l}
\hline Acronym & \multicolumn{1}{|c|}{ Region } & Acronym & \multicolumn{1}{|c}{ Region } \\
\hline \hline USA & U.S. & MENA & Middle East and North Africa \\
WEU & Western Europe & MEX & Mexico \\
JKSH & Japan, South Korea, Singapore and Hong Kong & SAF & South Africa \\
CHI & China & SAP & South Asia Pacific excluding Australia \\
IND & India & SLA & Latin America excluding Mexico and Brazil \\
RUS & Russian Federation & SOV & Former Soviet Central Asia \\
BRA & Brazil & SSA & Sub-Saharan Africa excluding South Africa \\
GBR & The U.K. & EEU & Eastern Europe \\
CAN & Canada, Australia and New Zealand & & \\
\hline
\end{tabular}

Table 1: Regions in the model and their acronyms.

\subsection{The Demographic Transition}

The model has 101 overlapping generations of agents of ages 0 to 100 . Children are born with the same skill as their parents and retain that skill for life. There are three skill levels - high, middle, and low. Children receive consumption from their guardians (either parents or grandparents) before entering the workforce. At a region- and skill-group $k$ specific age, $a_{w_{k}}$ between 18 and 21, agents enter the workforce and receive labor income until a region-specific age of retirement, after which they receive pensions. ${ }^{2}$ Agents give birth to fractional children between age 15 and 49. Children of agents who are too young to work (those from age 15 to $a_{w_{k}}-1$ ) are raised by their grandparents. Henceforth, we use the term "guardians" to refer to the parents and grandparents responsible for a given cohort of children and "dependents" to refer to their children and grandchildren. Agents can die at any age through age 100, after which they die with certainty.

The paths of demographics in each region, including year- and age-specific births and deaths are set to match United Nations (UN) projections through 2100. The UN projects births, deaths, and total population by country in every fifth year for five-year age groups. We aggregate these country-specific projections to generate region-specific projections. Next, we smooth the region-specific projections to generate births, deaths, and total population projections of agents in each region at each age in each future year. We calculate annual immigration by age and year to reconcile the smoothed age-

\footnotetext{
${ }^{1} \mathrm{~A}$ list of countries in each region is provided in table A1.

${ }^{2}$ We set the age of entry into the labor force to roughly match the fraction of individuals in a region that receive some college education. Low- and middle-skilled agents of developing and least-developed regions enter the labor force at 18. For the U.S. and other developed regions, all three skill groups enter the labor force at 21. See section 3.2 .3 for a detailed discussion of treatment of pension benefits.
} 


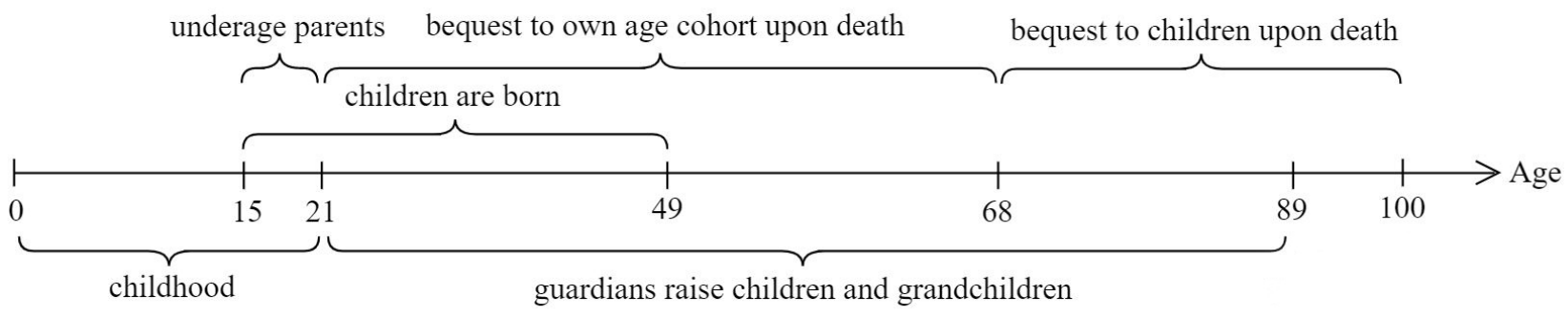

Figure 1: The individual life-cycle

and year-specific UN births and deaths to the smoothed age- and year-specific UN population totals. These age- and year-specific migrant "residuals" can be positive or negative.

There is striking disparity across regions in population trends. China's population is projected to fall from 1.4 billion now to approximately 1 billion by 2100 and, as birth rates stabilize, to 450 million by 2250. Much of the developed world - Europe, Japan and Korea - experience major population declines through the end of the century. Other developed regions age significantly. A total of 21.2 percent of Americans and 23.6 percent of Britons will be older than 70 by 2100, up from 9.0 and 11.6 percent in 2017, respectively. On the other hand, Sub-Saharan Africa and the Middle East grow by nearly 3 billion people by 2100 . This is due to persistently high fertility rates in the region -3.1 births per women in 2050, for example - combined with rapidly declining mortality.

These demographic dynamics have major implications for the adoption of technologies that substitute away from low- and middle-skilled labor. As the developed world ages, the pool of labor shrinks, tending to raise wages. Further, retirees have more assets relative to young workers. Hence, the aging of the world's most wealthy countries also lowers interest rates. Higher wages and lower interest rates caused by the global demographic transition both favor automation in developed regions.

\subsection{Sectors}

\subsubsection{Households}

Households are composed of agents who decide how much to work, save, and consume each year. Agents receive a fixed time endowment, $h$, in each period and maximize lifetime utility given by a nested, time-separable CES utility function. For a working agent of age $a$ in time $t$ and skill-group $k$, dropping regional subscripts, we have

$$
U_{a, t, k}=V_{a, t, k}+H_{a, t, k}
$$

where $U_{a, t, k}$ is the agent's utility, the sum of his or her utility $V_{a, t, k}$ derived from consumption and leisure, and $H_{a, t, k}$, is the utility derived from the consumption of their dependents, including both children and grandchildren of underage parents. The function $V_{a, t, k}$ is given by: 
Figure 2: UN and Model Population Projections
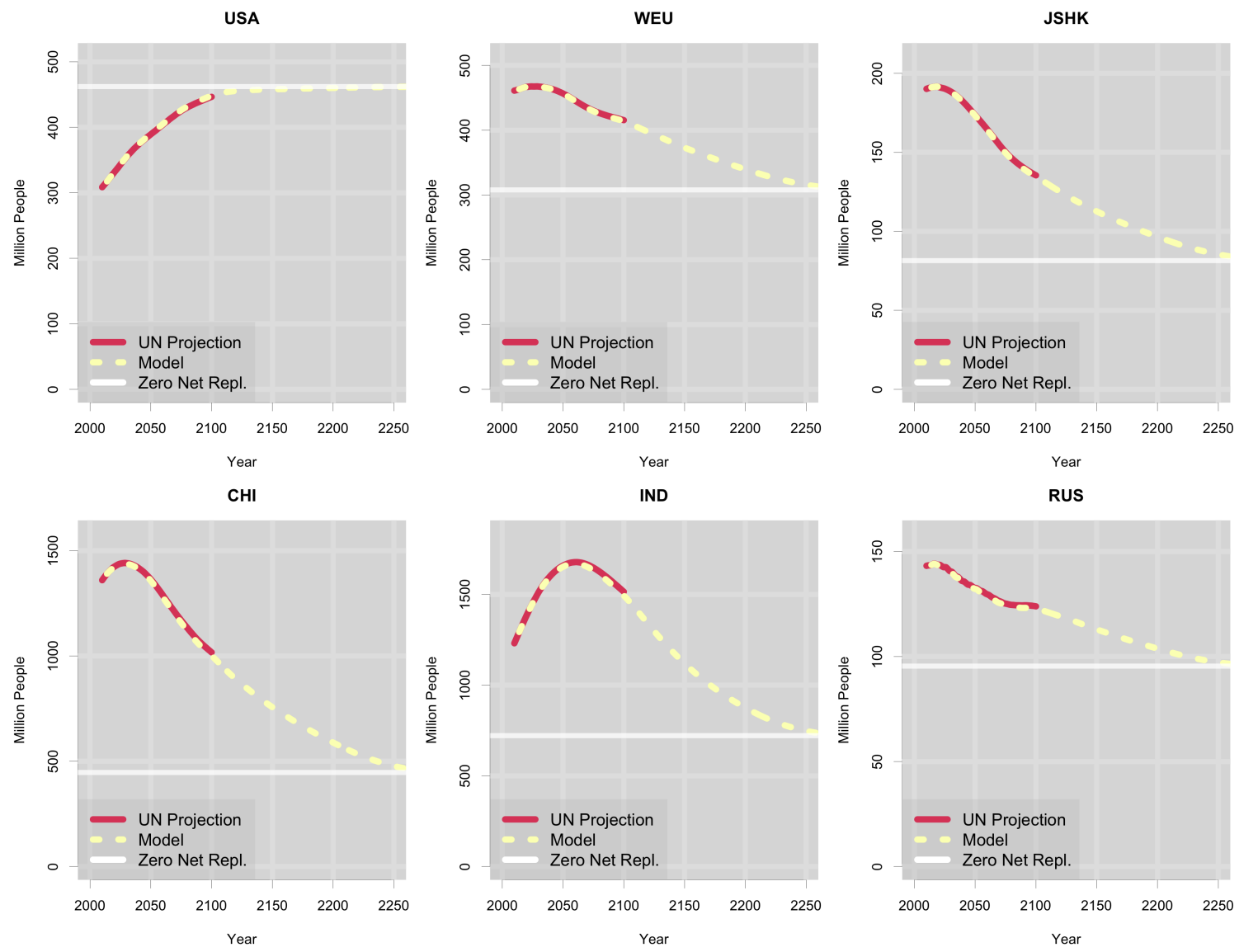

$$
V_{a, t, k}=\frac{1}{1-\frac{1}{\gamma}} \sum_{i=a}^{100}\left(\frac{1}{1+\delta_{t}}\right)^{i-a} P_{a, i, t}\left[c(i, t+i-a, k)^{1-\frac{1}{\rho}}+\varepsilon_{t, k} \ell(i, t+i-a, k)^{1-\frac{1}{\rho}}\right]^{\frac{1-\frac{1}{\gamma}}{1-\frac{1}{\rho}}}
$$

This equation represents discounted CES utility over consumption and leisure over the agent's remaining lifetime. $P_{a, i, t}$ is the probability that an agent of age $a$ at time $t$ survives to age $i$, which is not specific to skill group. $c(i, t+i-a, k)$ is the consumption of an agent of age- $a$, skill-group $k$, at time $t+i-a$, the period when they reach age $i$, and $\ell(i, t+i-a, k)$ is leisure for this group in the same period. The function $H_{a, t, k}$ is given by:

$$
H_{a, t, k}=\frac{1}{1-\frac{1}{\gamma}} \sum_{i=a-a_{w_{k}}}^{a_{w_{k}}-1}\left(\frac{1}{1+\delta_{t}}\right)^{i-a} P_{a, i, t} D_{a, i, t, k} c_{D_{a, i, t, k}}^{1-\frac{1}{\gamma}},
$$

which represents discounted utility over consumption $c_{D_{a, i, t, k}}$ of all of the agent's dependents $D_{a, i, t, k}$. $\delta_{t}$ denotes the time preference rate, which is assumed to be constant across age and skill but varies across regions and with time. $\rho$ and $\gamma$ are, respectively, the intratemporal elasticity of substitution (ELS) between consumption and leisure and the intertemporal ELS of utility over time. Both are 
assumed to be fixed across age-skill groups, regions, and time. $\varepsilon_{t, k}$ is the time- and skill-group specific subjective leisure preference parameter.

Assets of surviving agents evolve according to

$$
A_{a+1, t+1, k}=\left(A_{a, t, k}+I_{a, t, k}\right) R_{t+1}+\left(h-\ell_{a, t, k}\right) w_{a, t, k}-T_{a, t, k}-C_{a, t, k} .
$$

Agents earn a pre-tax rate of return, $R_{t+1}$, on their time- $t$ assets, $A_{a, t, k}$, and on total inheritances received by age- $a$ individuals $I_{a, t, k} . h-\ell_{a, t, k}$ represents the fraction of the fixed time endowment, $h$, spent on labor, and $w_{a, t, k}$ is the pre-tax wage of the sub-scripted agent. $T_{a, t, k}$ references an agent's personal taxes net of pensions and other transfer payments received. And $C_{a, t, k}=c_{a, t, k}+D_{a, t, k} \cdot c_{D_{a, t, k}}$.

The model's bequests arise due to an assumed lack of annuity markets; i.e., they are not intentional. Thus, agents will leave negative bequests if they die with negative assets. Agents give birth and leave bequests exclusively to agents in their own skill cohort. We assume that agents below age 68 bequeath to their spouses, represented as other agents in their own age cohort. Agents at or above 68 bequeath proportionally to all of their adult children. ${ }^{3}$ Note also that while grandparents raise children of their "underage" children, bequests always go to the grandparents' own adult children.

\subsubsection{Production}

Regional gross domestic product is the sum of output from a production sector, $Q_{t}$, and a natural resource endowment flow, $X_{t}$

$$
Y_{t}=Q_{t}+X_{t}
$$

Energy endowments are modeled as an annual flow of the consumption good net of extraction and transportation costs. They accrue, in part, to households as a private asset and, in part, to the government as revenue. We calibrate the size of the flow in each region, the fraction of which accrues to the public sector, and the date of exhaustion based on World Bank (2021) fossil-fuel and IMF (2017) fiscal data.

We define regional gross national income, $N_{t}$, as the sum of GDP and net foreign asset income $r_{t} F_{t}$,

$$
N_{t}=Y_{t}+r_{t} F_{t}
$$

where $r_{t}$ is the global rate of return and $F_{t}$ is net foreign assets.

Production is governed by

$$
Q_{t}=\phi_{t}\left(\varphi_{K} K_{t}\right)^{\alpha_{t}} L_{t, 1}^{\beta_{t, 1}} L_{t, 2}^{\beta_{t, 2}} L_{t, 3}^{\beta_{t, 3}}
$$

where $L_{t, k}=\varphi_{l_{k}} l_{t, k}, k \in(1,2,3)$ are productivity-adjusted labor inputs, $l_{t, k}$ is labor supply of group $k, \varphi_{l_{k}}$ is a skill-group specific labor productivity term, and $\varphi_{K}$ is capital productivity. ${ }^{4}$ Both $K_{t}$ and output are denominated in real 2017 dollars. The term $\phi_{t}$ captures time-varying total factor

\footnotetext{
${ }^{3}$ For example, an agent dying at 68 bequeaths to his or her age and skill cohort's distribution of working children, all of whom are between ages $a_{w_{k}}$ and 53 .

${ }^{4}$ Henceforth we use $k=1$ to represent low-skilled workers, $k=2$ for the middle-skilled, and $k=3$ for the high-skilled.
} 
productivity, the calibration of which is detailed in Appendix section A.

In our no-automation calibration, each skill group earns an equal share of total labor income. I.e.,

$$
\beta_{t, k}=\frac{1-\alpha_{t}}{3}
$$

for $k \in(1,2,3)$. Total labor supply, measured in efficiency units, of skill group $k$ at time $t, l_{t, k}$ satisfies

$$
l_{t, k}=\sum_{a=a_{w_{k}}}^{100}\left(h-\ell_{a, t, k}\right) E_{a, t, k} \cdot N_{a, t, k},
$$

where $N_{a, t, k}$ is the population of skill-group $k$ at age $a$ and time $t . E_{a, t, k}$ is an age- and time-specific productivity profile. This profile is that in Auerbach and Kotlikoff (1987), but modified to allow for different ages of labor force entry. To be precise,

$$
E_{a, t, k}=e^{4.47+0.033\left(a-a_{w_{k}}-1\right)-0.00067\left(a-a_{w_{k}-1}\right)^{2}}(1+\lambda)^{a-a_{w_{k}}} .
$$

We assume that $\lambda=0.01$, i.e. the time-endowment, rises at 1 percent per year. This assumption that the effective time endowment expands through time ensures the global economy will reach a steady state given our CES preferences.

Our perfectly competitive firms hire factors to maximize profits. Thus,

$$
\begin{aligned}
w_{t, k} & =\frac{\beta_{t, k} Q_{t}}{l_{t, k}}, k \in(1,2,3) \\
r_{t} & =\left(1-\tau_{t}^{K}\right)\left(\frac{\alpha_{t} Q_{t}}{K_{t}}-\delta_{K}\right),
\end{aligned}
$$

where $w_{t, k}$ are wages per efficient unit of labor for the respective skill groups, $\tau_{t}^{K}$ is the marginal effective tax rate (METR) on capital, and $\delta_{K}$ is a region-specific depreciation rate.

\subsubsection{Government}

Each region's government (which includes, in our calibration, central, provincial and local governments) collects taxes, borrows, and spends on both consumption and transfer payments. Spending includes direct government purchases of goods and services, $C_{t}^{g}$, a fraction, $\varrho$, of state-pension payments, $e_{t}$, which are not covered by payroll taxes, a variety of transfer payments to the private sector, $f_{t}$, and interest payments $r_{t} B_{t}$ on debt, $B_{t}$.

Government receipts comprise the government's share of energy sector rents, $X_{t}^{g}$, net borrowing, $\Delta B_{t}$, corporate income taxes, $T_{t}^{K}$, and personal taxes collected from each cohort within a given year, $T_{a, t, k}$. The government's flow budget is

$$
\sum_{k=1}^{3} \sum_{a=a_{w_{k}}}^{100} T_{a, t, k} N_{a, t, k}+T_{t}^{k}+X_{t}^{g}+\Delta B_{t}=C_{t}^{g}+\varrho e_{t}+f_{t}+r_{t} B_{t} .
$$


Households face taxes on capital, wage, and total income, as well as consumption. Firms face corporate income taxes. Capital income, corporate income and payroll tax rates are fixed, with the payroll tax financing a fixed fraction of state pensions. In our calibration, governments endogenously set income and consumption tax rates to maintain a constant level of debt-to-GDP, with the level of income tax progressivity fixed through time. ${ }^{5}$ Time- $t$ income tax revenue, $R_{t}$, is given by

$$
R_{t}=\sum_{k=1}^{3} \sum_{a=a_{w_{k}}}^{100}\left(\tau_{t} w_{a, t, k}+\frac{\xi_{t} w_{a, t, k}^{2}}{2}\right) N_{a, t, k},
$$

where $\tau_{t}$ endogenously adjusts to keep regional debt-to-GDP fixed. $\xi_{t}$ is a progressivity term calibrated to the ratio between the U.S. METR of the top 4 percent of households by labor earnings and the U.S. average income tax rate of working households. $w_{a, t, k}=w_{t, k} \cdot E(a, t, k)$ is the age-skill group's wage rate.

Corporate income taxes are assessed on all domestic output net of labor costs and depreciation.

$$
T_{t}^{K}=\tau_{t}^{K}\left(Y_{t}-\sum_{k=1}^{3} \sum_{a=a_{w_{k}}}^{100} w_{a, t, k} l_{a, t, k}-\delta_{K} K_{t}\right),
$$

where $\delta_{K}$ is the depreciation rate.

In each region, the payroll tax finances a fraction of pension payouts, and the remainder, $\varrho$, is financed through the general account. ${ }^{6}$ Payroll taxes are assumed to be proportional up to a regionspecific contribution ceiling, after which the marginal payroll tax rate is zero. ${ }^{7}$

Turning to government expenditures, education and healthcare are treated as a combination of direct government consumption (public schools, government purchases of medical infrastructure and supplies, etc.) and transfer payments to households. Both categories are calibrated separately.

Program- $p$ transfers are given by

$$
\operatorname{Tr}_{p, t}=\zeta_{p, t} Q_{t} v_{p} \sum_{k=1}^{3} \sum_{a=a_{w_{k}}}^{100} Z_{p, a} N_{a, t, k}
$$

where $Z_{p, a}$ is the region- and spending-program specific age-expenditure profile, and $\zeta_{p, t}$ is a regionand program-specific shift term. This term is calibrated to match program expenditure as a share of GDP and assumed to evolve through time to keep transfers constant as a ratio of per capita GNI. $v_{p}$ is the share of government expenditure on $p$ that is treated as a transfer. General welfare transfers include disability insurance and similar programs and are evenly distributed across adults. In contrast, education and healthcare transfers disproportionately benefit the young and old, respectively.

Pensions and general welfare transfers are fungible. Healthcare and education transfers are not. This prevents young agents from borrowing against healthcare benefits received later in life. In-kind consumption is inframarginal and, thus, doesn't impact utility maximization. Pension payouts are a time-varying and region- and skill-group specific fraction of an agent's average career earnings. An

\footnotetext{
${ }^{5}$ We set the rates endogenously such that the ratio of revenues raised by the two taxes is held constant. This ratio is calibrated to fiscal data.

${ }^{6}$ In some regions $\varrho<0$, in which case the payroll tax subsidizes other government spending.

${ }^{7}$ As discussed in section 3.3, our calibration implies that the highest skill group in all regions faces a marginal payroll tax rate of zero. This precludes kinks in budget frontiers.
} 
agent who retires at age $a_{r}$ in year $t$ receives pension benefits as a constant fraction of their average lifetime wage income.

$$
P B_{a_{r}, t, k}=\nu_{k} \frac{1}{a_{r}-a_{w_{k}}} \sum_{a=a_{w_{k}}}^{a_{r}} w_{a, t-a_{r}+a, k},
$$

where $\nu_{k}$ is skill group $k$ 's replacement rate.

\subsection{Solution Method and Calibration}

This section discusses our iterative solution method for precisely solving over four million equations in an equal number of unknowns. It then turns to calibrating our over 400 parameters using our automation calibration method.

\subsubsection{Solution Method}

We solve the model using a variant of Auerbach and Kotlikoff (1987)'s Gauss-Seidel method. Solving the model means finding region-specific paths of skill-specific wages and a global path of the return to capital such that region- and skill-specific supplies of labor equal their corresponding demands and the path of global capital supply equals the path of global capital demand.

The model's factor demands are governed by equations (11) and (12). The model's factor supplies are governed by equations (1) through (4). The model's solution begins with a guess of the path of the U.S. capital stock and guessed region-specific paths of skill-specific labor supplies. Given the guessed paths of U.S. skill-specific labor supplies, the guessed path of U.S. capital, and the U.S. METR on capital, we determine the path of the world interest rate, $r_{t}$. From the world interest-rate path and region- and skill-specific leisure guesses, we determine region-specific capital demand paths.

The implied paths of region-specific wages and the $r_{t}$ path as well as guessed paths of regionspecific average and marginal household tax rates lets us update region- and skill-specific paths of leisure and consumption demands and, thus, region- and skill-specific labor and region-specific asset supplies. Subtracting off the paths of the values of non-capital assets (debt and claims to energy endowments), yields a path of the world supply of capital. Subtracting the sum of paths of all nonU.S. capital demands from the path of the world supply of capital produces our new guess of the path of the U.S. capital stock.

We also update all endogenous region-specific taxes to satisfy region-specific annual government budget constraints and the paths of market values of non-capital assets. ${ }^{8}$ A weighted average of the new and prior guesses of the U.S. capital stock path is then used in the model's next iteration.

The initial year of the simulation is set at 2017, the most recent year for which comprehensive macro and fiscal data are available. The initial conditions consist of asset holdings by age, skill group,

\footnotetext{
${ }^{8}$ To be precise, region-specific paths of payroll tax rates endogeneously adjust to pay for their predesignated regionspecific shares of government pension benefits per equation (17). Region-specific paths of pension benefits are calculated in each iteration based on workers' past average wage earnings and an assumed progressive replacement rate function discussed in the Appendix. Regional-specific paths of non-pension transfer payments, both fungible and in-kind, are also calculated at this stage based on equation (16). As the equation indicates, non-pension transfer payments grow with gross national income (GNI) per capita and population. The same is true of region-specific government consumption. As for income tax functions, the region-specific linear components are adjusted to maintain region-specific debt to GDP ratios. This routine also updates region-specific paths of debt stocks.
} 
and region. We allow a maximum of 500 years for the model to converge. ${ }^{9}$ Updating stops when, for all years, the year-specific difference between global output demand and supply converges to within 0.01 percent of that year's global output.

\subsubsection{Calibration}

We calibrate the model's multitudinous parameters to fiscal aggregates, macro aggregates, and microeconomic estimates. This subsection summarizes these targets and their sources. Appendix section A provides details. Tables A12, A13, A14, and A15, which compare region-specific calibration targets with model output, show the extraordinary ability of our autocalibration method to simultaneously match, to a high degree of precision, hundreds of parameter values to their associated targets.

Region-specific shares of population in each skill-group are estimated using the World Inequality Database (Alvaredo et al., 2020). Capital shares in each region are calibrated to IMF capital stock data (IMF, 2019a). Production input shares and population shares by skill-group are reported in table A16. Region-specific macro and government fiscal targets are obtained from a number of data sources. ${ }^{10}$ We use the microeconomic estimates of Acemoglu et al. (2020) and Altig et al. (2020) to calibrate, respectively, $\varphi_{K}$, and the 2019 progressivity of the U.S. federal income tax. We assume all regions maintain this degree of income-tax progressivity through time.

Region-specific pension replacement rates in 2017 are calibrated to IMF (2017) data. Growth rates of pensions are calibrated to OECD projections of pension expenditures in 2050. Region-specific 2017 TFP values are based on each region's 2017 GDP. As mentioned, their growth rates are calibrated to long-term GDP estimates from Müller et al. (2019), who use a Bayesian model to predict countryspecific output levels through 2100. The authors graciously provide us with two projections. The first projects GDP paths of all countries jointly using a multivariate (cross-country) estimation strategy. The second projects each country's GDP path using a univariate (country-specific) estimation strategy. We grow TFPs in each region at a constant, region-specific rate between 2017 and 2100 such that, assuming no further automation occurs after 2017, each region's GDP in 2100 equals the average of these two 2100 projections.

We calibrate private consumption as a fraction of GDP by adjusting $\delta_{t}$, the time preference rate, to matched IMF fiscal data. Each region's $\delta_{t}$ is assumed to slowly converge to the GDP-weighted average time-preference rate of developed regions as of 2017, with full convergence occurring in $2100 .{ }^{11}$ Conceptually, it is unlikely that China and India maintain their strong desire to save as their economies develop. ${ }^{12}$ Hence, we assume time preferences of all regions gradually evolve toward our best guess of a single, global steady-state rate.

The shape of the initial age-skill asset distribution is calibrated to U.S. Survey of Consumer Finances (SCF; Bricker et al. 2017) data. Fossil fuel rent flows and the shares of rents that accrue to governments are calibrated to World Bank (2021) data. We interpret leisure as measuring labor force participation and calibrate leisure preferences to a combination of SCF and ILO data. Finally, we calibrate distributional aspects of each region's pension system (e.g., benefits by skill-group and contribution ceilings) to a combination of IMF and Social Security Administration (SSA) data.

\footnotetext{
${ }^{9}$ This is 250 years beyond the year each region's demographics stabilize.

${ }^{10}$ Most are sourced from the IMF, the World Bank, and the International Labour Organization (ILO). The remainder are sourced from country-specific treasury department (or equivalent) websites.

${ }^{11}$ We define developed regions as the U.S, Western Europe, JSHK, the U.K, Canada, Australia, and New Zealand.

${ }^{12}$ Similarly, the U.S. strong preference to consume is, fiscally, difficult to sustain in the long run.
} 


\subsubsection{Autocalibration}

A key advance over prior large-scale life-cycle CGE models is our auto-calibration algorithm, which jointly solves for the 464 parameters to produce the closest match between the model output and its calibration targets. The standard approach - calibrating by hand - is infeasible given our model's scale. This section briefly summarizes the procedure. Appendix section B provides details.

While some parameters are directly related to observables and, thus, can be directly set to accord with data, over 400 in our model are indirectly and jointly related and must be calibrated iteratively. This procedure is required due to the model's non-linearity. Consider, for example, setting regionspecific TFP growth rates. A unit increase in TFP causes a larger than unit increase in GDP because it induces capital inflows. Guessing TFPs by linear extrapolation will, therefore, consistently over- or under-shoot. Second, many parameters, in addition to TFP, influence economic output. Even in cases where there is a very straightforward connection between the parameter and a particular data target, it's difficult and prohibitively time-consuming to precisely match targets by adjusting one parameter at a time. ${ }^{13}$

Our solution partitions parameters into groups whose macroeconomic targets are most influenced by their modification. This is achieved in three steps. First, we simulate the model for a large grid of non-calibrated parameters. Second, using the results, we run LASSO regressions (see (Tibshirani, 1996)) of each targeted output against the entire set of parameters to rank them by a unique measure of explanatory power. LASSO is chosen here for its ability to set less important regression coefficients to zero. This produces equations relating targets to a small number of key parameters. This step identifies clusters of targets that can be matched jointly by adjusting an equal-sized subset of parameters.

Third, starting from a "naive" approach - attempting to hit each calibration target with a single parameter - we run a number of candidate parameter partitionings, each of which attempts to calibrate the model by jointly updating a subset of parameters and individually updating the rest. ${ }^{14}$ Each successive candidate parameter partitioning introduces one additional jointly updated set of parameters, with the order in which they are added determined by the ranking in step two. This process, which can be parallelized, continues until a candidate parameter partitioning is able to precisely calibrate the model. ${ }^{15}$ In all cases, we are able to successfully calibrate our model to our desired precision over all targets in less than 200 CPU-hours.

\subsection{Modeling Endogenous Automation}

As indicated, we model automation and skill-biased technological change as permitting regions to produce using their initial Cobb-Douglas technology or their year-specific frontier technology, which is also Cobb-Douglas, but with larger capital and high-skilled labor coefficients.

Assessing the impact of changes in production-share coefficients is more complex than simply considering improvements to TFP. To understand the issue, take the production of output, $Q_{e}$, based on a Cobb-Douglas function of capital, $K_{e}$, and labor, $L_{e}$, with TFP of $\phi_{e}$, share coefficient, $\alpha_{e}$, and productivity coefficients (conditional on input scaling), $\varphi_{K_{e}}$, and $\varphi_{L_{e}}$, where $e$ denotes example.

\footnotetext{
${ }^{13}$ In our model, parameter-by-parameter calibration would require thousands of non-parallelizable CPU-hours to parameterize a single version of the model. An exhaustive grid search over all parameters would be even more demanding and, consequently, infeasible.

${ }^{14}$ The procedure is detailed in Appendix section B.

${ }^{15}$ We define this as a maximum of 2 percent deviation or, for targets that can be either negative or positive, 2 percentage points.
} 


$$
Q_{e}=\phi_{e}\left(\varphi_{K_{e}} K\right)^{\alpha_{e}}\left(\varphi_{L_{e}} L\right)^{1-\alpha_{e}}
$$

For given measured output, $Q_{e}$, given measured inputs, $K_{e}$ and $L_{e}$, and given share parameter, $\alpha_{e}$, the product $\phi_{e}\left(\varphi_{K_{e}}\right)^{\alpha_{e}}\left(\varphi_{L_{e}}\right)^{1-\alpha_{e}}$ is defined, but not $\phi_{e},\left(\varphi_{K_{e}}\right)^{\alpha_{e}}$, or $\left(\varphi_{L_{e}}\right)^{1-\alpha_{e}}$ separately. Were $\alpha_{e}$ fixed, it would suffice to call the product $\hat{\phi}_{e}$ and consider how output changes when this product, $K, L$, or some combination changes. But we need separate values for $\phi_{e}, \varphi_{K_{e}}$, and $\varphi_{L_{e}}$ to assess the impact on output of a change in $\alpha_{e}$. Two normalizations are available to help pin down these three values. The first is TFP scaling, namely $\phi_{e}=1$. The second is the normalization $\left(\varphi_{K_{e}}\right)^{\alpha_{e}}\left(\varphi_{L_{e}}\right)^{1-\alpha_{e}}=1$. This gives us one equation in $\varphi_{K_{e}}$ and $\varphi_{L_{e}}$. An empirical estimate or an assumed relationship can provide the second equation.

\subsubsection{Calibrating Labor and Capital Productivity Coefficients in our Model}

In our model, we have five productivity parameters. We use the same first and second normalization, e.g. $\phi=1$ and $\varphi_{K}^{\alpha} \varphi_{l_{1}}^{\beta_{1}} \varphi_{l_{2}}^{\beta_{2}} \varphi_{l_{3}}^{\beta_{3}}=1$, as in the example. A third is provided by Acemoglu et al. (2020). Using French factory-level data, the authors estimates that, holding inputs fixed, a one percentage point increase in capital's share, $\varphi_{K}$, generates a 0.3 percent increase in productivity.

The remaining two equations needed to determine the four unknowns are provided by two assumptions biased against our finding major impacts of automation on output. Specifically, we assume, in our base case, that a rise in the high-skilled or middle-skill labor shares coupled with an equal-sized decline in the low-skilled share lead to no change in output. These assumptions provide a lower-bound estimate for automation's impact. ${ }^{16}$

To generate what may represent an upper bound estimate, we also simulate, as part of our sensitivity analysis, the model assuming a 0.3 percent output increase for a 1 percentage point increase in the high-skilled (middle-skilled) labor shares offset, again, by a 1 percentage point reduction in the low-skilled labor share. As detailed in Appendix section C, this assumption slightly raises regional growth rates and speeds up the adoption of the frontier technology in some regions, but otherwise makes little difference to our results.

The following four equations make our calibration of the four productivity coefficients precise. Our first normalization sets U.S. TFP to 1.0 in 2017. Equation (19) is the aforementioned second normalization,

$$
\varphi_{K}^{\alpha} \cdot \varphi_{l_{1}}^{\beta_{1}} \varphi_{l_{2}}^{\beta_{2}} \varphi_{l_{3}}^{\beta_{3}}=1
$$

Differentiating equation (7), dropping time subscripts, and holding inputs constant yields

$$
\frac{1}{Q} \frac{d Q}{d \alpha}=\log \left(\varphi_{K} K\right)-\frac{1}{3} \sum_{k=1}^{3} \log \left(\varphi_{l_{k}} l_{t, k}\right)=0.3 .
$$

The two remaining equations come from differentiating $Q$ with regard to $\beta_{2}$ and $\beta_{3}$ assuming $\beta_{1}$ declines pari passus.

\footnotetext{
${ }^{16}$ Unlike capital-use intensivity, there are no empirical estimates of the output effects of changes in labor skill-group coefficients. However, given the well-documented, global increase in the share of income of high earners, it stands to reason that replacing low-skilled tasks with higher-skilled ones should not lower output.
} 


$$
\frac{1}{Q} \frac{d Q}{d \beta_{2}}=\log \left(\varphi_{l_{2}} l_{2}\right)-\log \left(\varphi_{l_{1}} l_{1}\right)=\chi_{2}
$$

and

$$
\frac{1}{Q} \frac{d Q}{d \beta_{3}}=\log \left(\varphi_{l_{3}} l_{3}\right)-\log \left(\varphi_{l_{1}} l_{1}\right)=\chi_{3}
$$

where $\chi_{2}$ and $\chi_{3}$ are both set to 0 in our baseline and 0.3 in our sensitivity analysis. ${ }^{17}$

This system of four equations in $\varphi_{K}, \varphi_{l_{1}}, \varphi_{l_{2}}$, and $\varphi_{l_{3}}$ is solved for the U.S. for 2017. The derived coefficients are then applied to the U.S. and all other regions through time.

\subsubsection{Endogenous Automation Choice}

Producers in each region choose between legacy and frontier technology to maximize output. They determine, in each period, whether

$$
\frac{Q^{*}}{Q}=\frac{\phi\left(\varphi_{K} K\right)^{\alpha^{*}} L_{1}^{\beta_{1}^{*}} L_{2}^{\beta_{2}^{*}} L_{3}^{\beta_{3}^{*}}}{\phi\left(\varphi_{K} K\right)^{\alpha} L_{1}^{\beta_{1}} L_{2}^{\beta_{2}} L_{3}^{\beta_{3}}}=\left(\varphi_{K} K\right)^{\alpha^{*}-\alpha} L_{1}^{\beta_{1}^{*}-\beta_{1}} L_{2}^{\beta_{2}^{*}-\beta_{2}} L_{3}^{\beta_{3}^{*}-\beta_{3}},
$$

the ratio of output using the frontier technology to output using legacy technology, exceeds $1 .{ }^{18}$

Note that the frontier technology changes neither the TFP term, nor how it evolves, nor factor productivities. However, a region's adoption of the frontier technology impacts its capital and labor demands. Such changes to regional factor demands impact the course of region-specific wage-rates as well as the evolution of the global interest rate. Moreover, changes in the world interest-rate path as well as region- and skill-specific wage paths will change each region's annual saving as well as skillspecific annual labor supply. These supply-side changes will further impact the evolution of interest and wage rates. Thus, one region's adoption of technology, in one or more years, influences all others regions' paths of automation by altering the global, dynamic equilibrium.

\section{Results}

\subsection{No Automation}

We first simulate our model assuming no automation occurs post 2017. As table A2 shows, this no-automation scenario entails a very major change in world economic power over this century - one,

\footnotetext{
${ }^{17}$ To be precise, we set $\chi_{2}=\chi_{3}=\epsilon=0.01$ in our baseline to weakly prefer the frontier production function under scenarios when either the middle-skilled or high-skilled labor-share coefficients increase with a commensurate decline in the low-skilled labor-share coefficient. Results assuming $\chi_{2}=\chi_{3}=0.3$ are discussed in Appendix section C.

${ }^{18}$ It is easy to show, as detailed in Benzell et al. (2016), in the two-factor case that if a range of Cobb-Douglas production functions are available, firms will only choose between functions with the most extreme $\beta$ values available. Therefore, our algorithm compares only the 2017 technology and the frontier technology. The adoption of frontier technology is not a permanent decision. A region that automated in the past may choose, in any year, to return to its 2017 production method. And, of course, it can opt to never adopt.
} 
which we shall show, is little impacted by automation. Between 2017 and the end of the century, China's share of global output rises from 16.6 percent to 25.1 percent. India's share rises from 7.0 percent to 11.4 percent. In contrast, the U.S. share of world GDP falls from 16.4 percent to 12.5 percent, and Western Europe and the UK's combined share falls from 19.7 percent to 11.7 percent.

As indicated in table A3, by Century's end, China catches up to within 15 percent of the U.S. in terms of per capital output. India's per capita output, however, reaches only 26.5 percent of the U.S. level by Century's end. Other regions make even less headway. In 2100, per capita output in Sub-Saharan Africa is 5.3 percent of the U.S. level - down from 6.0 percent in 2017. Sub-Saharan Africa's 2100 per capita output barely exceeds that of China in 2017.

Given their exceptionally high saving rates, China's rapid productivity catch-up growth and India's rapid demographic growth result in a massive buildup of assets in these regions. Table A4 documents this. In 2017, 2050, and 2100, China accounts for 17.4 percent, 35.7 percent, and 34.9 percent of global assets, respectively. For India, the corresponding three shares are 6.6 percent, 11.7 percent, and 13.1 percent. China and India's asset holdings are invested globally, including in the U.S. In 2050 and 2100, 32.9 percent and 19.5 percent of China's assets are invested abroad. The corresponding figures for India are 15.4 percent and 12.5 percent.

The combined advanced economies' - U.S., U.K., CAN, WEU, and JSHK- global asset share falls from 46.8 percent in 2017 to 20.2 percent in 2100 . For the U.S., the 2017 to 2100 decline is from 16.8 percent to 5.4 percent. Yet its relatively high capital share and high worker productivity levels make it a good place to invest. Hence, its 2100 share of world capital usage - 13.6 percent - is still relatively high. The U.S.'s (negative) net foreign asset position grows from 34 percent of GDP in 2017 to over 200 percent by $2050{ }^{19}$

The huge glut of savings drives down the global rate of return to roughly 2.8 percent by 2050 and 2 percent by 2100, with two major implications. First, revenue raised by capital income and corporate income taxes will fall substantially across all regions, requiring compensating increases in income and consumption taxes. Second, global capital abundance stimulates the adoption of the more capital-intensive frontier technology.

In addition to losing economic hegemony, the U.S. faces, per our simulation, major fiscal challenges through the remainder of the century. As table A5 shows, tax rates increase significantly over time in the U.S. even under our optimistic assumption that debt remains fixed relative to GDP. As the U.S. ages, pension expenditures grow from approximately 5 percent of GDP in 2017 to 10 percent in 2100. At the same time, the shrinking income tax base and the U.S.' reliance on income as opposed to consumption taxation compounds the fiscal burden on successive young generations. It also significantly undermines work incentives. In 2017, American workers face, on average, a marginal effective tax rate on labor earnings of 40.8 percent. This rate reaches 55.4 percent by 2100 .

\subsection{Baseline Findings}

Our baseline simulation incorporates automation with the U.S. frontier technology factor-share coefficients changing at the same pace through 2050 as they did between 1980 and 2017. As for the other regions, their frontier capital, high-skill, and middle-skill technology share coefficients change at the same annual percentage rate as the U.S. share coefficients. Recall, each region, in each year, can use its 2017 technology or its current frontier technology. Hence, as in Brezis et al. (1993), the model permits less advanced regions to leapfrog more advanced regions in their use of advanced technology.

\footnotetext{
${ }^{19}$ While this increase is striking, it is in line with extrapolations of the net International Investment Position (IIP) data from 2000 to 2017 as well as the actual net IIP for 2018-2020.
} 
Tables A6 through A10 contrast the frontier technology's input shares in 2050 with shares of the 2017 production function. Between 2018 and 2050, shares are assumed to evolve at a constant rate as the technology develops. For example, in 2050 and thereafter the U.S. has the option of producing with the 2017 technology: $\alpha_{t}=0.341$ and $\beta_{t, k}=0.22$, or with the 2050-frontier technology: $\alpha_{2050}=0.369$, $\beta_{2050,1}=0.161, \beta_{2050,2}=0.205$, and $\beta_{2050,3}=0.264$.

Some regions adopt the frontier technology as soon as it is introduced. Some, such as India and the Middle East, never do. Others adopt in the future. For example, China automates in 2027 and Southeast Asia automates in 2064. Regions' automation choices are displayed in figure 3. Overall, the choice and timing of adopting frontier technologies strongly correlates with the level of economic prosperity. The five richest regions in our model, measured by GDP per capita, all automate immediately. On the other hand, three of the five poorest regions never automate, and the other two automate after 2050. While they have the option to do so, no region in the baseline chooses to return to the 2017 technology after adopting the frontier technology.

Figure 3: Choice of Production Function by Region

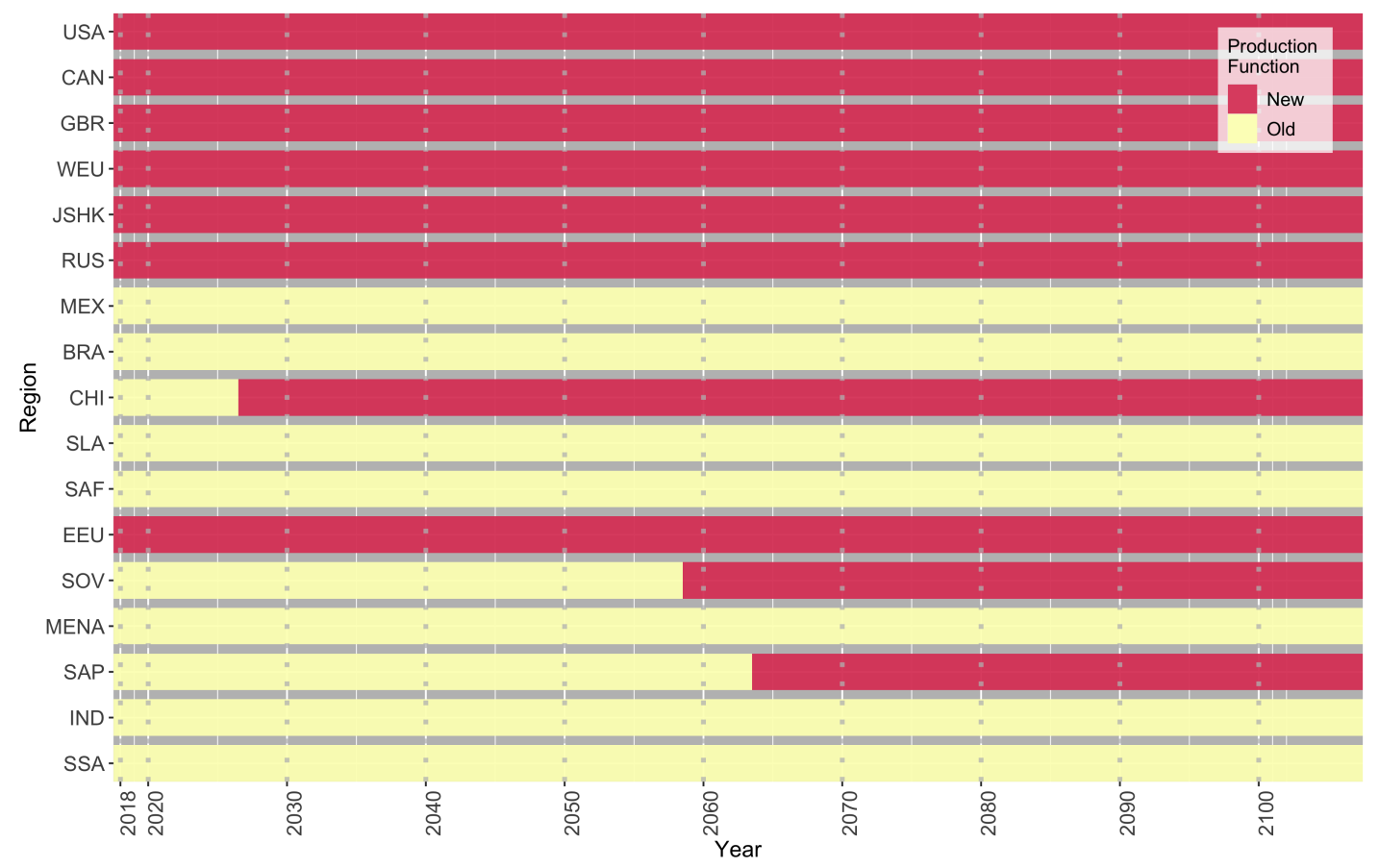

Why do some countries benefit more from automation than others, and why do some countries never choose to adopt? First note that, as derived in (20), the marginal product of automation (i.e. the partial derivative of output with respect to an increase in capital's share) is increasing in the ratio of effective labor to effective capital. Output is always positive, so a country will automate so long as the supply of effective capital is larger than the supply of effective labor. In other words, automation requires

$$
\log \left(\varphi_{K} K\right) \geq \frac{1}{3} \sum_{k=1}^{3} \log \left(\varphi_{l_{k}} l_{t, k}\right)
$$


i.e.

$$
\varphi_{K} K \geq \prod_{k=1}^{3} \varphi_{l_{k}} l_{k}
$$

The question then becomes what determines the ratio of effective labor to effective capital. Three of the most important factors are regions' starting capital intensivity, share of high-skilled labor, and most importantly, TFP. To see why, we focus on a simplified case. Consider a small open economy with Cobb-Douglas production over capital and one type of labor $l$ in fixed supply. Output is

$$
Q=\phi\left(\varphi_{K} K\right)^{\alpha}\left(\varphi_{l} l\right)^{1-\alpha},
$$

where, setting the marginal product of capital equal to the interest rate $r$, rearranges to

$$
\frac{\varphi_{K} K}{\varphi_{l} l}=\left(\frac{\alpha \varphi_{K} \phi}{r}\right)^{\frac{1}{1-\alpha}}
$$

A country will automate so long as the right hand side of (27) is greater than one. This ratio is increasing in $\varphi_{K} \phi . \varphi_{K}$ is equal in each region as shown in (19). Hence, $\phi$ is the only productivity term that varies across countries. Countries with higher TFPs are better at making use of capital. Hence, they tend to have higher capital to labor ratios. With factor price equalization, they demand and, necessarily, import more capital per unit of labor and benefit more from automation.

The starting capital share of a region, $\alpha$, plays a more complex role. For regions where $\frac{\alpha \varphi_{K} \phi}{r}>1$, a high initial capital share unambiguously boosts the positive productivity effect of automation. On the other hand, when $\frac{\alpha \varphi_{K} \phi}{r}<1$, a larger $\alpha$ worsens the negative effect on output. In other words, initial $\alpha$ intensifies the productivity effect of automation. A one percentage point increase in $\alpha$ from 50 to 51 percent increases the ratio of capital's share to labor's marginally. A one percentage point increase in $\alpha$ from 98 percent to 99 percent approximately doubles it. ${ }^{20}$

Unlike capital, labor is not globally mobile. As $\varphi_{l}$ is equal across countries and skill-groups receive equal shares of total labor income, equation (22) makes clear that, all else equal, countries with a larger quantity of high-skilled labor will benefit more from skill-biased automation, and those with a smaller quantity will benefit less.

Each of these analyses are complicated by multiple factors. Demographics, government policies and preferences all influence the decision to automate. Regions with aging populations such as Japan and Western Europe maintain large payroll taxes to sustain their pension systems, leading to higher post-tax costs of labor. Higher post-tax costs of labor incentivize firms to automate. ${ }^{21}$ Regions with supply-elastic high-skilled workers who reduce their hours significantly in response to higher wages are less likely to automate. Similarly, regions with more inequality are disinclined to automate because they face larger wealth effects from skill-biased technologies.

Finally, the outcome of figure 3 is a consequence of the global distribution of capital. Corporate taxes introduce wedges between rates of return across countries. Countries with low corporate tax

\footnotetext{
${ }^{20}$ To get an intuition for why larger initial $\alpha$ 's intensify the output response of automation, consider the case of an small open economy moving from 99 percent capital intensity to 100 percent. Such a change would transforms it from a Solow into an AK economy with knife-edge growth characteristics. If the country is very good at using capital (i.e. $\varphi_{K} \phi$ is large), it could hypothetically absorb a huge share of the world's capital supply and increase output massively. The reverse is true if the country is very bad at using capital: automation will come at a huge cost to the country's output.

${ }^{21}$ Table A18 summarizes calibrated tax rates by region in 2017.
} 
rates face lower post-tax costs of capital and accumulate more capital. When $r_{t}$ is low, all countries use a higher ratio of capital to effective labor and benefit relatively more from automation. Over time, more countries automate due to decreasing interest rates.

If the increase to capital demand from automating exceeds the savings response, some regions will end up with less capital compared to a world where no region automates. The actual impact of automation on $r_{t}$ is, however, relatively small. As figure 4 shows, automation drives up $r_{t}$, but by only 0.1-0.4 percentage points above the no-automation path. This weak response is a result of a limited number of regions automating and, more importantly, high savings rates of China, India, and, in the latter half of the century, the Middle East. It takes much more capital- and high-skilled labor-biased technological change to absorb the world's accelerating stock of assets. ${ }^{22}$

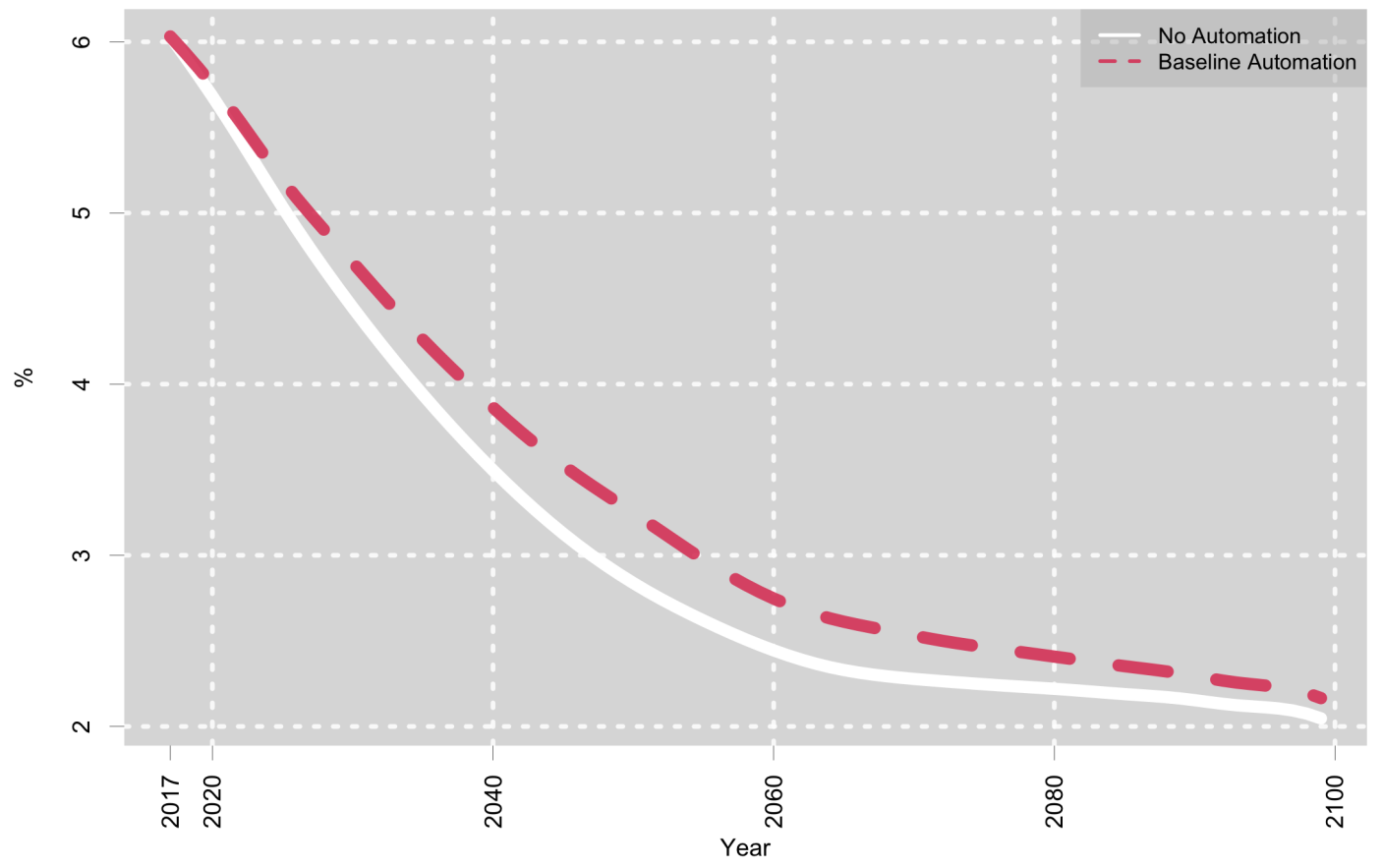

Figure 4: Global Post-Corporate Tax Rate of Return

The weak response of $r_{t}$ has two important consequences for welfare and policy. First, the primary channel through which automation could benefit households nearing or in retirement is by raising investment returns (Benzell et al., 2015b). But since automation doesn't matter much to the global interest-rate path, the current old gain little relative to high-skilled young workers. Second, automation does not substantially increase government borrowing costs. Hence, debt-financed redistributive policies are not made prohibitively expensive by global capital demand. As we discuss in section 4.4, the low $r_{t}$ path makes it easier to implement Pareto-improving intergenerational transfer policies.

Automation produces winners and losers across regions in terms of GDP. Comparing regions in 2050, JSHK gains the most with a 12.9 percent GDP increase relative to no-automation. The regions with the second, third, and fourth largest gains are Western Europe, CAN, and the U.K, which respectively experience gains of $12.7,12.1$, and 9.9 percent. The U.S. experiences the fifth largest GDP increase relative to no automation - 5.1 percent in 2050 . Global output in the same period increases by 3.4 percent. Table A11 summarizes GDP gains and losses in the baseline relative to no automation. Figure 5 contrasts GDP percent changes, relative to no automation, of the U.S., Western

\footnotetext{
${ }^{22}$ Section 4.3.3 discusses these simulations in detail.
} 
Europe, China, and the world average.

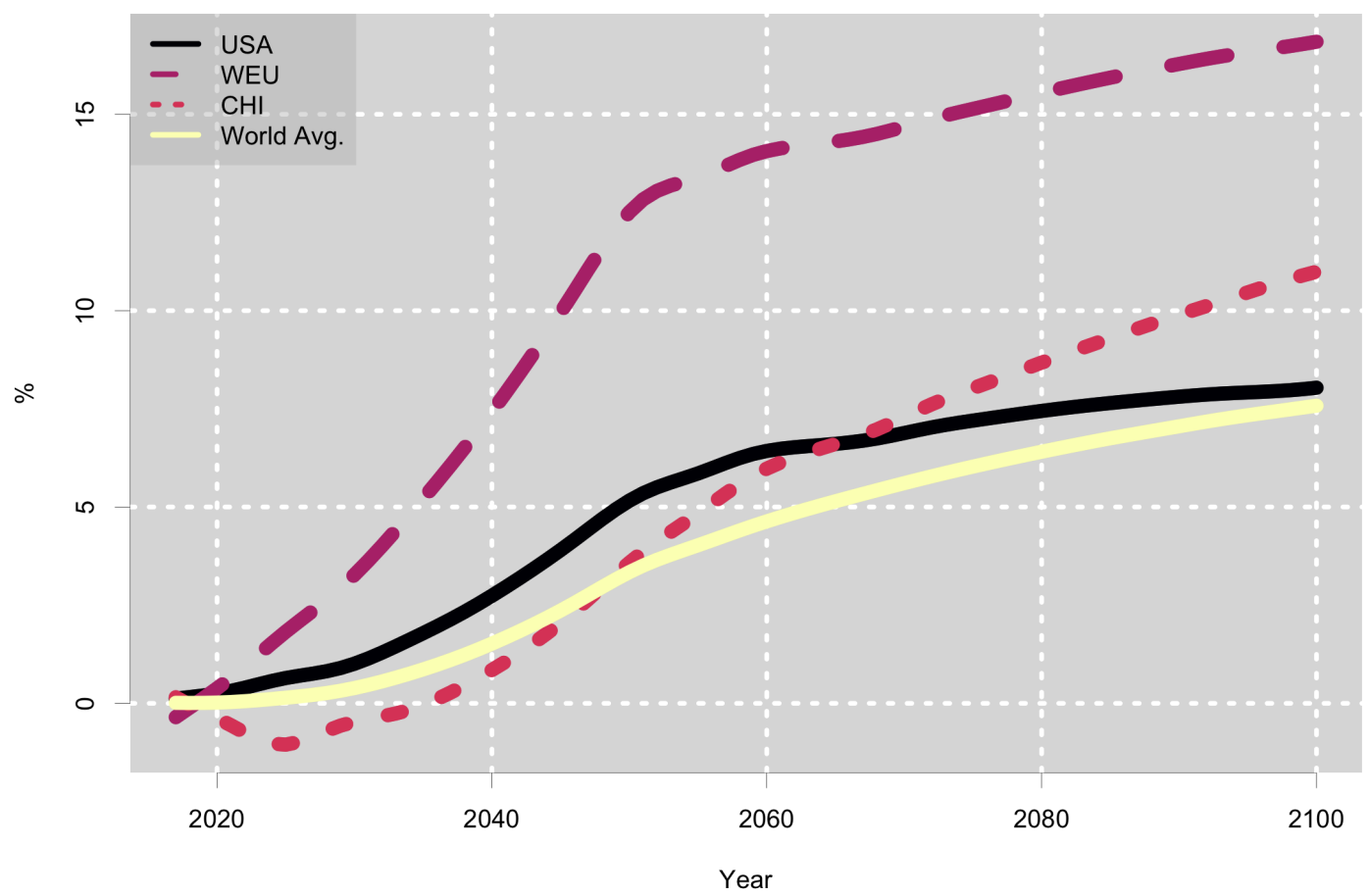

Figure 5: GDP Percent Change in Baseline Relative to 'No Automation' Scenario

The economic windfall from automating technologies accrues disproportionately to a small fraction of workers. Sixty-three percent of all adults alive in 2017 experience an increase in remaining lifetime welfare from baseline automation relative to no automation. However, this rate is deceptively high because of gains to retirees. Among all adults alive in 2050, only 28.5 percent experience an improvement, a fraction that decreases to 22.5 percent by 2100 . On the other hand, automation makes nearly all high-skilled workers globally better off - 92.5 percent of those alive in 2050 and 78.2 percent in 2100 - but these workers only account for 5 percent of the world's adult population. ${ }^{23}$

Globally, the average worker is made slightly worse off by automation throughout most of the 21st century, by 0.9 percent in 2050, and 1.1 percent in 2100 relative to no automation. These trends are summarized in figure 6. By 2050 and relative to no automation, the global average low-, middle- and high-skilled workers experience, respectively, a lifetime welfare decrease of 2.3 percent, an increase of 2 percent, and an increase of 10.3 percent.

Not all skilled workers fare equally well from automation. Figure A3 summarizes welfare changes by skill group and year of birth. No high-skilled workers and virtually no middle-skilled workers born before 2050 are made more than 1 percent worse off in terms of lifetime welfare. However, among workers born in 2020, only 47.7 percent of high-skilled and 27.3 percent of middle-skilled workers are made at least 1 percent better off. Workers in regions that do not adopt the frontier technology suffer regardless of skill level, but their welfare loss is tempered by consumption-leisure substitution and, for those with wealth, slightly better returns on assets. Regions that do automate significantly lower the pre-tax wages of low-skilled workers. But the progressivity of tax and pension systems prevent such workers from bearing the full impact of rising wage inequality. For example, low-skilled workers in

\footnotetext{
${ }^{23}$ The middle-skilled and low-skilled groups represent 19.7 percent and 75.3 percent, respectively.
} 

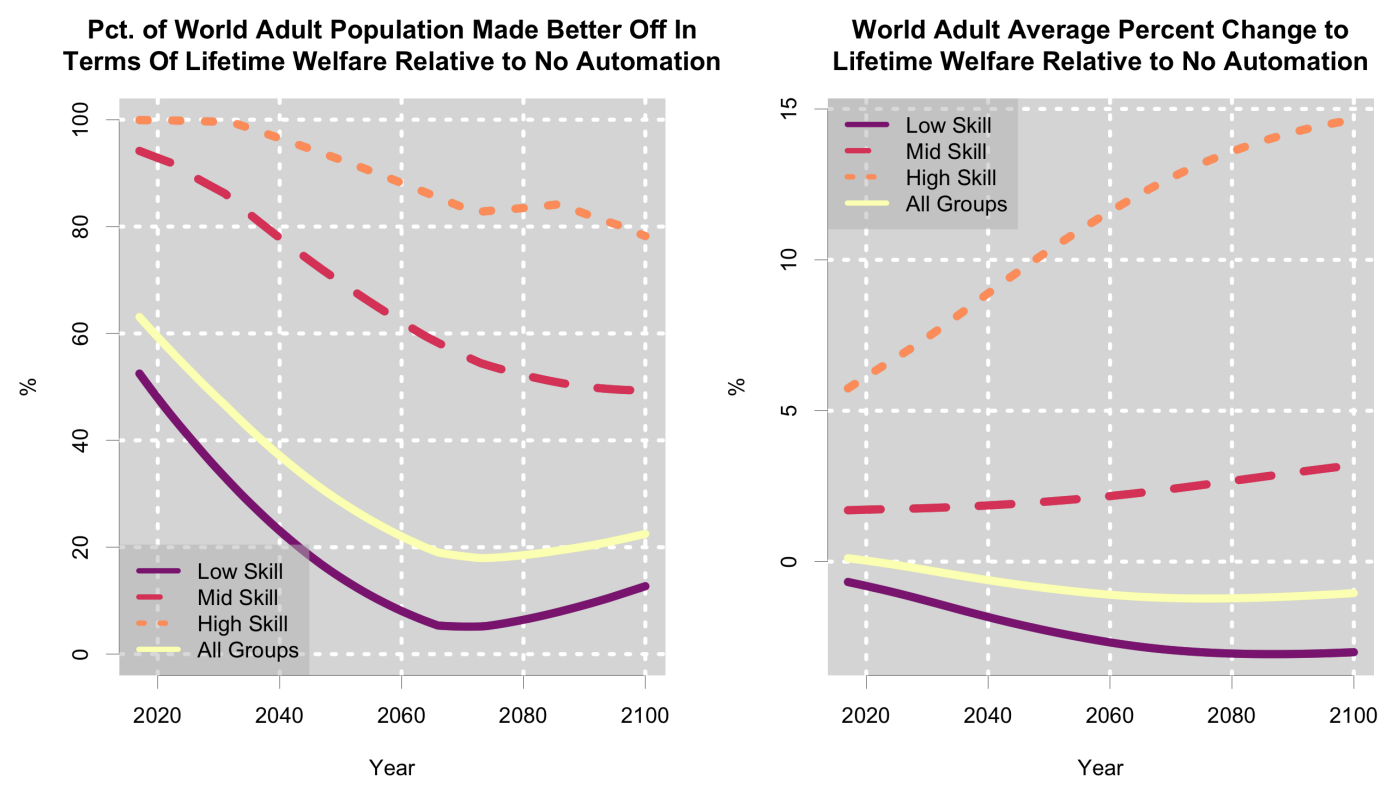

Figure 6: Global Lifetime Welfare Consequences of Baseline Automation

Japan born after 2027 are made better off assuming baseline automation, and no low-skilled cohorts in Western Europe are made more than 2.1 percent worse off.

We now focus on the U.S. Despite automating continually, the U.S's relative economic power is only marginally bolstered. Figure A4 presents U.S. GDP and capital stock as a share of the world's values with and without automation. Relative to no-automation, the U.S's share of world GDP increases by only 0.24 percentage points or 1.7 percent in 2050 with baseline automation. Its share of world capital, thanks to capital inflows, increases by 0.7 percentage points to 15.8 percent. In the same year and relative to no automation, U.S. gross investment increases from 33.5 percent to 35.7 percent of GDP.

Automation primarily benefits high-skilled U.S. workers. Their wages increase by 28.8 percent in 2050 and by 37.5 percent in 2100 relative to no automation. Low-skilled U.S. workers see their wages fall by 22.9 percent in 2050 and 21.7 percent in 2100. Older workers also benefit from automation but by a much smaller amount. A high-skilled worker born in 1951 experiences, relative to no automation, an increase in remaining lifetime welfare of only 1.5 percent. Middle- and low-skilled workers born in the same year experience welfare increases of 0.8 percent and 0.3 percent.

As figure A5 shows, the average U.S. worker born in 1950, 1980, and 2020 are made, respectively, 0.4 percent better, 4 percent worse, and 8 percent worse off in terms of lifetime welfare from automation. However, the young and high-skilled enjoy extraordinary gains, with the average high-skilled worker born in 2020 and alive in 2020 becoming, respectively, 24.2 and 6.2 percent better off.

\subsection{Alternate Technology Scenarios}

We now consider three alternate technology scenarios. In the first, only the U.S. can automate. In the second, technological change increases only capital's share, while reducing low-skilled, middle-skilled, and high-skilled workers' shares equally. In the third, we consider a far more rapid rise in the frontier technology's capital share, with the most rapid rate being ten times the pace of the capital share 
increase since 1980 .

\subsubsection{U.S-Only Automation}

As in the baseline, the U.S. automates immediately. The global rate of return is now virtually unchanged from the no-automation scenario, with U.S. demand for capital driving up $r_{t}$ by only 0.06 percentage points in 2050 and 0.02 percentage points in 2100. Since other regions aren't automating and, therefore, aren't demanding more capital, the U.S. benefits more from automation. Relative to no automation, 2050 U.S. GDP is 8.3 percent higher and the 2050 U.S. capital stock is 15.5 percent higher. This increase to U.S. output has a tiny net positive effect on the rest of the global economy; relative to no-automation, aggregate GDP of non-U.S. regions in 2050 increases by 0.1 percent.

The U.S's gains are, however, insufficient to prevent it from declining as a share of the world economy. In 2050, the U.S's share of world GDP with U.S-only automation is 14.8 percent, higher than under global automation, but still lower than the 2017 share of 16.4 percent. Hence, even were the U.S. able to prevent other countries from automating, its share of global GDP would still fall.

Results for wages and welfare are largely consistent with section 4.2. Gains to young, highskilled workers are moderately larger and losses to young, low-skilled workers are ameliorated through faster economic growth. 2017 retirees experience almost no change in lifetime welfare relative to noautomation, as their pension payouts are not impacted by future economic growth.

\subsubsection{Automation Without Labor Share Dispersion}

Our second alternate scenario considers only increases is capital's share. For example, a general purpose AI algorithm might reduce demand for a wide range of occupational categories from customer service to management and executive positions. ${ }^{24}$ We assume an identical share shift toward capital as section 4.2 , amounting to a 4.25 percent decline in the share of labor by 2050 . The new shares are specified in tables A6 through A10.

In this scenario, regions with less income inequality generally do not immediately adopt the new technology. ${ }^{25}$ With the only productivity gain from automation coming from capital, a number of regions that immediately adopt in the baseline, such as Japan and Western Europe, delay adoption. Regions with more income inequality, on the other hand, prefer technologies which do not further enrich high-skilled workers. Brazil and Mexico, for example, never adopt baseline automation but eventually adopt non-skill-biased automation. Globally, the capital accumulation rate falls between that of no-automation and baseline automation. The same is true for global GDP, which increases by 0.5 percent relative to no-automation in 2050 , and by 3.2 percent in 2100 .

Relative to baseline automation, the U.S. is made slightly better off with non labor-share dispersing technology, mostly through additional accumulation of capital. In 2050, this scenario increases U.S. GDP by 6.1 percent relative to no automation and by 0.9 percent relative to baseline automation. Welfare gains are comparable across skill groups. low-skilled workers born between 1990 and 2050 are 0.8-4.3 percent better off relative to no automation, and middle and and high-skilled workers born in the same time interval are $2-7$ percent better off. ${ }^{26}$

\footnotetext{
${ }^{24}$ Our goal is to eventually calibrate the degree to which capital is a substitute to various occupations with the Suitability for Machine Learning (SML) dataset (Brynjolfsson et al., 2018a).

${ }^{25}$ Figure A6 summarizes the choice of production function under this scenario.

${ }^{26}$ Middle-skilled workers gain nearly as much as high-skilled workers. The high-skilled own more assets but also face higher marginal taxes.
} 
These results suggest that the U.S. would be better off with automating technologies that do not further enrich high earners. This may contrast with the intuition that the most productive members of society should be given more tasks to perform. However, this technology, which also economizes on the expensive labor of the high skill, is both better for economic growth and contributes less to inequality.

\subsubsection{Faster Rates of Automation}

The final alternate scenario simulates technologies with the same relative impact on labor skill-group shares, in terms of percent increased or reduced, as section 4.2 , but with much larger share shifts toward capital. Specifically, we simulate a gradual and linear reduction in the total labor share (TLS) accumulating to declines of 8.5 percent, 21.3 percent, and 42.5 percent in 2050, respectively representing technologies that reduce labor use at a rate twice, five times, and ten times the historical experience of the U.S. ${ }^{27}$ In the U.S. and in contrast to the baseline's capital share of 36.9 percent in 2050, the three scenarios correspond to capital shares of 39.7 percent, 48.1 percent, and 62.1 percent in the same year.

Three observations stand out from this set of simulations. First, regions' choices of whether to adopt the new technology are not substantively influenced by the rate at which capital shares increase. As shown in figures A7 and A8, all regions that adopt the baseline technology between 2017 and 2100 eventually adopt automation at the faster rates of decline to the TLS. However, such technologies delay adoption for some regions. The U.K, for example, chooses to immediately automate in the baseline but automates in 2028 at five times the baseline rate and 2032 at ten times the rate. These faster rates drive up $r_{t}$ and, consequently, regions that are relatively less efficient at using capital must now wait for global capital to accumulate. The U.S. automates immediately in all cases.

Second, as a result of immediately automating, the U.S becomes a progressively bigger winner of the endogenous automation process as the frontier technology involves greater capital use. With a relatively capital-intensive economy, high TFP, and low effective corporate taxes, the U.S. is among the regions best-poised to adopt high capital use intensivity technologies.

As presented in figure 7, by 2050 and relative to no-automation, U.S. output increases by 11.9 percent, 37.3 percent, and 115.3 percent, respectively, for automating technologies which substitute away from labor at twice, five times, and ten times the historical rate. Lifetime welfare gains are similarly substantial, with the average U.S. worker born in 2020 made 42 percent better off, relative to no-automation, at the highest assumed rate of reduction to the labor share.

Third, and perhaps most interesting, the global rate of return on capital will continue to decline unless labor is replaced with capital globally and at a massive scale. As shown in figure A9, a technology that, if adopted, utilizes capital as a majority input factor by middle-century will not raise the interest rate in 2050 above the 2017 level. By mid-century, automating at twice the baseline capital substitution rate increases $r_{t}$ to 3.7 percent. At five times the rate, $r_{t}$ is 5.7 percent in 2050 , still below the 2017 level of 6 percent. At ten times the rate, $r_{t}$ is 8.7 percent in 2050 .

These exercises highlight the U.S's excellent position with respect to benefiting from automation. In addition, the interest rate response to automating technologies depends strongly on the extent to which capital use intensifies. Although $r_{t}$ plays a relatively small role in the baseline, any discussion of more substantive innovations may be incomplete without a formal treatment of their impact on the cost of accessing capital.

\footnotetext{
${ }^{27}$ The reason that we do not simulate matching labor share shifts is that such changes massively reduce the income share of low-skilled workers, leading to instability of the model as wages in some regions converge to close to zero.
} 


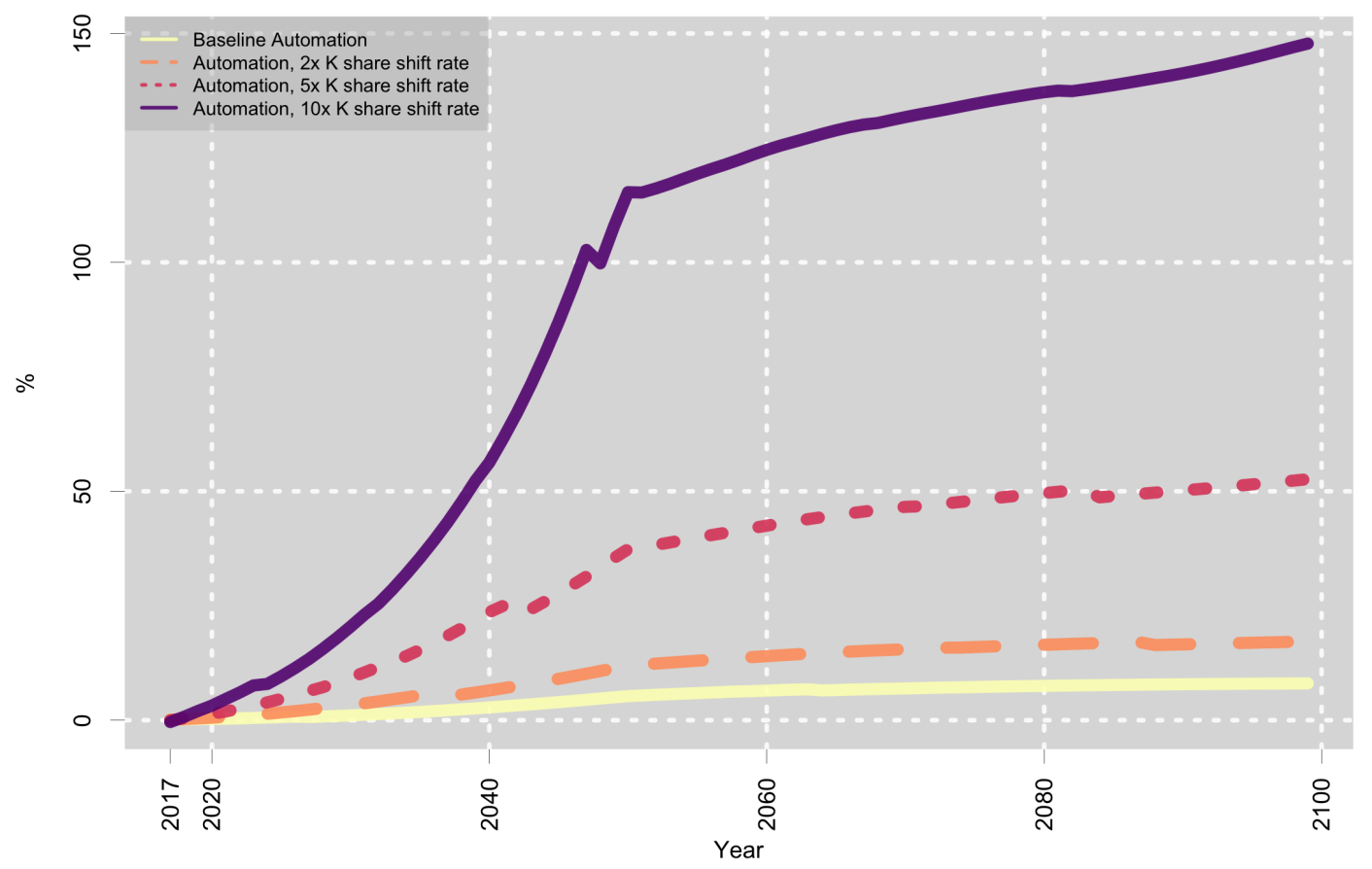

Figure 7: U.S. GDP Percent Change Relative To No Automation Under Alternate Scenarios

\subsection{Policy}

\subsubsection{Mandating Automation}

As we discuss in section 4.2, some regions choose to never automate. A natural question that arises is whether or not there is a rationale for the government to intervene. The concept of mandating capital intensive production can be traced back to early Soviet economic thinking such as Chayanov (1925) and Preobrazhensky (1926). ${ }^{28}$ When a region switches to a more capital intensive technology, they utilize more capital. On balance, this lowers wages and, via the income effect, raises labor supply. Paradoxically, then, requiring use of a technology that, in partial equilibrium, lowers output can, in general equilibrium raise it.

This is the case for India, which never automates. Figure 8 plots Indian GDP and Gross National Income (GNI) relative to no-automation. ${ }^{29}$ In the baseline, India's GDP is lower, relative to no automation, by 2.8 percent in 2050 and 0.8 percent in 2100. If India mandates automation in 2067, its GDP increases slightly. In 2050, 2100, and 2120, respectively, its GDP is $0.4,0.8$, and 1.5 percentage points higher than without the mandate.

Figure A11 shows India's labor-supply response. Low-skilled labor supply increases by up to 4.2 percent relative to the baseline scenario prior to 2067, and middle-skilled labor supply increases by up to 0.5 percent. In contrast, high-skilled workers reduce their labor supply. Their income effect, in this case arising from a higher wage, dominates the substitution effect. ${ }^{30}$. Notwithstanding the general

\footnotetext{
${ }^{28}$ Erlich (1950) analyzes such policies in detail.

${ }^{29}$ Recall that our definition of GNI is GDP plus net income from foreign assets.

${ }^{30}$ The dominance of income over substitution effects in reasonably calibrated OLG models was stressed byAuerbach et al. (1989)
} 

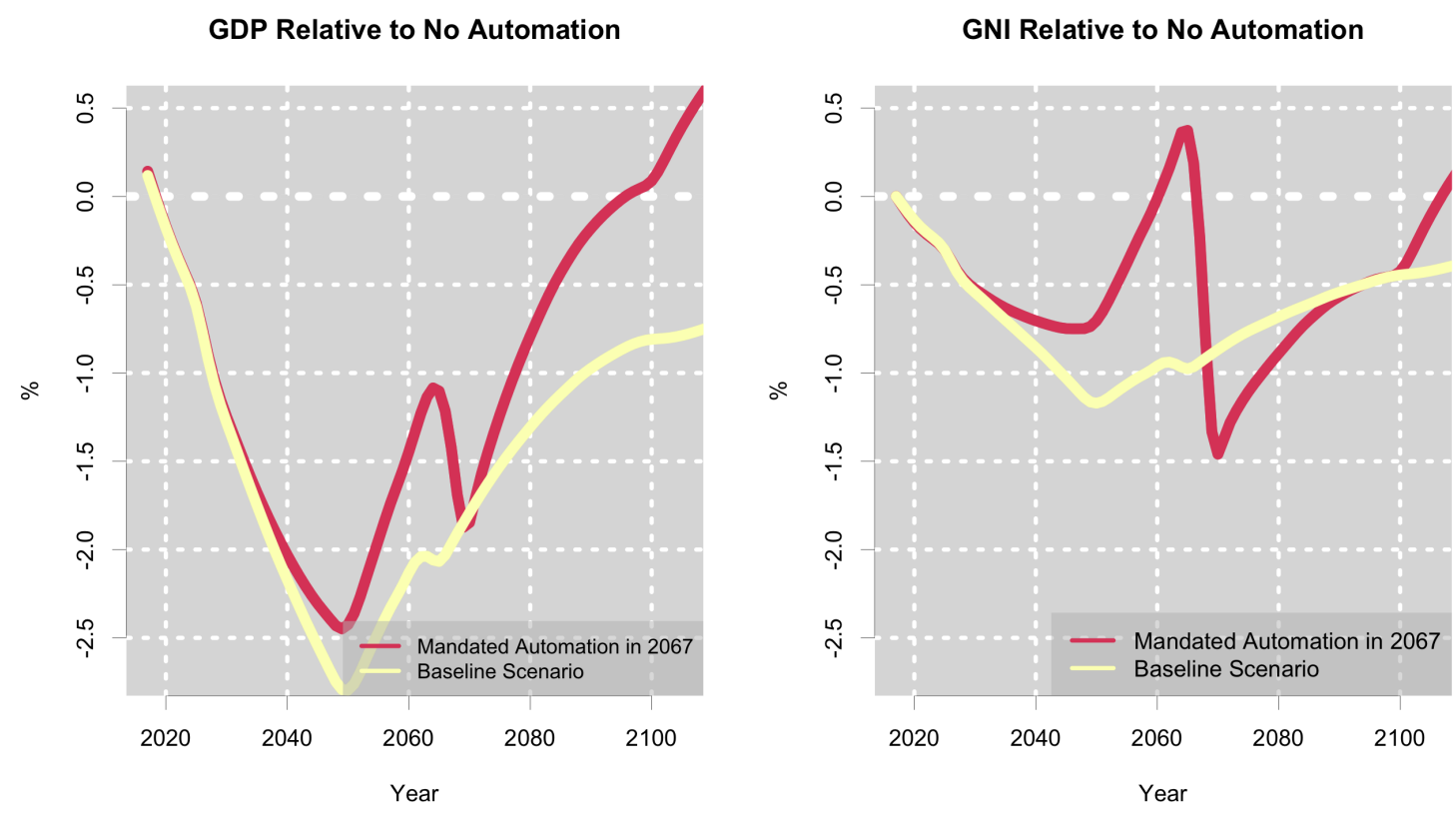

Figure 8: India GDP and GNI Relative to No Automation With and Without Forced Automation Policy

equilibrium impacts, Indian firms operate less efficiently using their frontier technology. Given the option, they immediately return to the 2017 technology.

Timing the mandate matters. As indicated, the world interest rate falls over the transition. This makes automation more efficient. Indeed, forcing automation earlier than 2067 in India decreases GDP in some years relative to the baseline scenario. The major impact of mandating automation is on inequality. The policy makes young, high-skilled Indian workers substantially better off - a 10 to 20 percent gain in lifetime welfare relative to the baseline scenario - at the cost of an 11 to 20 percent welfare loss to the low-skilled, and a 1-3 percent loss to the middle-skilled. Welfare consequences by birth cohort, relative to the baseline scenario, are summarized in figure A12. ${ }^{31}$

\subsubsection{Universal Basic Income}

Our second policy considers establishing a universal basic income (UBI) to maintain the welfare of low-skilled workers in a world with skill-biased automation. Ideally, such a policy would be Paretoimproving relative to no-automation. We construct one such example for the U.S. As indicated in figure 9, our proposal involves a UBI whose cost grows to 1.9 percent of U.S. GDP in 2025, 5.1 percent of GDP in 2050, and 3.9 percent of GDP in 2100. This means that the size of the transfer would be, monthly per adult, about 650 dollars, in 2017 dollars, in 2050. The UBI program is assumed to operate in addition to existing U.S. redistributive policies. ${ }^{32}$

The UBI is financed by a separate progressive income tax levied on middle- and high-skilled workers, delayed to 2037 through debt financing. Debt financing is required to prevent old workers nearing retirement from shouldering an excessive burden. The UBI, as presented in figures A14 and

\footnotetext{
${ }^{31}$ Despite this policy's adverse impact for most Indians, it might align the national security sector, interested in increased industrial power, and high earners with disproportionate political influence.

${ }^{32}$ For context, in 2017 U.S. social security payments constitute $4.9 \%$ of GDP.
} 
Annual UBI in 2017 Dollars

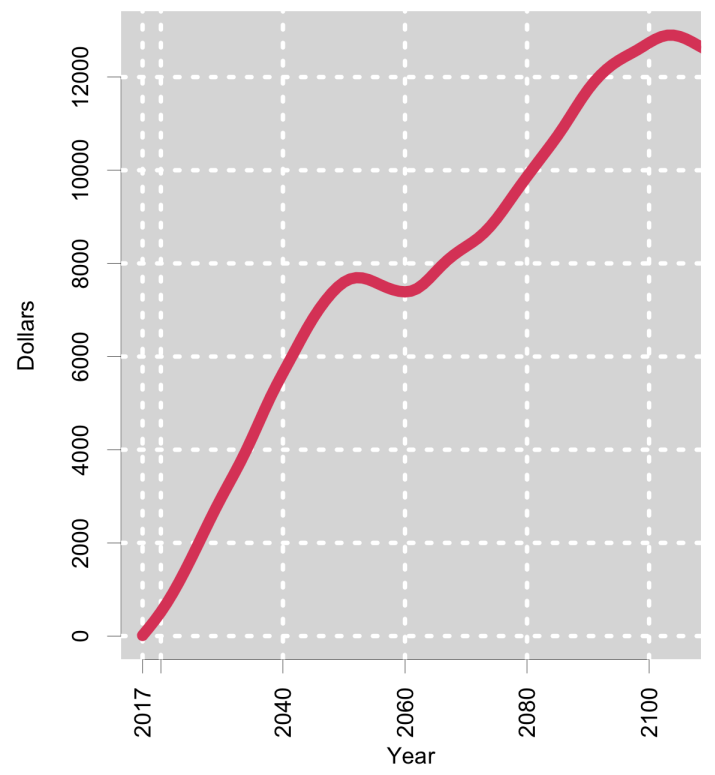

UBI as Percent of GDP

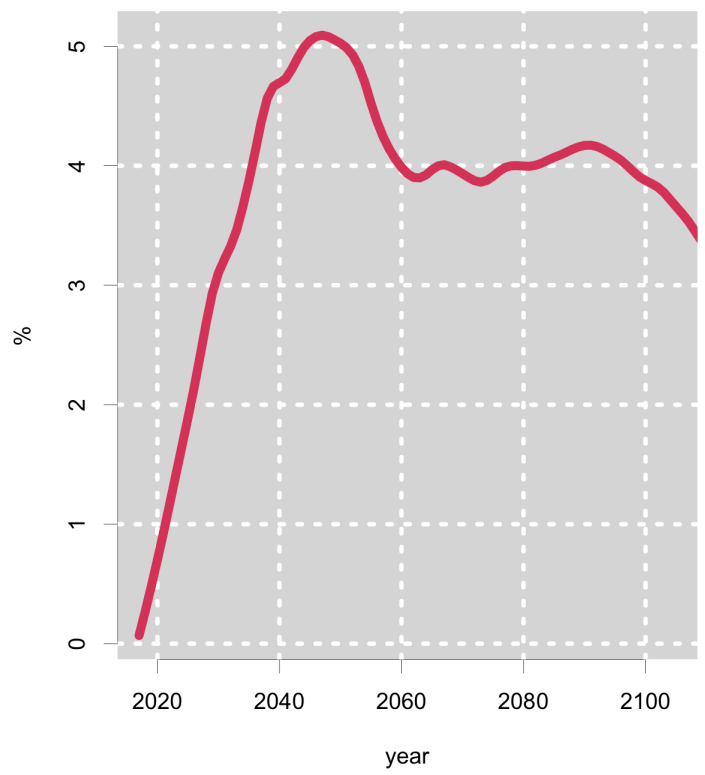

Figure 9: Minimum Pareto-Improving U.S. Universal Basic Income Path With 20-Year Debt Financing

A15, would require increasing income tax rates by 10 to 14 percentage points (to 49-53 percent) for high-skilled workers, and by 3.5 to 5 percentage points (to $26-28$ percent) for middle-skilled workers. It is important that middle-skilled workers contribute toward the UBI, as the high-skilled alone don't constitute a sufficient tax base to make the policy Pareto-improving. ${ }^{33}$ Depending on the duration of debt financing, middle-skilled workers must contribute 20 to 30 percent of the UBI. ${ }^{34}$

A period of debt financing significantly shorter than 20 years leaves initial older agents worse off. However, a longer period of deficit finance permits a range of Pareto-improving UBIs. Figures A14 and A15 present tax rates required for a 30-year debt financing period. The debt-to-GDP ratio increases from 151 percent at stabilization with 20-year financing to 214 percent with 30-year financing. However, the tax burden of delayed collection is tempered by low interest rates. ${ }^{35}$ In our 30-year financing scenario, the extra debt can be addressed by a roughly 1 to 1.5 percentage point increase in income taxes levied on middle- and high-skilled workers.

Figure A16 summarizes U.S. GDP relative to baseline- and no-automation scenarios. Our proposed UBI imposes a moderate cost to economic output of 0.5 percent of GDP in 2017, 2.3 percent of GDP in 2050, and 2.5 percent in 2100. Utilizing 30 years instead of 20 years of debt financing further decreases GDP by 0.7 percent in 2050. By 2100, the 30-year policy imposes virtually no additional output loss relative to the 20-year policy. In both cases, the UBI leaves GDP significantly above that of no-automation, which is 4.9 percent below baseline automation in 2050 .

This policy leave low-skilled workers minimally better off relative to no automation but preserves

\footnotetext{
${ }^{33}$ Note, though, after 2100 , transfers received by middle-skilled workers exceed their tax burden.

${ }^{34}$ It is possible to finance a Pareto-improving UBI with a combination of debt financing and a consumption tax hike. However, because the consumption tax is proportional and the burden falls partially on low-skilled workers, the UBI required and the deadweight loss incurred are both significantly larger. With the same duration of debt financing, a consumption tax-funded Pareto-improving UBI will cost 1.5-2.5 percent of GDP more than one funded by income taxes.

${ }^{35}$ In the baseline we assume that the U.S. stabilizes at the 2017 debt level of 105.8 percent.
} 
much of the gains of middle and high-skilled workers. Figure 10 contrasts remaining lifetime welfare effects by birth cohorts. The UBI, with 20-year debt financing, provides transfers compensating up to 12.5 percent of lifetime welfare loss to low-skilled workers. Young low-skilled workers born after 1990 are essentially indifferent to automation. Old low-skilled workers born before 1980 are 2 to 5 percent better off, as they receive the UBI but suffer smaller declines in lifetime income.
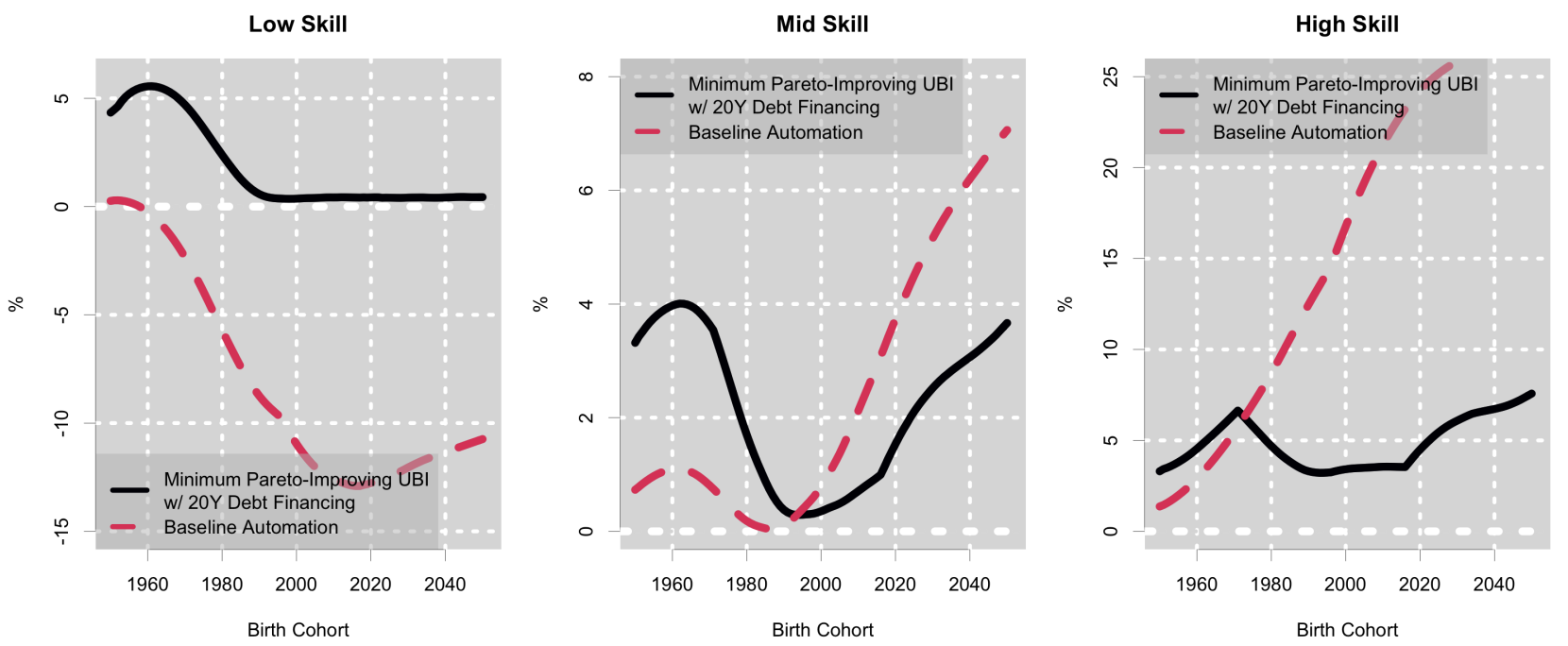

Figure 10: Relative Remaining Lifetime Welfare By Skill Group and Birth Cohort

The UBI reduces welfare gains of middle- and high-skilled workers. A high-skilled worker born in 1980 is, relative to no-automation, 4.7 percent better off with the UBI, and 8.7 percent better off without. For a high-skilled worker born in 2050, the differences are 4.5 percent and 24.2 percent. High-skilled workers born between 2000 and 2050 are the most affected by the income tax hike. In contrast, middle-skilled worker's relative welfare losses are much smaller, by approximately 24 percentage points of forgone lifetime welfare for young workers, relative to baseline automation without the UBI.

It may be tempting to consider a "soak the rich" policy of financing this UBI through taxes on capital or corporate income. This is, however, virtually impossible because declining interest rates shrink both tax bases. Additionally, the U.S. becomes relatively unattractive for investments as such tax rates increase, further reducing the revenue raised. In the case of corporate income taxes, financing a UBI of 5 percent of U.S. GDP requires tax rates of nearly 100 percent. Capital income tax rates must also exceed 40 percent to finance such a transfer which, in combination with taxes on asset income, imposes a severe drain on the U.S. capital stock.

\section{Conclusion}

This paper develops a large-scale computable general equilibrium model to evaluate the global consequences of automation, which we model as capital and high-skill biased technological change. Building on previous, foundational models, our approach lets us quantify the importance of theorized automation effects in general equilibrium. Our model is rich in macro detail, including region-specific demographics, production technologies, TFP growth. The model also features a highly detailed microfoundation, including endogenous labor supply, idiosyncratic mortality risk, and progressivity of tax and transfer systems. 
We find that projected rates of automation slightly increase the world interest rate, moderately increase output in automating regions, and significantly exacerbate inequality within and across regions. Through the mechanism theorized by Zeira (1998b), automation benefits developed countries such as the U.S., while leaving the least developed countries worse off. We evaluate forced industrialization policies for regions that would not otherwise automate. Additionally, we show that a UBI policy can make automation Pareto-improving for all U.S. workers.

In our baseline automation scenario, which projects innovations through 2050 consistent with the U.S.'s share shifts between 1980 and 2017, the U.S. labor share falls from 65.9 to 63.1 percent and the high-skilled share rises from 22.0 to 26.4 percent. The global increase in capital demand raises interest rates slightly relative to no-automation. However, due to an intensifying global capital glut, interest rates fall through the end of the century, stabilizing at roughly 2 percent. Automation dramatically exacerbates intra-region inequality. High-skilled Americans born in 2020 are 24.2 percent better off, and low-skilled Americans born in the same year are 12.8 percent worse off. Globally, 71.5 percent of people alive in 2050 are made worse off by automation, but the high-skilled are 10.3 percent better off on average.

Inter-region inequality is also exacerbated by automation. Countries with high TFPs, low corporate tax rates, and structural features that lead to high wages benefit the most from automation. Consequently, they tend to immediately adopt frontier technologies. Less developed regions delay adoption or never adopt. Nations that fail to adopt receive less investment, as capital flows to automating regions, and produce less output. The region that made worst off is Mexico, whose GDP declines by 3.6 percent in 2050 due, in large part, to a 9.2 percent relative decline in their capital stock. Nonetheless, the U.S.'s main competitors eventually adopt. Therefore, automation has a relatively marginal impact on the future global balance of economic power.

The U.S. would benefit more - by an additional 1 to 3 percent of GDP - were it the only region to automate or have access to the new technology. Automating technologies that do not disproportionately benefit high-skilled workers induce slightly more economic growth in the U.S. without substantially increasing wage inequality. Faster rates of labor-substituting technological change, which are not skill biased, are even more beneficial to the U.S. economy.

For regions that don't endogenously adopt automation, we evaluate a policy of forced industrialization, i.e. mandating that firms use the frontier technology. In India, but in no other non-automating region, this policy increases GDP due to capital onshoring and increased labor supply from immiserated low- and middle-skilled workers. However, automation remains inefficient in India and lowers welfare for the average worker. For regions that do adopt, the economic injury to low-skilled workers can be mitigated with fiscal policy. We consider universal basic income policies that redistribute automation's gains, improving the welfare of all U.S. workers, current and future. Paying for the UBI comes at a peak GDP cost of 5.1 percent, which we assume is covered, after a period of deficit finance, by progressive income taxation. The UBI imposes a relatively manageable burden on the U.S. economy, reducing GDP by 2.3 percent compared to the baseline by 2050 and reducing the welfare increase for the high-skilled from 6 to 30 percent to 3 to 14 percent. 


\section{References}

Daron Acemoglu and Pascual Restrepo. The race between man and machine: Implications of technology for growth, factor shares, and employment. American Economic Review, 108(6):1488-1542, 2018a.

Daron Acemoglu and Pascual Restrepo. Automation and new tasks: The implications of the task content of production for labor demand. Journal of Economic Perspectives, 33(2):3-30, 2018b.

Daron Acemoglu and Pascual Restrepo. The race between man and machine: Implications of technology for growth, factor shares, and employment. American Economic Review, 108(6):1488-1542, 2018c.

Daron Acemoglu and Pascual Restrepo. Automation and new tasks: How technology displaces and reinstates labor. Journal of Economic Perspectives, 33(2):3-30, May 2019. doi: 10.1257/jep.33.2.3. URL https://www. aeaweb.org/articles?id=10.1257/jep.33.2.3.

Daron Acemoglu and Pascual Restrepo. Robots and jobs: Evidence from us labor markets. Journal of Political Economy, 128(6):2188-2244, 2020.

Daron Acemoglu, Claire Lelarge, and Pascual Restrepo. Competing with robots: Firm-level evidence from france. 110:383-88, 2020.

David Altig, Alan J Auerbach, Laurence J Kotlikoff, Kent A Smetters, and Jan Walliser. Simulating Fundamental Tax Reform in the United States. American Economic Review, pages 574-595, 2001.

David Altig, Alan J Auerbach, Laurence J Kotlikoff, Elias Ilin, and Victor Yifan Ye. Marginal net taxation of americans' labor supply. Working Paper 27164, National Bureau of Economic Research, May 2020. URL http://www.nber.org/papers/w27164.

Facundo Alvaredo, Anthony B. Atkinson, Thomas Blanchet, Lucas Chancel, Luis Bauluz, Matthew Fisher-Post, Ignacio Flores, Bertrand Garbinti, Jonathan Goupille-Lebret, Clara MartínezToledano, Marc Morgan, Theresa Neef, Thomas Piketty, Anne-Sophie Robilliard, Emmanuel Saez, Li Yang, and Gabriel Zucman. Distributional national accounts guidelines: Methods and concepts used in the world inequality database. 2020.

Alan J Auerbach and Laurence J Kotlikoff. National savings, economic welfare, and the structure of taxation. Working Paper 729, National Bureau of Economic Research, August 1981. URL http: //www . nber.org/papers/w0729.

Alan J Auerbach and Laurence J Kotlikoff. National Savings, Economic Welfare, and the Structure of Taxation. In Behavioral Simulation Methods in Tax Policy Analysis, pages 459-498. University of Chicago Press, 1983.

Alan J Auerbach and Laurence J Kotlikoff. Dynamic Fiscal Policy, volume 11. Cambridge University Press Cambridge, 1987.

Alan J. Auerbach, Laurence J. Kotlikoff, Robert P. Hagemann, and Giuseppe Nicoletti. The economic dynamics of an ageing population. (62), 1989. doi: https://doi.org/https://doi.org/10.1787/ 054502801660. URL https://www.oecd-ilibrary.org/content/paper/054502801660.

Alan J Auerbach, Laurence J Kotlikoff, and Darryl R Koehler. US Inequality, Fiscal Progressivity, and Work Disincentives: An Intragenerational Accounting. Technical report, National Bureau of Economic Research, 2016.

David Autor, David Dorn, Lawrence F Katz, Christina Patterson, and John Van Reenen. The fall of the labor share and the rise of superstar firms. The Quarterly Journal of Economics, 135(2): 645-709, 2020.

David H. Autor. Why are there still so many jobs? the history and future of workplace automation. Journal of Economic Perspectives, 29(3):3-30, September 2015. doi: 10.1257/jep.29.3.3. URL https://www . aeaweb.org/articles?id=10.1257/jep.29.3.3. 
Seth G Benzell and Erik Brynjolfsson. Digital abundance and scarce genius: Implications for wages, interest rates, and growth. Technical report, National Bureau of Economic Research, 2019.

Seth G Benzell and Guillermo Lagarda. Can russia survive economic sanctions? Asian Economic Papers, 16(3):78-120, 2017.

Seth G Benzell, Eugene Goryunov, Maria Kazakova, Laurence J Kotlikoff, Guillermo LaGarda, Kristina Nesterova, and Andrey Zubarev. Simulating Russia's and Other Large Economies' Challenging and Interconnected Transitions. National Bureau of Economic Research Working Paper, 2015a.

Seth G Benzell, Laurence J Kotlikoff, Guillermo LaGarda, and Jeffrey D Sachs. Robots are us: Some economics of human replacement. Technical report, National Bureau of Economic Research, 2015b.

Seth G Benzell, Laurence J Kotlikoff, Guillermo Lagarda, and Jeffrey D Sachs. Robots Are Us: Some Economics of Human Replacement. NBER Working Paper, 2016.

Seth G. Benzell, Laurence J. Kotlikoff, Guillermo Lagarda, and Victor Yifan Ye. Simulating u.s. business cash flow taxation. 2020. URL https://kotlikoff.net/wp-content/uploads/2020/ 10/Simulating_Business_Cash_Flow_Taxation-2.pdf.

Elise Brezis, Paul Krugman, and Daniel Tsiddon. Leapfrogging in international competition: A theory of cycles in national technological leadership. American Economic Review, 83(5):1211-19, 1993. URL https://EconPapers.repec.org/RePEc:aea:aecrev:v:83:y:1993:i:5:p:1211-19.

Jesse Bricker, Lisa Dettling, Alice Henriques, Joanne W. Hsu, Lindsay Jacobs, Kevin B. Moore, Sarah Pack, John Sabelhaus, Jeffrey Thompson, and Richard A. Windle. Changes in u.s. family finances from 2013 to 2016: Evidence from the survey of consumer finances. Board of Governors of the Federal Reserve System, 2017. URL https://www.federalreserve.gov/econres/scf_2016.htm.

Erik Brynjolfsson, Tom Mitchell, and Daniel Rock. What can machines learn, and what does it mean for occupations and the economy? AEA Papers and Proceedings, 108:43-47, May 2018a. doi: 10. 1257/pandp.20181019. URL https://www . aeaweb.org/articles?id=10.1257/pandp. 20181019.

Erik Brynjolfsson, Tom Mitchell, and Daniel Rock. What can machines learn, and what does it mean for occupations and the economy? AEA Papers and Proceedings, 108:43-47, 2018b.

Bureau Census. Historical income tables: Households. 2019. URL https://www. census.gov/data/ tables/time-series/demo/income-poverty/historical-income-households.html.

Alexander V Chayanov. The Theory Of Peasant Economy. 1925.

Herbert Dawid. Chapter 25 agent-based models of innovation and technological change. volume 2 of Handbook of Computational Economics, pages 1235-1272. Elsevier, 2006. doi: https://doi. org/10.1016/S1574-0021(05)02025-3. URL https://www.sciencedirect.com/science/article/ pii/S1574002105020253.

Jan Philipp Dietrich, Christoph Schmitz, Hermann Lotze-Campen, Alexander Popp, and Christoph Müller. Forecasting technological change in agriculture - an endogenous implementation in a global land use model. Technological Forecasting and Social Change, 81:236-249, 2014.

Barry Eichengreen. Secular stagnation: the long view. The American Economic Review, 105(5): 66-70, 2015.

Alexander Erlich. Preobrazhenski and the Economics of Soviet Industrialization. The Quarterly Journal of Economics, 64(1):57-88, 02 1950. ISSN 0033-5533. doi: 10.2307/1881959. URL https: //doi.org/10.2307/1881959.

Hans Fehr, Sabine Jokisch, and Laurence Kotlikoff. The Developed World's Demographic Transition - The Roles of Capital Flows, Immigration, and Policy. (10096), November 2003.

Hans Fehr, Sabine Jokisch, Ashwin Kambhampati, and Laurence J Kotlikoff. Simulating the Elimination of the U.S. Corporate Income Tax. 2013a.

Hans Fehr, Sabine Jokisch, and Laurence Kotlikoff. The world's interconnected demographic/fiscal 
transition. The Journal of the Economics of Ageing, 2013b.

Carl Benedikt Frey and Michael A Osborne. The future of employment: how susceptible are jobs to computerisation. Retrieved September, 2013. URL http://arche.depotoi.re/autoblogs/ wwwinternetactunet\{_\}8a3fe3331e0ad7327e18d9fe6ec3f0ad04dcea58/media/3722fa7d.

The \{_\}Future\{_\}of \{_\}Employment.pdf.

Milton Friedman. The case for a negative income tax: A view from the right. Retrieved from the Anthology - Basic income: An anthology of contemporary research, pages 11-16, 1966.

Don Fullerton and Diane Lim Rogers. Lifetime Effects of Fundamental Tax Reform. Economic Effects of Fundamental Tax Reform, pages 321-354, 1996.

Maarten Goos, Alan Manning, and Anna Salomons. Explaining Job Polarization in Europe: The Roles of Technology, Globalization and Institutions. CEP Discussion Papers, 2011. URL http: //ideas.repec.org/p/cep/cepdps/dp1026.html.

ILOStat. Statistics on the working-age population and labour force. 2020. URL https://ilostat. ilo.org/topics/population-and-labour-force/.

IMF. Imf investment and capital stock dataset, 2019. 2019a.

IMF. Balance of payments and international investment position statistics. 2019b.

International Monetary Fund. Government Finance Statistics. IMF, 2017.

Kenneth L. Judd. Redistributive taxation in a simple perfect foresight model. Journal of Public Economics, 28(1):59-83, 1985. ISSN 0047-2727. doi: https://doi.org/10.1016/0047-2727(85)90020-9. URL https://www. sciencedirect.com/science/article/pii/0047272785900209.

Loukas Karabarbounis and Brent Neiman. The global decline of the labor share. The Quarterly journal of economics, 129(1):61-103, 2014.

Lawrence F Katz and Robert A Margo. Technical change and the relative demand for skilled labor: The united states in historical perspective. In Human capital in history: The American record, pages 15-57. University of Chicago Press, 2014.

John Maynard Keynes. Economic possibilities for our grandchildren. In Essays in persuasion; as reproduced in 2010 edition., pages 321-332. Springer, 1930.

Florian Knobloch, Hector Pollitt, Unnada Chewpreecha, Richard Lewney, Mark AJ Huijbregts, and Jean-Francois Mercure. Ftt: Heat - a simulation model for technological change in the european residential heating sector. Energy Policy, 153:112249, 2021.

Karl Marx. Capital: volume one. Courier Dover Publications, 1867. 2019 printing in English translation.

Andrew McAfee and Erik Brynjolfsson. Machine, platform, crowd: Harnessing our digital future. WW Norton \& Company, 2017.

Ulrich K Müller, James H Stock, and Mark W Watson. An econometric model of international long-run growth dynamics. Technical report, National Bureau of Economic Research, 2019.

Jaeger Nelson and Kerk Phillips. Macroeconomic effects of reducing oasi benefits: A comparison of seven overlapping-generations models. National Tax Journal, 2019.

Pietro F Peretto and John J Seater. Factor-eliminating technical change. Journal of Monetary Economics, 60(4):459-473, 2013.

Yevgeni Preobrazhensky. The New Economics: Experience of the Theoretical Analysis of the Soviet Economy. 1926.

Jeffrey D Sachs, Seth G Benzell, and Guillermo LaGarda. Robots: Curse or blessing? a basic framework. Working Paper 21091, National Bureau of Economic Research, April 2015a. URL http://www . nber.org/papers/w21091.

Jeffrey D Sachs, Seth G Benzell, and Guillermo LaGarda. Robots: Curse or blessing? a basic framework. Technical report, National Bureau of Economic Research, 2015b. 
Robert Tibshirani. Regression shinkage and selection via the lasso. Journal of the Royal Statistical Society, Series B (Methodological), 58(1):267-288, 1996.

Wikipedia contributors. Imagenet - Wikipedia, the free encyclopedia, 2021. URL https:// en.wikipedia.org/w/index.php?title=ImageNet\&oldid=1021861077. [Online; accessed 9-May2021].

World Bank. Fossil Fuel Rents, Natural Resource Rents, 2021. Data Retrieved from World Development Indicators, http://data.worldbank.org/indicator.

Joseph Zeira. Workers, Machines, and Economic Growth. The Quarterly Journal of Economics, 113 (4):1091-1117, 1998a. URL http://ideas.repec.org/a/oup/qjecon/v113y1998i4p1091-1117. .html.

Joseph Zeira. Workers, machines, and economic growth. The Quarterly Journal of Economics, 113 (4):1091-1117, 1998b.

Hernando Zuleta. Factor saving innovations and factor income shares. Review of Economic Dynamics, 11(4):836-851, 2008.

\section{Appendix}

Figure A1: UN and Model Population Projections (Continued)
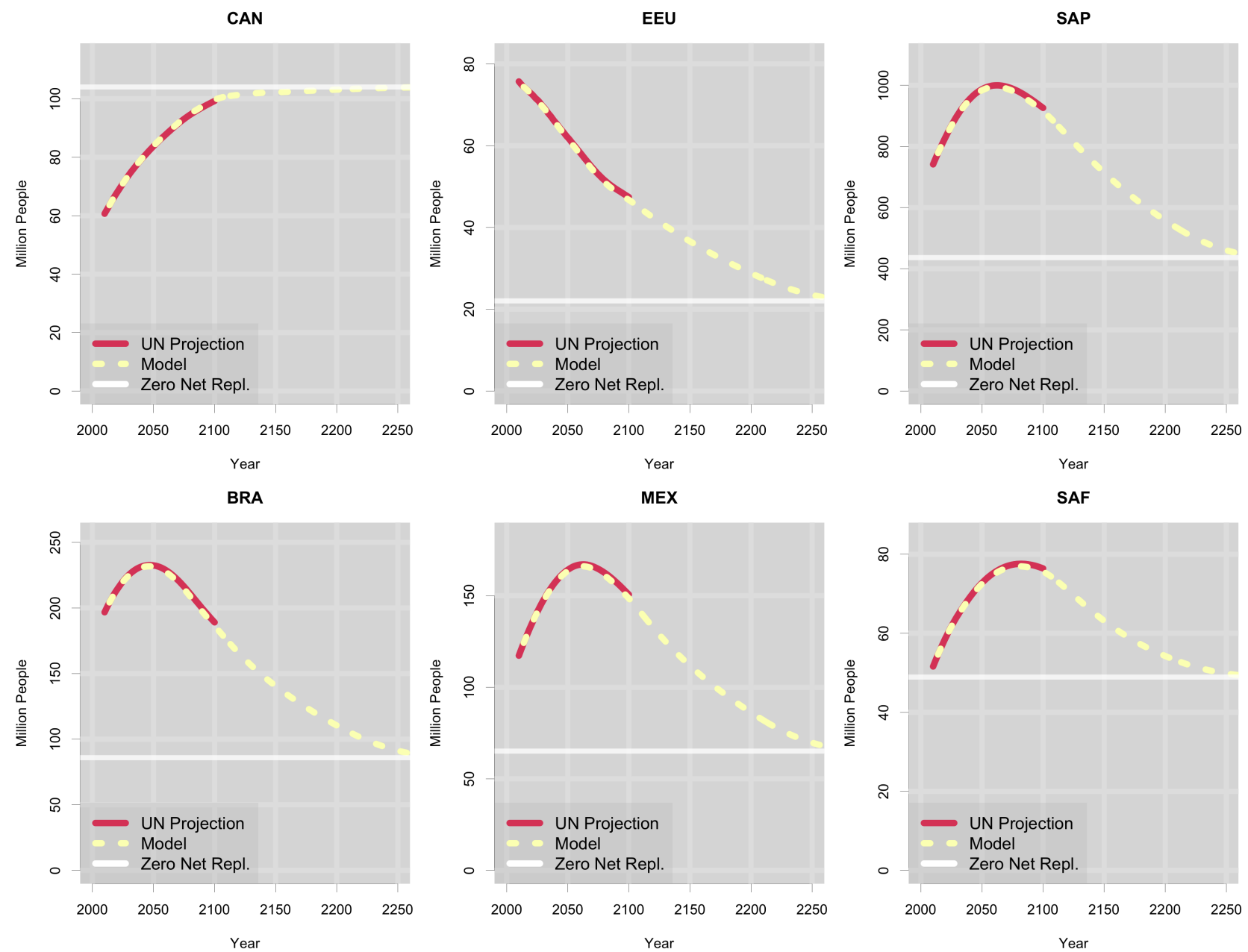
Figure A2: UN and Model Population Projections (Continued)
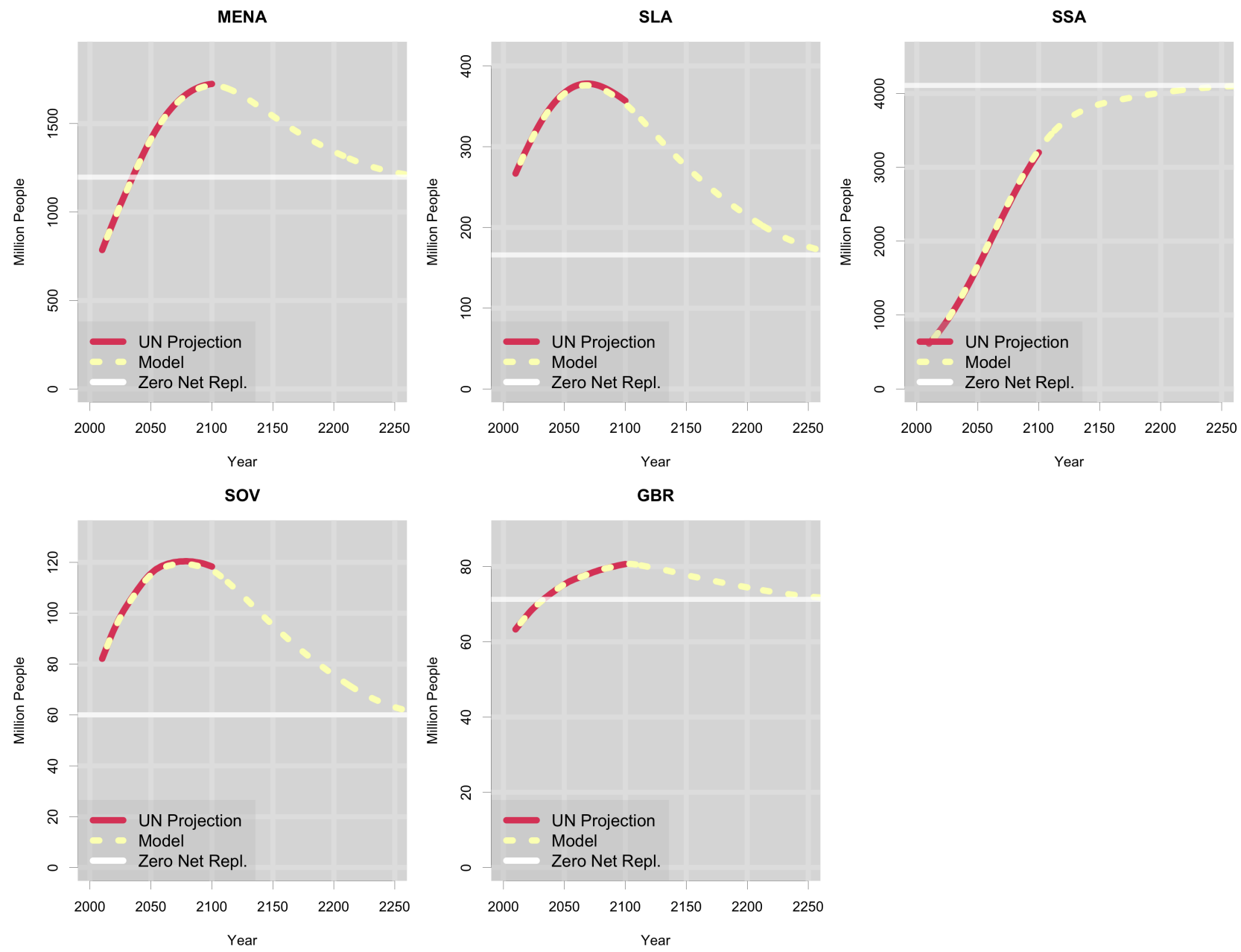

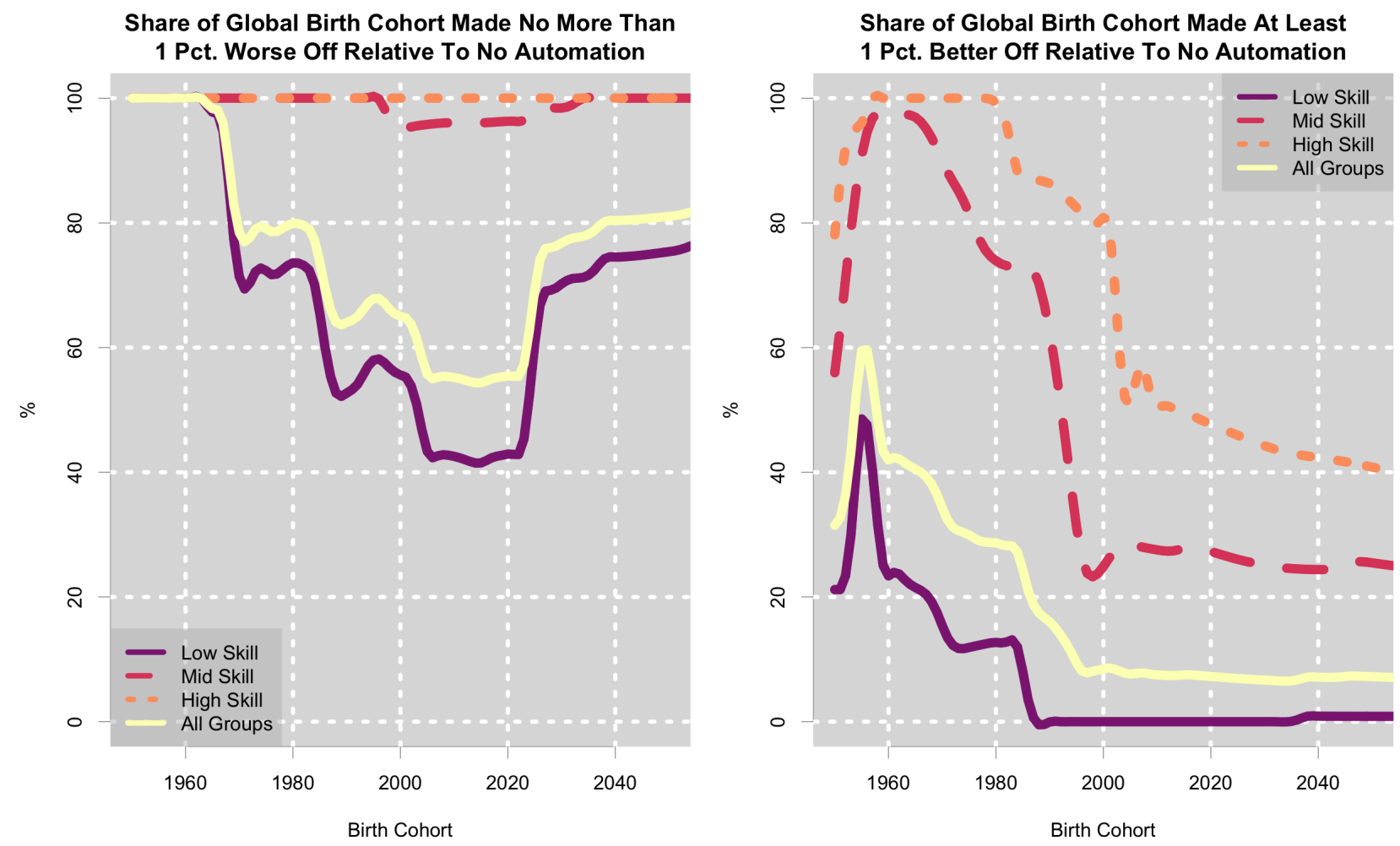

Figure A3: Global Lifetime Welfare Consequence of Baseline Automation By Birth Cohort
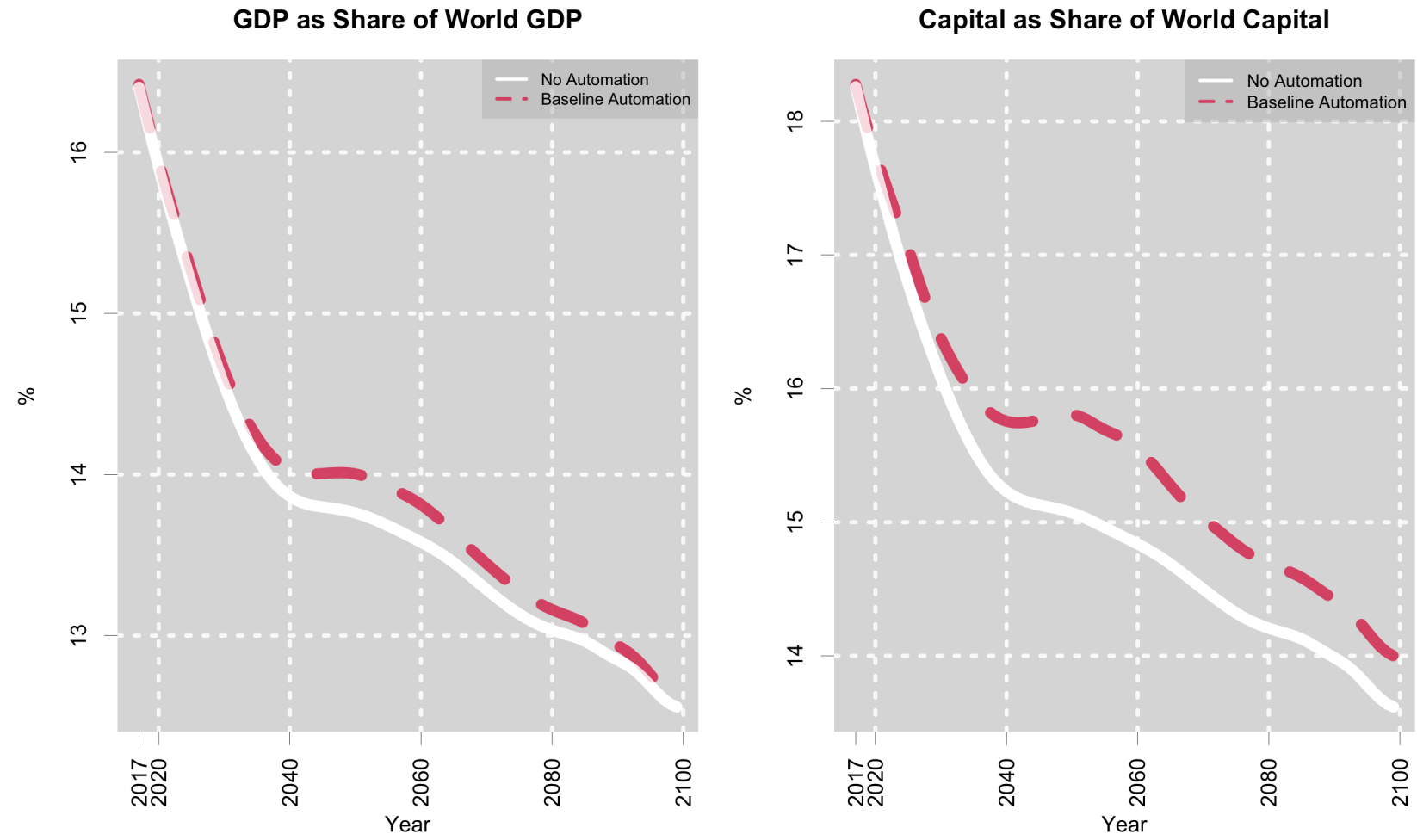

Figure A4: U.S. GDP and Capital as Share of World With and Without Baseline Automation 
U.S. Birth Cohort Average Percent Change to Lifetime Welfare Relative to No Automation

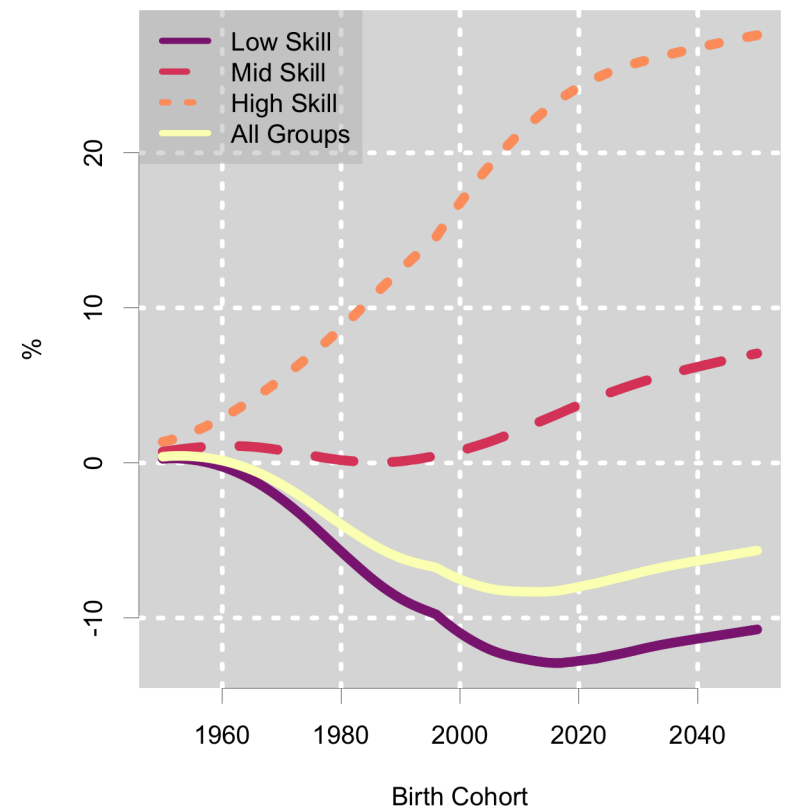

U.S. Adult Average Percent Change to Lifetime Welfare Relative to No Automation

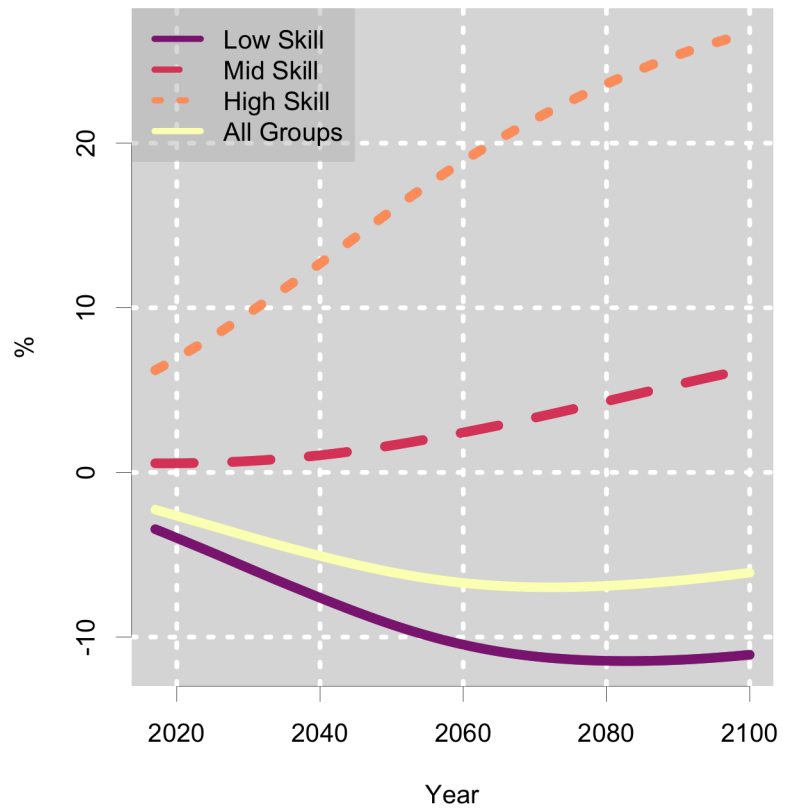

Figure A5: U.S. Lifetime Welfare Consequence of Baseline Automation By Year and Birth Cohort

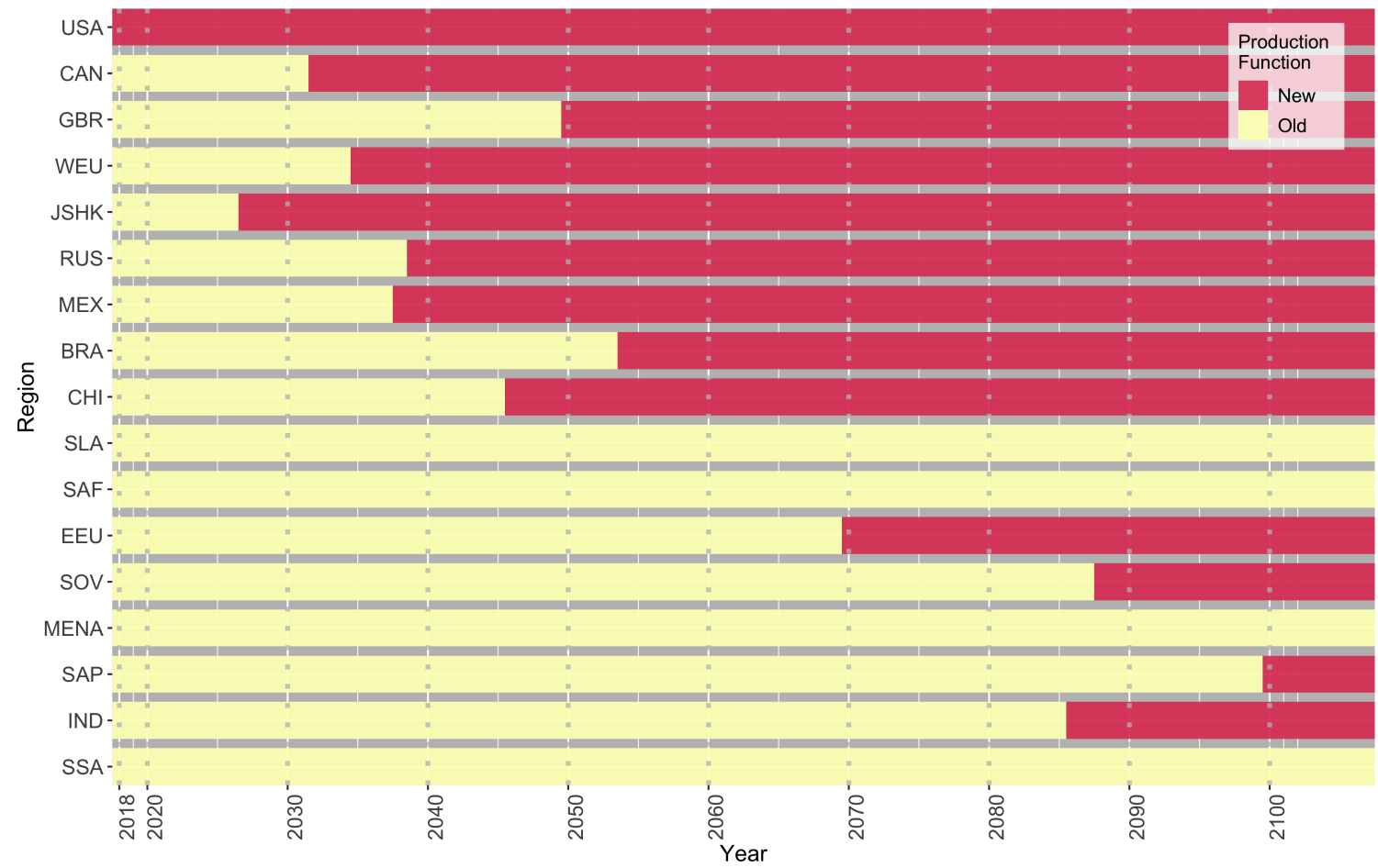

Figure A6: Choice Of Production Function By Region, Automation Without Rising Inequality 


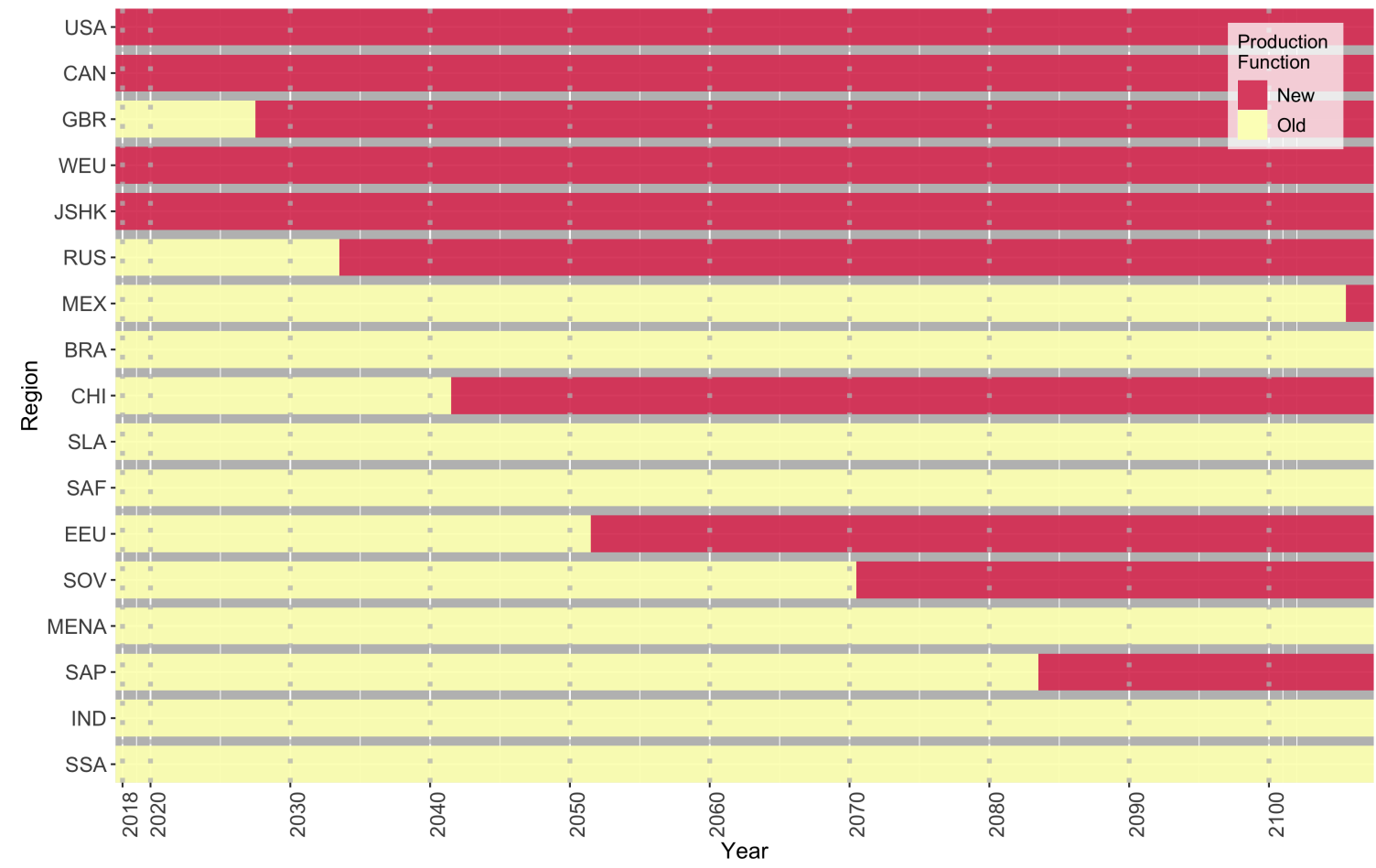

Figure A7: Choice Of Production Function, Automation With Five Times the Baseline Rate of Capital Share Increase

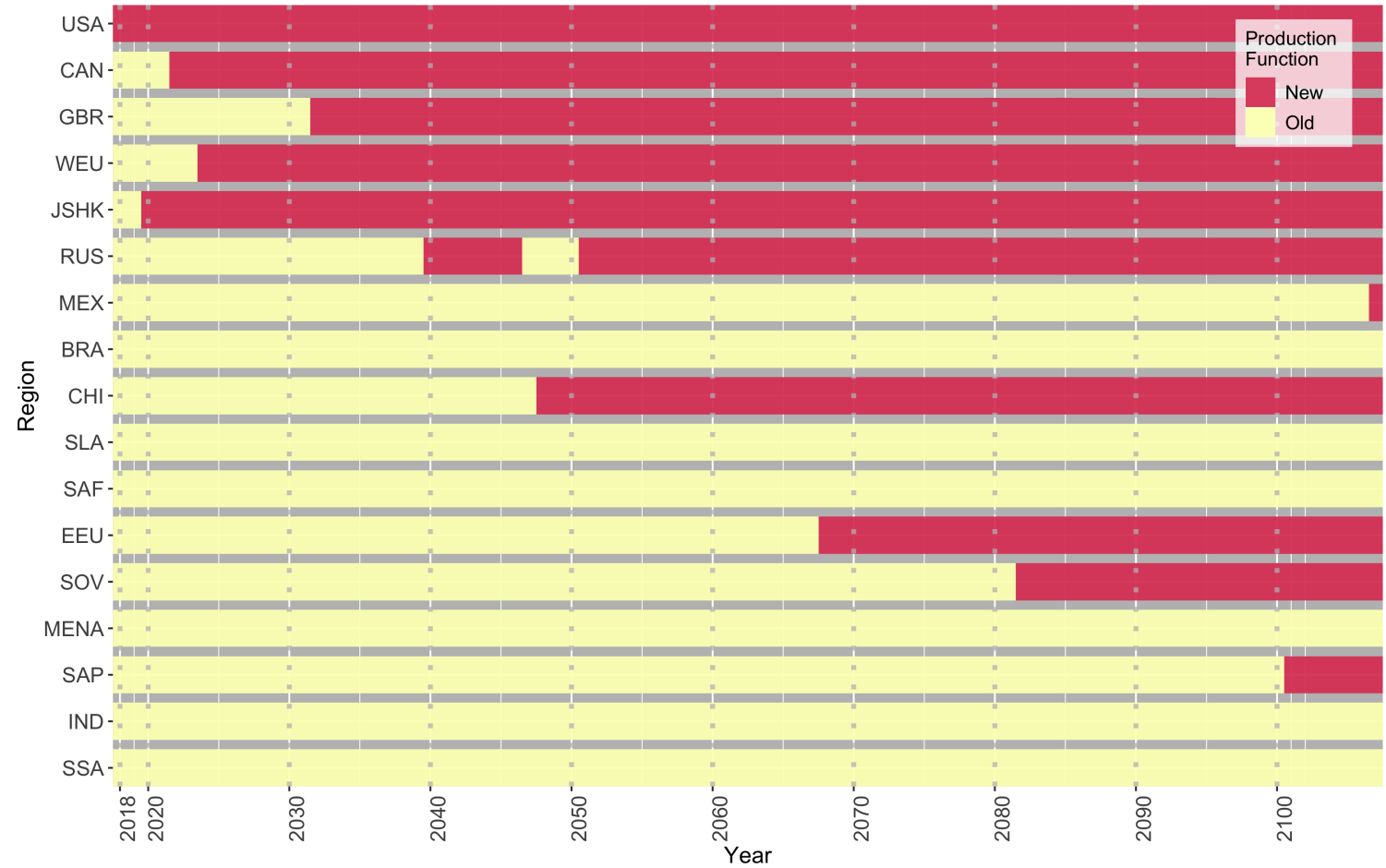

Figure A8: Choice Of Production Function, Automation With Ten Times the Baseline Rate of Capital Share Increase 


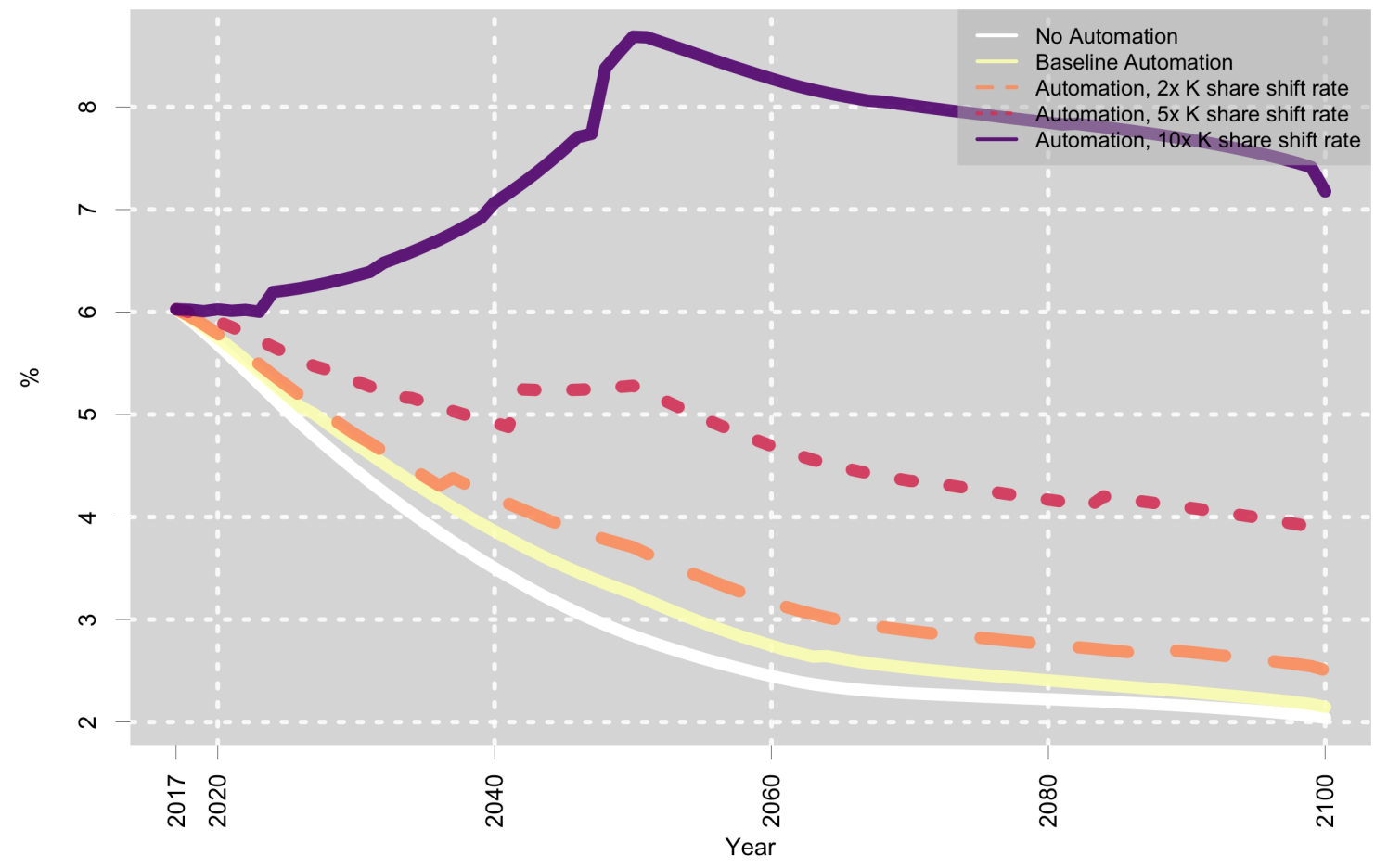

Figure A9: World Interest Rate By Automation Rate Scenario

Capital Stock Relative to No Automation

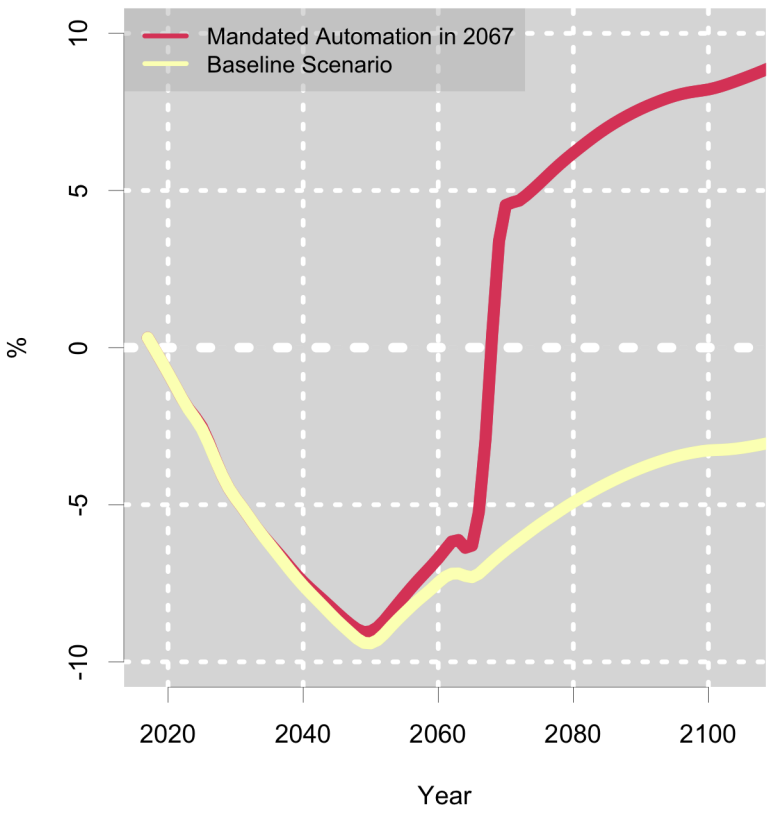

Net Foreign Assets Relative to No Automation

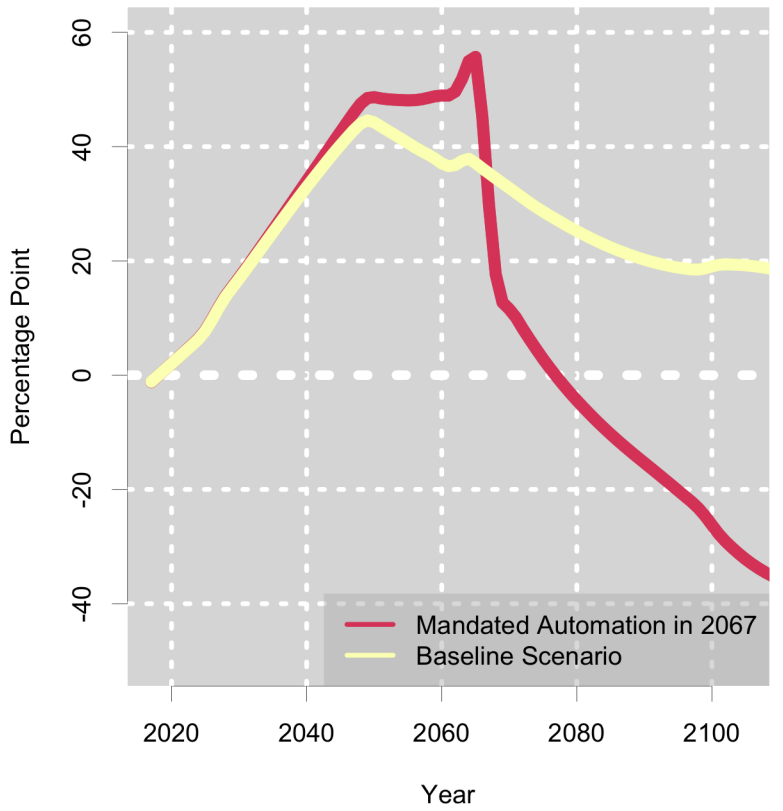

Figure A10: Indian Capital Stock and Net Foreign Asset Position Relative to No-Automation 

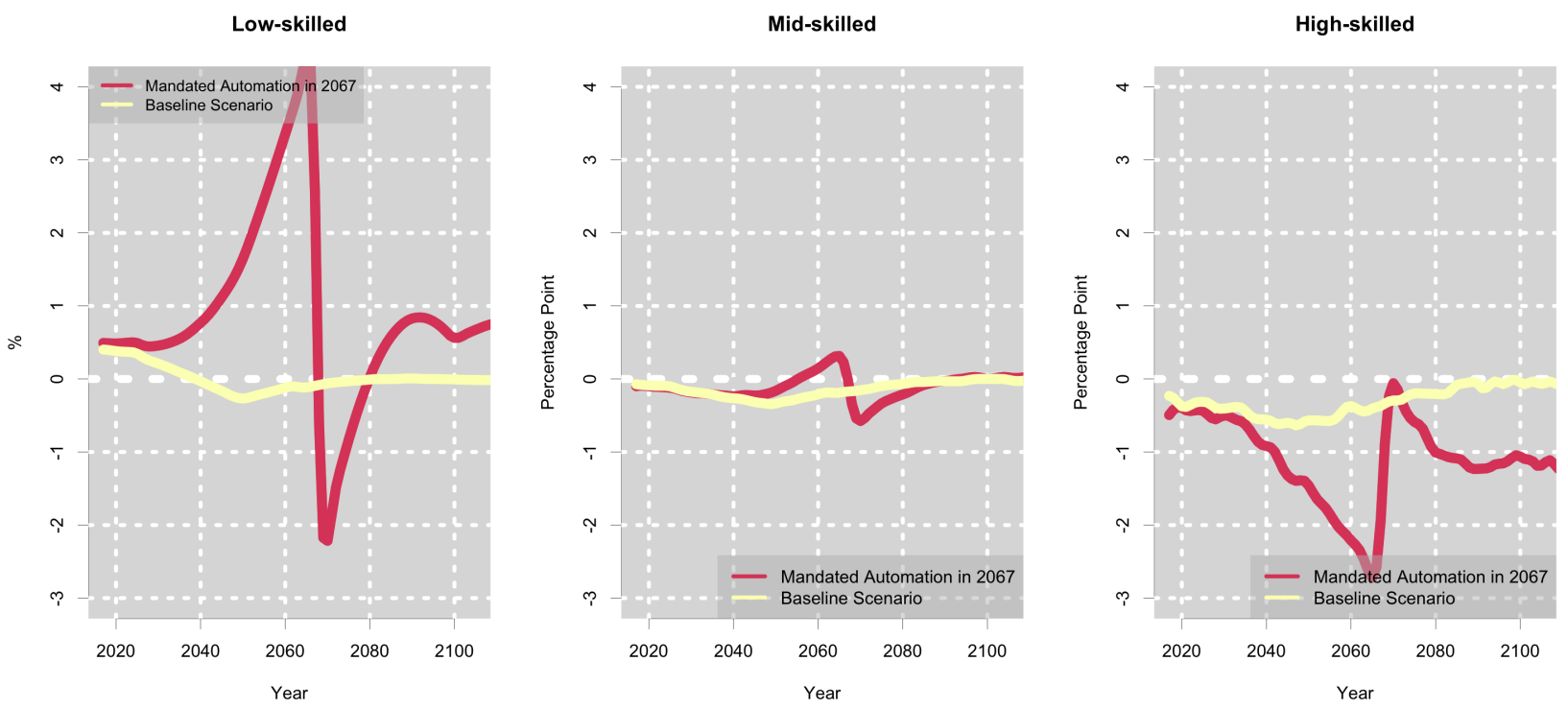

Figure A11: Indian Labor Supply Relative to No-Automation

Relative to Baseline

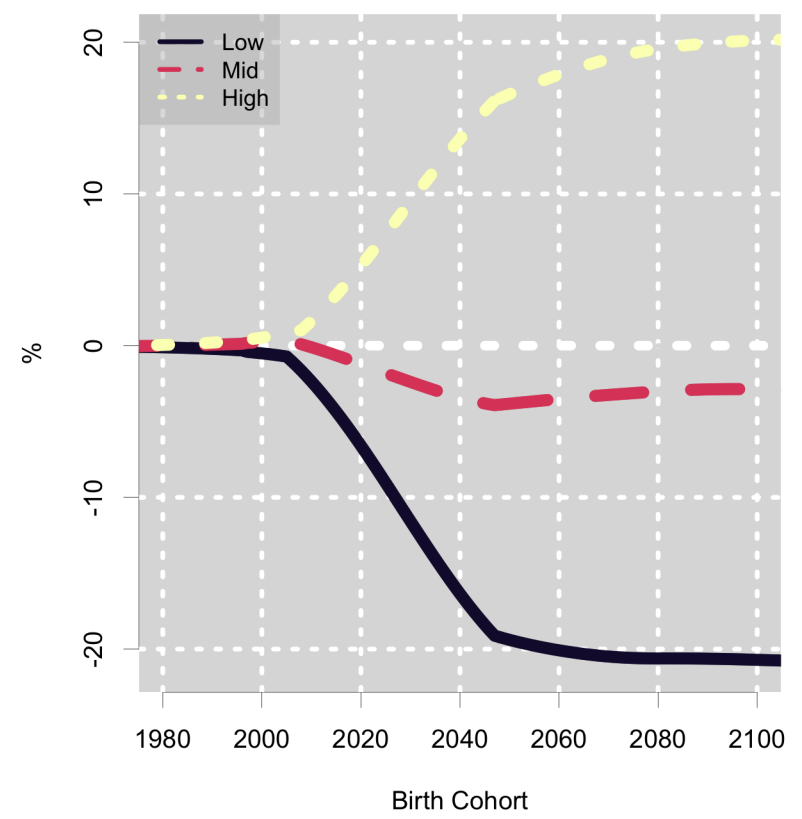

Relative To No Automation

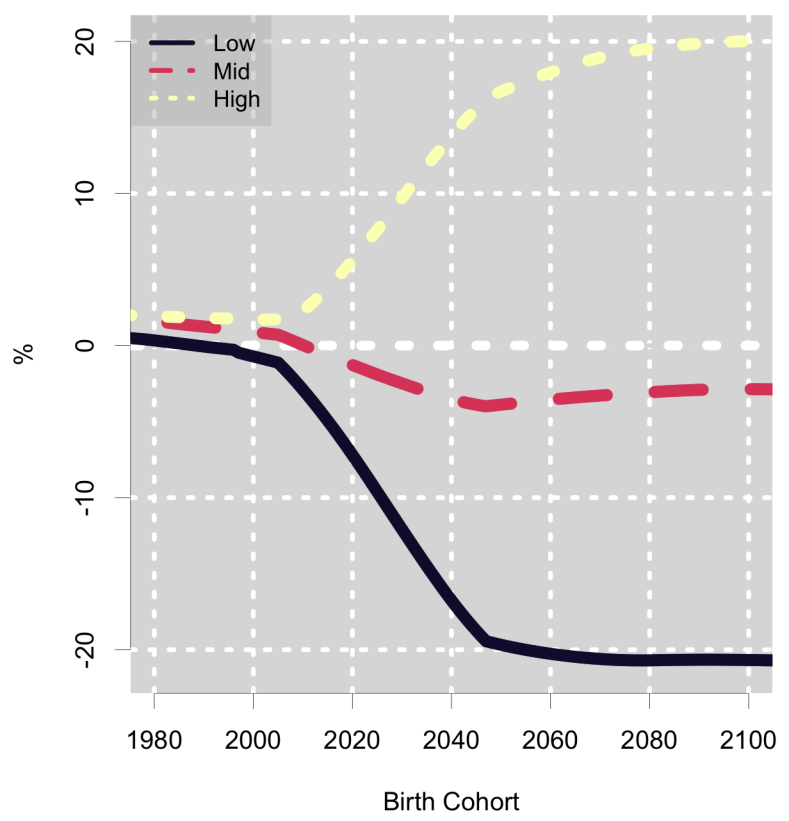

Figure A12: Indian Workers' Lifetime Welfare Change from Mandating Automation, Baseline Scenario 
Relative to Non-Skill-Biased Automation

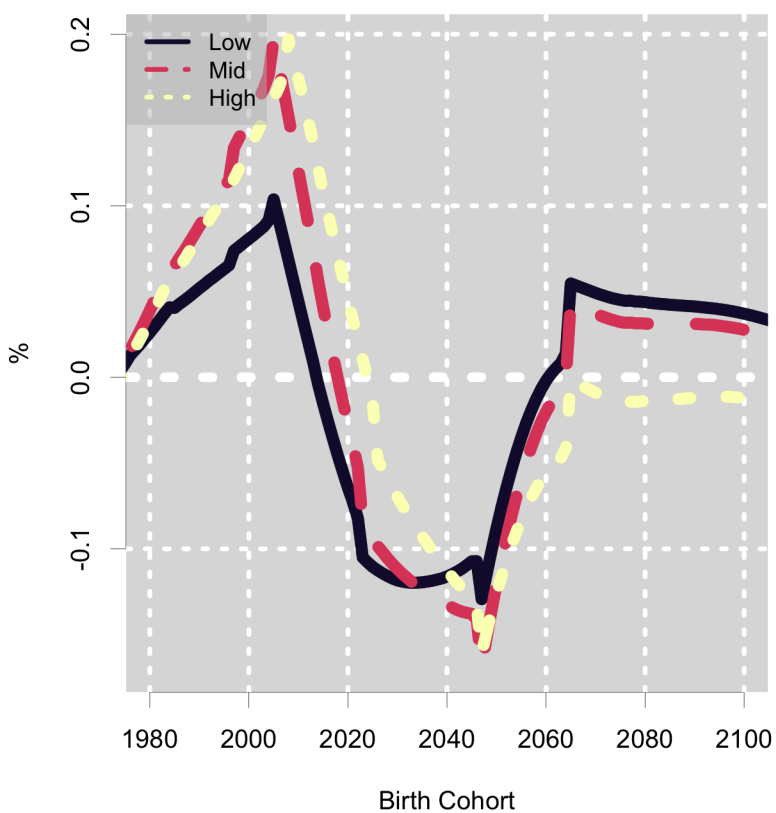

Relative To No Automation

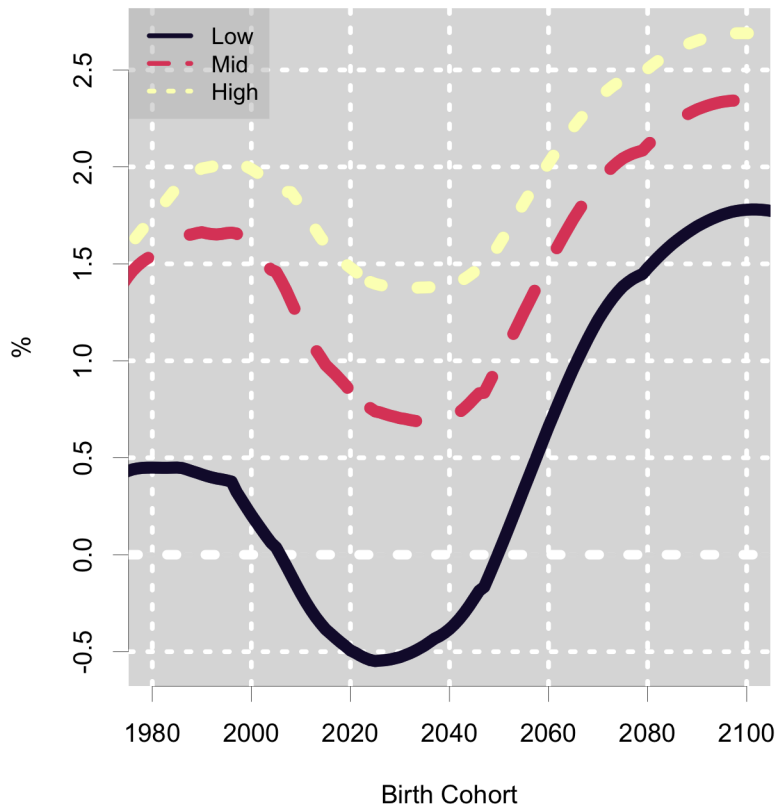

Figure A13: Indian Workers' Lifetime Welfare Change from Mandating Automation, Non-Skill-Biased Automation

Avg. Income Tax Rate

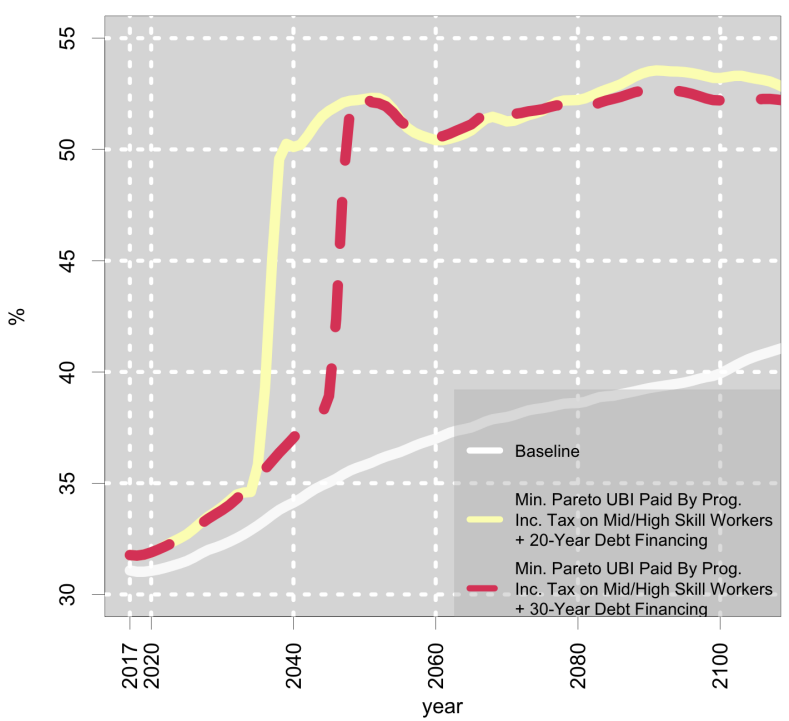

Income Tax Percent Increase From Baseline

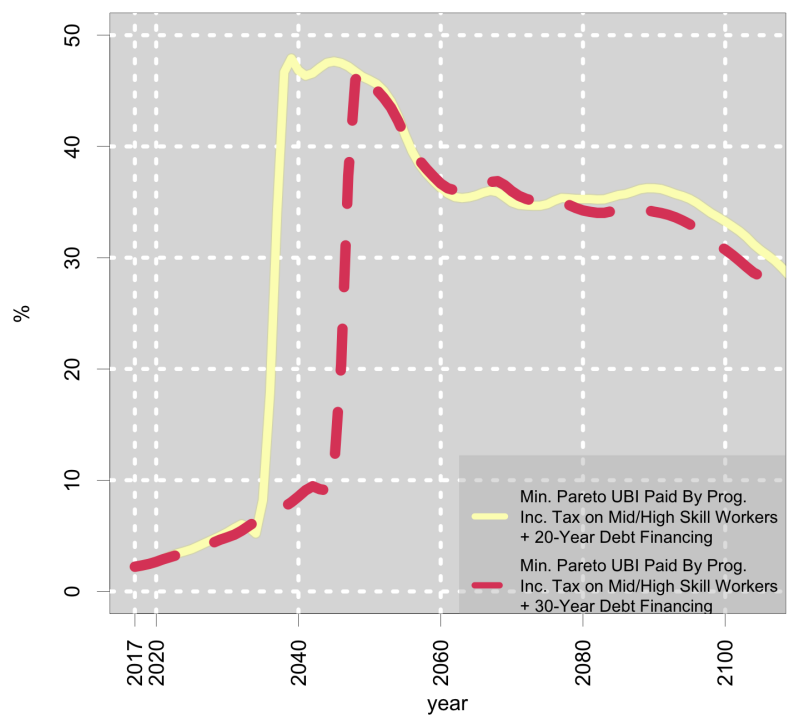

Figure A14: Income Tax Rate By UBI Scenario, High-skilled Workers 

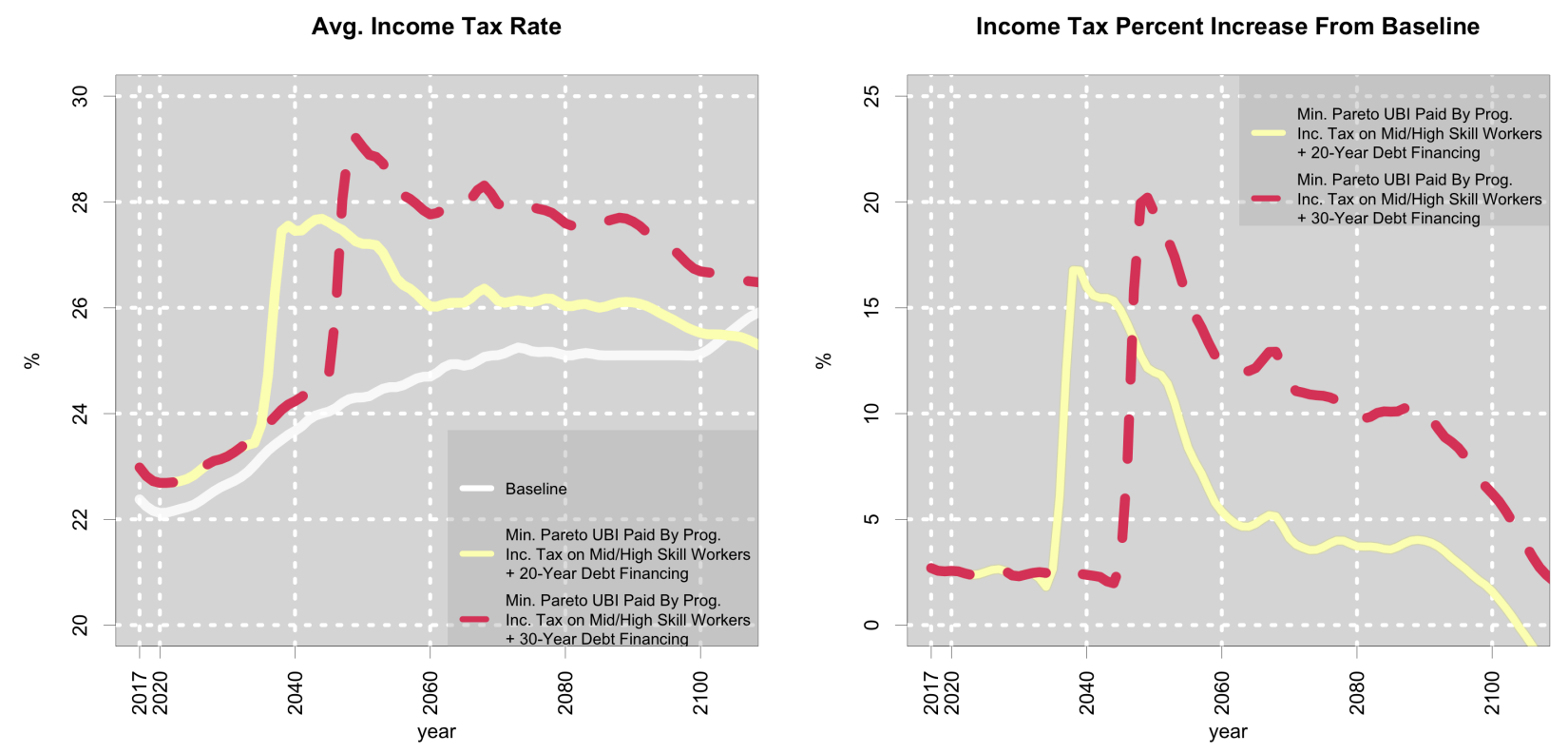

Figure A15: Income Tax Rate By UBI Scenario, middle-skilled Workers

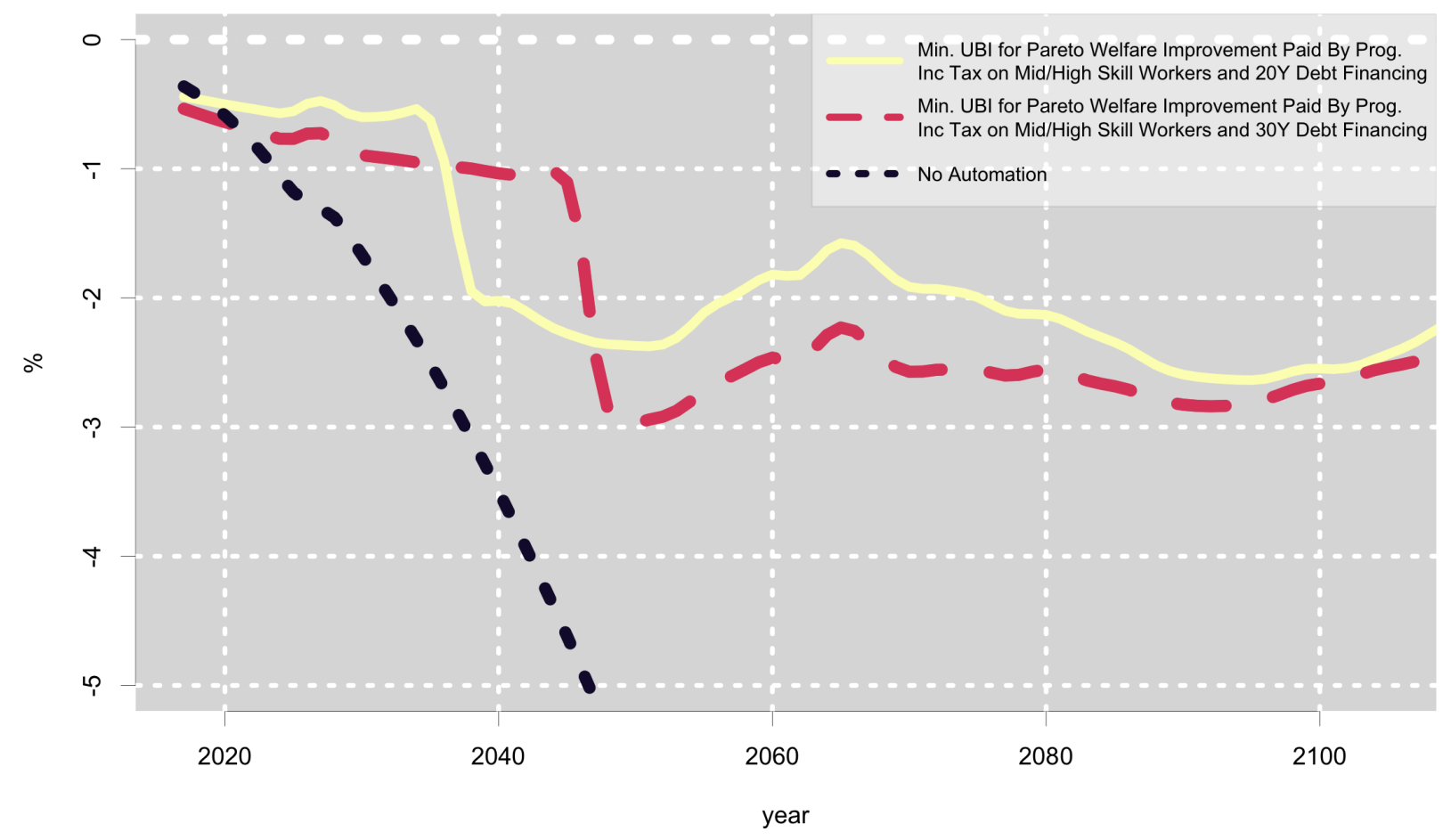

Figure A16: GDP Under UBI Policies Relative to Baseline Automation 


\begin{tabular}{|c|c|}
\hline Region & Countries \\
\hline BRA & Brazil \\
\hline CAN & Canada, Australia, New Zealand \\
\hline $\mathrm{CHI}$ & China \\
\hline EEU & Belarus, Republic of Moldova, Ukraine, Albania, Bosnia and Herzegovina, Montenegro, Serbia \\
\hline GBR & United Kingdom \\
\hline IND & India \\
\hline JSHK & China, Hong Kong SAR, Japan, Republic of Korea, Singapore \\
\hline MENA & $\begin{array}{l}\text { Ethiopia, Algeria, Egypt, Libya, Morocco, Sudan, Tunisia, Western Sahara, Mali, Afghanistan, } \\
\text { Iran (Islamic Republic of), Pakistan, Bahrain, Iraq, Jordan, Kuwait, Lebanon, Oman, Qatar, } \\
\text { Saudi Arabia, Syrian Arab Republic, Turkey, United Arab Emirates, Yemen }\end{array}$ \\
\hline MEX & Mexico \\
\hline RUS & Russian Federation \\
\hline SAF & South Africa \\
\hline SAP & $\begin{array}{l}\text { Bangladesh, Nepal, Sri Lanka, Brunei Darussalam, Cambodia, Indonesia, Lao People's Demo- } \\
\text { cratic Republic, Malaysia, Philippines, Thailand, Timor-Leste, Viet Nam }\end{array}$ \\
\hline SLA & $\begin{array}{l}\text { Sao Tome and Principe, Antigua and Barbuda, Bahamas, Barbados, Dominican Republic, } \\
\text { Grenada, Haiti, Jamaica, Saint Lucia, Saint Vincent and the Grenadines, Trinidad and To- } \\
\text { bago, Belize, Costa Rica, El Salvador, Guatemala, Honduras, Nicaragua, Panama, Argentina, } \\
\text { Bolivia (Plurinational State of), Chile, Colombia, Ecuador, Guyana, Paraguay, Peru, Suriname, } \\
\text { Uruguay, Venezuela (Bolivarian Republic of) }\end{array}$ \\
\hline SOV & $\begin{array}{l}\text { Mongolia, Kazakhstan, Kyrgyzstan, Tajikistan, Turkmenistan, Uzbekistan, Armenia, Azerbai- } \\
\text { jan, Georgia }\end{array}$ \\
\hline SSA & $\begin{array}{l}\text { Eritrea, Kenya, Madagascar, Mozambique, Rwanda, South Sudan, Uganda, United Republic of } \\
\text { Tanzania, Zambia, Zimbabwe, Angola, Cameroon, Central African Republic, Congo, Democratic } \\
\text { Republic of the Congo, Equatorial Guinea, Gabon, Botswana, Lesotho, Namibia, Swaziland, } \\
\text { Burkina Faso, Côte d'Ivoire, Gambia, Ghana, Liberia, Niger, Nigeria, Senegal, Sierra Leone, } \\
\text { Togo, Tonga }\end{array}$ \\
\hline USA & United States of America \\
\hline WEU & $\begin{array}{l}\text { Cyprus, Israel, Bulgaria, Czechia, Hungary, Poland, Romania, Slovakia, Channel Islands, Den- } \\
\text { mark, Estonia, Finland, Iceland, Ireland, Latvia, Lithuania, Norway, Sweden, Croatia, Greece, } \\
\text { Italy, Malta, Portugal, Slovenia, Spain, Austria, Belgium, France, Germany, Luxembourg, } \\
\text { Netherlands, Switzerland }\end{array}$ \\
\hline
\end{tabular}

Table A1: Full List of Countries in Each Region

\begin{tabular}{l|ccc}
\hline & 2017 & 2050 & 2100 \\
\hline \hline USA & 16.4 & 13.8 & 12.5 \\
WEU & 17.1 & 11.9 & 10.1 \\
JSHK & 6.9 & 6.5 & 6.2 \\
CHI & 16.6 & 22.1 & 25.1 \\
IND & 7.0 & 9.6 & 11.4 \\
RUS & 3.2 & 1.8 & 1.4 \\
\hline CAN & 2.7 & 2.4 & 2.2 \\
EEU & 0.8 & 0.7 & 0.7 \\
SAP & 6.6 & 7.5 & 6.9 \\
BRA & 2.5 & 2.2 & 1.5 \\
MEX & 2.1 & 2.0 & 1.3 \\
SAF & 0.6 & 0.5 & 0.4 \\
\hline MENA & 8.7 & 9.5 & 10.1 \\
SLA & 3.2 & 3.1 & 2.4 \\
SSA & 2.2 & 3.3 & 4.7 \\
SOV & 0.9 & 1.2 & 1.4 \\
GBR & 2.6 & 1.9 & 1.6 \\
\hline
\end{tabular}

Table A2: Share of GDP As Percent of Global Output, No Automation 


\begin{tabular}{l|ccc}
\hline & 2017 & 2050 & 2100 \\
\hline \hline USA & 1.00 & 1.94 & 3.96 \\
WEU & 0.93 & 1.79 & 4.16 \\
JSHK & 0.72 & 2.05 & 6.43 \\
CHI & 0.23 & 0.89 & 3.44 \\
IND & 0.10 & 0.32 & 1.05 \\
RUS & 0.44 & 0.76 & 1.58 \\
\hline CAN & 0.81 & 1.55 & 3.15 \\
EEU & 0.15 & 0.46 & 1.54 \\
SAP & 0.16 & 0.42 & 1.05 \\
BRA & 0.24 & 0.53 & 1.13 \\
MEX & 0.32 & 0.67 & 1.22 \\
SAF & 0.21 & 0.41 & 0.76 \\
\hline MENA & 0.19 & 0.37 & 0.83 \\
SLA & 0.22 & 0.46 & 0.95 \\
SSA & 0.06 & 0.11 & 0.21 \\
SOV & 0.20 & 0.56 & 1.69 \\
GBR & 0.76 & 1.36 & 2.78 \\
\hline
\end{tabular}

Table A3: GDP Per Capita Relative to 2017 U.S. Level, No Automation

\begin{tabular}{l|ccc|ccc}
\hline & \multicolumn{3}{|c}{ Asset Share (\%) } & \multicolumn{3}{c}{ Capital Share (\%) } \\
& 2017 & 2050 & 2100 & 2017 & 2050 & 2100 \\
\hline \hline USA & 16.8 & 6.1 & 5.4 & 18.2 & 15.1 & 13.6 \\
WEU & 16.1 & 10.4 & 7.9 & 16.7 & 10.9 & 9.0 \\
JSHK & 9.3 & 5.9 & 4.9 & 8.4 & 7.4 & 6.8 \\
CHI & 17.4 & 35.7 & 34.9 & 18.8 & 25.7 & 29.3 \\
IND & 6.6 & 11.7 & 13.1 & 6.2 & 9.0 & 10.9 \\
RUS & 4.1 & 2.4 & 1.5 & 3.8 & 2.4 & 2.0 \\
\hline CAN & 2.7 & 1.4 & 1.2 & 2.8 & 2.5 & 2.3 \\
EEU & 0.7 & 0.1 & 0.3 & 0.8 & 0.7 & 0.7 \\
SAP & 5.5 & 7.9 & 8.8 & 6.1 & 7.1 & 6.5 \\
BRA & 3.0 & 2.3 & 1.9 & 2.5 & 2.4 & 1.7 \\
MEX & 1.9 & 1.5 & 1.3 & 2.2 & 2.2 & 1.4 \\
SAF & 0.6 & 0.6 & 0.5 & 0.5 & 0.5 & 0.4 \\
\hline MENA & 9.0 & 9.0 & 10.2 & 6.4 & 7.1 & 7.6 \\
SLA & 2.0 & 1.8 & 2.2 & 2.1 & 1.9 & 1.5 \\
SSA & 1.9 & 1.7 & 3.8 & 1.8 & 2.8 & 4.1 \\
SOV & 0.6 & 0.8 & 1.4 & 0.7 & 0.9 & 1.1 \\
GBR & 1.9 & 0.5 & 0.8 & 2.0 & 1.3 & 1.1 \\
\hline
\end{tabular}

Table A4: Shares of Assets and Capital as Percent of Global Assets and Capital, No Automation

\begin{tabular}{l|ccc}
\hline & 2017 & 2050 & 2100 \\
\hline \hline $\begin{array}{l}\text { Avg. Pension } \\
\text { Tax Rate (\%) }\end{array}$ & 13.5 & 16.3 & 26.8 \\
$\begin{array}{l}\text { Pension Benefits } \\
\text { as Share of GDP (\%) } \\
\text { Consumption }\end{array}$ & 5.0 & 6.0 & 10.0 \\
$\begin{array}{l}\text { Tax Rate (\%) } \\
\text { Avg. Income }\end{array}$ & 9.0 & 9.9 & 10.8 \\
Tax Rate (\%) & 24.4 & 27.4 & 28.6 \\
\hline
\end{tabular}

Table A5: U.S. Endogenous Tax Rates and Pension Benefits, No Automation 


\begin{tabular}{l|ccc}
\hline & $\begin{array}{c}\text { No } \\
\text { Automation }\end{array}$ & $\begin{array}{c}\text { Baseline } \\
\text { Automation }\end{array}$ & $\begin{array}{c}\text { Automation } \\
\text { W/O Rising } \\
\text { Inequality }\end{array}$ \\
\hline \hline K & 0.341 & 0.369 & 0.369 \\
L High & 0.220 & 0.264 & 0.210 \\
L Med & 0.220 & 0.205 & 0.210 \\
L Low & 0.220 & 0.161 & 0.210 \\
\hline
\end{tabular}

\begin{tabular}{l|ccc}
\hline \multicolumn{4}{c}{ USA } \\
\hline & $\begin{array}{c}\text { No } \\
\text { Automation }\end{array}$ & $\begin{array}{c}\text { Baseline } \\
\text { Automation }\end{array}$ & $\begin{array}{c}\text { Automation } \\
\text { W/O Rising } \\
\text { Inequality }\end{array}$ \\
\hline \hline K & 0.487 & 0.509 & 0.509 \\
L High & 0.171 & 0.206 & 0.164 \\
L Med & 0.171 & 0.160 & 0.164 \\
L Low & 0.171 & 0.125 & 0.164 \\
\hline
\end{tabular}

JSHK

\begin{tabular}{l|ccc}
\hline & $\begin{array}{c}\text { No } \\
\text { Automation }\end{array}$ & $\begin{array}{c}\text { Baseline } \\
\text { Automation }\end{array}$ & $\begin{array}{c}\text { Automation } \\
\text { W/O Rising } \\
\text { Inequality }\end{array}$ \\
\hline \hline K & 0.368 & 0.395 & 0.395 \\
L High & 0.211 & 0.254 & 0.202 \\
L Med & 0.211 & 0.197 & 0.202 \\
L Low & 0.211 & 0.154 & 0.202 \\
\hline
\end{tabular}

\begin{tabular}{l|ccc}
\hline \multicolumn{4}{c}{ WEU } \\
\hline & $\begin{array}{c}\text { No } \\
\text { Automation }\end{array}$ & $\begin{array}{c}\text { Baseline } \\
\text { Automation }\end{array}$ & $\begin{array}{c}\text { Automation } \\
\text { W/O Rising } \\
\text { Inequality }\end{array}$ \\
\hline \hline K & 0.383 & 0.409 & 0.409 \\
L High & 0.206 & 0.248 & 0.197 \\
L Med & 0.206 & 0.192 & 0.197 \\
L Low & 0.206 & 0.151 & 0.197 \\
\hline
\end{tabular}

CHI

Table A6: 2050 Output Shares of Capital and Labor By Skill Group

\begin{tabular}{|c|c|c|c|}
\hline & $\begin{array}{c}\text { No } \\
\text { Automation }\end{array}$ & $\begin{array}{l}\text { Baseline } \\
\text { Automation }\end{array}$ & $\begin{array}{c}\text { Automation } \\
\text { W/O Rising } \\
\text { Inequality }\end{array}$ \\
\hline K & 0.267 & 0.298 & $\begin{array}{c}0.298 \\
\end{array}$ \\
\hline L High & 0.244 & 0.294 & 0.234 \\
\hline L Med & 0.244 & 0.228 & 0.234 \\
\hline L Low & 0.244 & 0.179 & 0.234 \\
\hline \multicolumn{4}{|c|}{ IND } \\
\hline & $\begin{array}{c}\text { No } \\
\text { Automation }\end{array}$ & $\begin{array}{l}\text { Baseline } \\
\text { Automation }\end{array}$ & $\begin{array}{c}\text { Automation } \\
\text { W/O Rising } \\
\text { Inequality }\end{array}$ \\
\hline$\overline{\mathrm{K}}$ & 0.388 & 0.414 & 0.414 \\
\hline L High & 0.204 & 0.246 & 0.195 \\
\hline L Med & 0.204 & 0.191 & 0.195 \\
\hline L Low & 0.204 & 0.150 & 0.195 \\
\hline
\end{tabular}

CAN

\begin{tabular}{|c|c|c|c|}
\hline & $\begin{array}{c}\text { No } \\
\text { Automation }\end{array}$ & $\begin{array}{c}\text { Baseline } \\
\text { Automation }\end{array}$ & $\begin{array}{c}\text { Automation } \\
\text { W/O Rising } \\
\text { Inequality }\end{array}$ \\
\hline K & 0.405 & 0.431 & 0.431 \\
\hline L High & 0.198 & 0.239 & 0.190 \\
\hline L Med & 0.198 & 0.185 & 0.190 \\
\hline L Low & 0.198 & 0.145 & 0.190 \\
\hline \multicolumn{4}{|c|}{ RUS } \\
\hline & $\begin{array}{c}\text { No } \\
\text { Automation }\end{array}$ & $\begin{array}{c}\text { Baseline } \\
\text { Automation }\end{array}$ & $\begin{array}{c}\text { Automation } \\
\text { W/O Rising } \\
\text { Inequality }\end{array}$ \\
\hline$\overline{\mathrm{K}}$ & 0.416 & 0.440 & 0.440 \\
\hline L High & 0.195 & 0.235 & 0.187 \\
\hline L Med & 0.195 & 0.182 & 0.187 \\
\hline L Low & 0.195 & 0.143 & 0.187 \\
\hline
\end{tabular}

EEU

Table A7: 2050 Output Shares of Capital and Labor By Skill Group, Continued 


\begin{tabular}{l|ccc}
\hline & $\begin{array}{c}\text { No } \\
\text { Automation }\end{array}$ & $\begin{array}{c}\text { Baseline } \\
\text { Automation }\end{array}$ & $\begin{array}{c}\text { Automation } \\
\text { W/O Rising } \\
\text { Inequality }\end{array}$ \\
\hline \hline K & 0.326 & 0.355 & 0.355 \\
L High & 0.225 & 0.270 & 0.215 \\
L Med & 0.225 & 0.210 & 0.215 \\
L Low & 0.225 & 0.165 & 0.215 \\
\hline \multicolumn{4}{|c}{ SAP } \\
\hline & No & Baseline & Automation \\
& Automation & Automation & Inequality \\
\hline \hline K & 0.365 & 0.392 & 0.392 \\
L High & 0.212 & 0.255 & 0.203 \\
L Med & 0.212 & 0.198 & 0.203 \\
L Low & 0.212 & 0.155 & 0.203 \\
\hline \multicolumn{4}{l}{}
\end{tabular}

\begin{tabular}{l|ccc}
\hline & $\begin{array}{c}\text { No } \\
\text { Automation }\end{array}$ & $\begin{array}{c}\text { Baseline } \\
\text { Automation }\end{array}$ & $\begin{array}{c}\text { Automation } \\
\text { W/O Rising } \\
\text { Inequality }\end{array}$ \\
\hline \hline K & 0.288 & 0.318 & 0.318 \\
L High & 0.237 & 0.286 & 0.227 \\
L Med & 0.237 & 0.222 & 0.227 \\
L Low & 0.237 & 0.174 & 0.227 \\
\hline \multicolumn{4}{|c}{ BRA } \\
\hline & No & Baseline & Automation \\
& W $/$ O Rising \\
& Automation & Automation & Inequality \\
\hline \hline K & 0.292 & 0.322 & 0.322 \\
L High & 0.236 & 0.284 & 0.226 \\
L Med & 0.236 & 0.221 & 0.226 \\
L Low & 0.236 & 0.173 & 0.226 \\
\hline
\end{tabular}

SAF

Table A8: 2050 Output Shares of Capital and Labor By Skill Group, Continued

\begin{tabular}{|c|c|c|c|}
\hline & $\begin{array}{c}\text { No } \\
\text { Automation }\end{array}$ & $\begin{array}{c}\text { Baseline } \\
\text { Automation }\end{array}$ & $\begin{array}{c}\text { Automation } \\
\text { W/O Rising } \\
\text { Inequality }\end{array}$ \\
\hline $\mathrm{K}$ & 0.335 & 0.363 & 0.363 \\
\hline L High & 0.222 & 0.267 & 0.212 \\
\hline L Med & 0.222 & 0.207 & 0.212 \\
\hline L Low & 0.222 & 0.163 & 0.212 \\
\hline \multicolumn{4}{|c|}{ MENA } \\
\hline & $\begin{array}{c}\text { No } \\
\text { Automation }\end{array}$ & $\begin{array}{c}\text { Baseline } \\
\text { Automation }\end{array}$ & $\begin{array}{c}\text { Automation } \\
\text { W/O Rising } \\
\text { Inequality }\end{array}$ \\
\hline $\mathrm{K}$ & 0.281 & 0.311 & 0.311 \\
\hline L High & 0.240 & 0.289 & 0.230 \\
\hline L Med & 0.240 & 0.224 & 0.230 \\
\hline L Low & 0.240 & 0.176 & 0.230 \\
\hline
\end{tabular}

SSA

\begin{tabular}{|c|c|c|c|}
\hline & $\begin{array}{c}\text { No } \\
\text { Automation }\end{array}$ & $\begin{array}{c}\text { Baseline } \\
\text { Automation }\end{array}$ & $\begin{array}{c}\text { Automation } \\
\text { W/O Rising } \\
\text { Inequality }\end{array}$ \\
\hline $\mathrm{K}$ & 0.265 & 0.296 & 0.296 \\
\hline L High & 0.245 & 0.295 & 0.235 \\
\hline L Med & 0.245 & 0.229 & 0.235 \\
\hline L Low & 0.245 & 0.180 & 0.235 \\
\hline \multicolumn{4}{|c|}{ SLA } \\
\hline & $\begin{array}{c}\text { No } \\
\text { Automation }\end{array}$ & $\begin{array}{c}\text { Baseline } \\
\text { Automation }\end{array}$ & $\begin{array}{c}\text { Automation } \\
\text { W/O Rising } \\
\text { Inequality }\end{array}$ \\
\hline $\mathrm{K}$ & 0.356 & 0.383 & 0.383 \\
\hline L High & 0.215 & 0.259 & 0.206 \\
\hline L Med & 0.215 & 0.201 & 0.206 \\
\hline L Low & 0.215 & 0.158 & 0.206 \\
\hline
\end{tabular}

SOV

Table A9: 2050 Output Shares of Capital and Labor By Skill Group, Continued

\begin{tabular}{l|ccc}
\hline & $\begin{array}{c}\text { No } \\
\text { Automation }\end{array}$ & $\begin{array}{c}\text { Baseline } \\
\text { Automation }\end{array}$ & $\begin{array}{c}\text { Automation } \\
\text { W/O Rising } \\
\text { Inequality }\end{array}$ \\
\hline \hline K & 0.335 & 0.363 & 0.363 \\
L High & 0.222 & 0.267 & 0.212 \\
L Med & 0.222 & 0.207 & 0.212 \\
L Low & 0.222 & 0.163 & 0.212 \\
\hline
\end{tabular}

GBR

Table A10: 2050 Output Shares of Capital and Labor By Skill Group, Continued 


\begin{tabular}{l|ccc|ccc}
\hline & \multicolumn{5}{|c}{2050} & \multicolumn{3}{c}{2100} \\
\hline & $\begin{array}{c}\text { No } \\
\text { Automation }\end{array}$ & $\begin{array}{c}\text { Baseline } \\
\text { Automation }\end{array}$ & \% Diff & $\begin{array}{c}\text { No } \\
\text { Automation }\end{array}$ & $\begin{array}{c}\text { Baseline } \\
\text { Automation }\end{array}$ & \% Diff \\
\hline \hline USA & 45.3 & 47.7 & 5.1 & 107.7 & 116.3 & 8.0 \\
WEU & 39.3 & 44.3 & 12.7 & 86.6 & 101.1 & 16.8 \\
JSHK & 21.4 & 24.2 & 12.9 & 53.4 & 63.6 & 19.1 \\
CHI & 72.7 & 75.3 & 3.6 & 216.5 & 240.4 & 11.0 \\
IND & 31.7 & 30.8 & -2.9 & 98.2 & 97.4 & -0.8 \\
RUS & 6.0 & 6.2 & 2.4 & 12.0 & 12.9 & 8.1 \\
\hline CAN & 7.8 & 8.8 & 12.1 & 19.1 & 22.0 & 15.5 \\
EEU & 2.4 & 2.5 & 6.6 & 6.2 & 7.0 & 12.3 \\
SAP & 24.7 & 24.0 & -3.0 & 59.6 & 62.6 & 5.0 \\
BRA & 7.4 & 7.1 & -3.3 & 13.1 & 12.9 & -1.0 \\
MEX & 6.6 & 6.4 & -3.6 & 11.2 & 11.1 & -1.1 \\
SAF & 1.8 & 1.7 & -3.6 & 3.5 & 3.5 & -1.1 \\
\hline MENA & 31.3 & 30.6 & -2.3 & 87.4 & 86.8 & -0.7 \\
SLA & 10.2 & 10.0 & -2.0 & 20.7 & 20.5 & -0.6 \\
SSA & 10.8 & 10.5 & -2.4 & 40.4 & 40.1 & -0.8 \\
SOV & 3.8 & 3.7 & -2.7 & 12.1 & 12.7 & 5.4 \\
GBR & 6.2 & 6.8 & 10.0 & 13.7 & 15.5 & 13.2 \\
\hline World & 329.5 & 340.6 & 3.4 & 861.3 & 926.6 & 7.6 \\
\hline
\end{tabular}

Table A11: GDP in Trillions of 2017 Dollars

\begin{tabular}{l|cccccc|cc}
\hline & \multicolumn{2}{|c}{$\begin{array}{l}\text { GDP in 2017 } \\
\text { (Trillion Dollars) }\end{array}$} & \multicolumn{2}{c}{$\begin{array}{c}\text { Capital Stock in 2017 } \\
\text { (Trillion Dollars) }\end{array}$} & $\begin{array}{r}\text { Net Intl. Investment } \\
\text { Position in 2017 } \\
\text { (Trillion Dollars) }\end{array}$ & \multicolumn{2}{c}{$\begin{array}{c}\text { GDP in 2100 } \\
\text { (Trillion 2017 Dollars) }\end{array}$} \\
& Target & Model & Target & Model & Target & Model & Target & Model \\
\hline \hline USA & 19.49 & 19.49 & 59.44 & 59.44 & -6.71 & -6.70 & 112.37 & 108.03 \\
WEU & 20.32 & 20.35 & 54.27 & 54.12 & 1.87 & 2.18 & 88.95 & 86.67 \\
JSHK & 8.24 & 8.25 & 27.27 & 27.22 & 7.02 & 7.16 & 54.97 & 53.44 \\
CHI & 19.76 & 19.75 & 62.05 & 61.82 & 3.85 & 3.89 & 226.04 & 215.64 \\
IND & 8.26 & 8.27 & 20.40 & 20.33 & -1.22 & -1.25 & 102.12 & 97.59 \\
RUS & 3.81 & 3.81 & 13.90 & 13.88 & 0.76 & 0.83 & 12.59 & 12.02 \\
CAN & 3.20 & 3.19 & 9.18 & 9.10 & -0.25 & -0.22 & 19.90 & 19.12 \\
EEU & 0.92 & 0.92 & 2.74 & 2.73 & -0.43 & -0.41 & 6.45 & 6.18 \\
SAP & 7.82 & 7.83 & 20.34 & 20.27 & -1.36 & -1.32 & 61.89 & 59.58 \\
BRA & 3.01 & 3.01 & 8.19 & 8.17 & -0.83 & -0.79 & 13.77 & 13.08 \\
MEX & 2.47 & 2.46 & 7.47 & 7.44 & -1.04 & -1.02 & 11.66 & 11.26 \\
SAF & 0.72 & 0.72 & 1.76 & 1.75 & 0.08 & 0.08 & 3.70 & 3.51 \\
MENA & 10.28 & 10.29 & 24.37 & 24.29 & -0.37 & -0.38 & 89.80 & 87.35 \\
SLA & 3.82 & 3.82 & 6.88 & 6.84 & -0.74 & -0.73 & 21.56 & 20.62 \\
SSA & 2.59 & 2.59 & 6.16 & 6.17 & -0.80 & -0.78 & 41.11 & 40.62 \\
SOV & 1.06 & 1.06 & 2.50 & 2.49 & -0.34 & -0.34 & 12.72 & 12.05 \\
GBR & 3.03 & 3.03 & 6.42 & 6.40 & -0.39 & -0.37 & 14.07 & 13.71 \\
\hline
\end{tabular}

Table A12: Calibration Targets: Macro Aggregates 


\begin{tabular}{l|cccc|cc|cc}
\hline & \multicolumn{2}{|c}{$\begin{array}{c}\text { Private Consumption } \\
\text { (\% of GDP) }\end{array}$} & \multicolumn{2}{c}{$\begin{array}{c}\text { Government } \\
\text { Consumption }\end{array}$} & \multicolumn{2}{c}{$\begin{array}{c}\text { Health } \\
\text { Expenditure } \\
\text { (\% of GDP) }\end{array}$} & \multicolumn{2}{c}{$\begin{array}{c}\text { Education } \\
\text { Expenditure } \\
\text { (\% of GDP) }\end{array}$} \\
& Target & Model & Target & Model & Target & Model & Target & Model \\
\hline \hline USA & 68.20 & 68.08 & 14.13 & 14.08 & 9.28 & 9.28 & 6.05 & 5.99 \\
WEU & 53.36 & 53.43 & 20.32 & 20.21 & 6.75 & 6.72 & 4.73 & 4.77 \\
JSHK & 53.25 & 53.40 & 17.75 & 17.96 & 6.38 & 6.45 & 3.46 & 3.49 \\
CHI & 39.00 & 39.06 & 14.62 & 14.53 & 2.98 & 2.96 & 3.73 & 3.71 \\
IND & 58.90 & 58.92 & 10.76 & 10.70 & 1.00 & 1.00 & 3.80 & 3.79 \\
RUS & 52.87 & 52.93 & 18.22 & 18.17 & 3.02 & 3.02 & 3.48 & 3.48 \\
CAN & 57.28 & 57.28 & 19.65 & 19.59 & 7.36 & 7.36 & 5.32 & 5.32 \\
EEU & 67.28 & 67.14 & 18.07 & 18.06 & 3.87 & 3.87 & 5.57 & 5.56 \\
SAP & 59.06 & 59.03 & 10.76 & 10.72 & 1.33 & 1.33 & 2.88 & 2.88 \\
BRA & 64.48 & 64.04 & 20.17 & 20.24 & 3.80 & 3.82 & 6.00 & 6.02 \\
MEX & 65.27 & 65.41 & 11.63 & 11.64 & 2.85 & 2.84 & 4.91 & 4.90 \\
SAF & 59.43 & 59.48 & 20.93 & 20.85 & 4.32 & 4.31 & 5.59 & 5.58 \\
MENA & 55.46 & 55.35 & 15.88 & 15.99 & 3.94 & 3.97 & 3.16 & 3.19 \\
SLA & 66.76 & 66.77 & 14.91 & 14.91 & 4.75 & 4.74 & 4.94 & 4.93 \\
SSA & 70.16 & 70.17 & 10.84 & 10.82 & 1.36 & 1.36 & 4.09 & 4.08 \\
SOV & 57.62 & 57.37 & 11.85 & 11.80 & 2.27 & 2.26 & 3.57 & 3.56 \\
GBR & 64.50 & 64.42 & 18.72 & 18.87 & 7.48 & 7.52 & 4.95 & 4.99 \\
\hline
\end{tabular}

Table A13: Calibration Targets: Consumption and Expenditure

\begin{tabular}{|c|c|c|c|c|c|c|c|c|c|c|}
\hline & \multicolumn{2}{|c|}{$\begin{array}{c}\text { Pension Benefits } \\
\text { in } 2017 \\
(\% \text { of GDP })\end{array}$} & \multicolumn{2}{|c|}{$\begin{array}{l}\text { Pension Benefits } \\
\text { in } 2050 \\
(\% \text { of } 2050 \mathrm{GDP})\end{array}$} & \multicolumn{2}{|c|}{$\begin{array}{l}\text { Gov. G\&S Purchases } \\
\text { Excl. Health \& Educ. } \\
(\% \text { of GDP })\end{array}$} & \multicolumn{2}{|c|}{$\begin{array}{c}\text { Welfare Expenditure } \\
\text { Excl. Pensions } \\
(\% \text { of GDP })\end{array}$} & \multicolumn{2}{|c|}{$\begin{array}{c}\text { Net Payment } \\
\text { on Debt/Assets } \\
(\% \text { of GDP) }\end{array}$} \\
\hline & Target & Model & Target & Model & Target & Model & Target & Model & Target & Model \\
\hline USA & 5.00 & 5.00 & 6.02 & 6.01 & 11.05 & 11.03 & 2.66 & 2.66 & 3.94 & 4.03 \\
\hline WEU & 10.05 & 10.05 & 10.14 & 10.04 & 13.64 & 13.55 & 8.86 & 8.82 & 1.84 & 1.89 \\
\hline JSHK & 8.04 & 8.03 & 7.11 & 7.06 & 10.01 & 10.11 & 5.47 & 5.52 & 1.50 & 1.53 \\
\hline CHI & 4.90 & 4.90 & 11.35 & 11.37 & 14.62 & 14.53 & 3.59 & 3.57 & 0.86 & 0.88 \\
\hline IND & 4.30 & 4.30 & 4.30 & 4.31 & 7.34 & 7.30 & 1.56 & 1.56 & 5.00 & 5.11 \\
\hline RUS & 8.75 & 8.73 & 11.89 & 11.72 & 16.05 & 16.03 & 4.41 & 4.41 & 0.92 & 0.94 \\
\hline CAN & 4.02 & 4.01 & 4.64 & 4.64 & 13.52 & 13.51 & 5.80 & 5.80 & 2.14 & 2.20 \\
\hline EEU & 6.91 & 6.91 & 9.43 & 9.43 & 13.10 & 13.07 & 7.59 & 7.59 & 2.98 & 3.04 \\
\hline SAP & 0.43 & 0.43 & 0.58 & 0.57 & 10.71 & 10.68 & 1.27 & 1.27 & 1.39 & 1.43 \\
\hline BRA & 12.00 & 12.01 & 17.81 & 18.00 & 10.37 & 10.40 & 7.12 & 7.15 & 8.95 & 9.16 \\
\hline MEX & 2.10 & 2.10 & 3.50 & 3.52 & 7.31 & 7.30 & 5.40 & 5.40 & 2.93 & 3.00 \\
\hline SAF & 1.51 & 1.51 & 2.27 & 2.28 & 20.93 & 20.85 & 5.73 & 5.72 & 3.94 & 4.02 \\
\hline MENA & 4.63 & 4.62 & 5.87 & 5.82 & 15.88 & 15.99 & 3.83 & 3.86 & 1.35 & 1.39 \\
\hline SLA & 2.12 & 2.12 & 2.74 & 2.75 & 14.08 & 14.04 & 3.45 & 3.44 & 0.96 & 0.98 \\
\hline SSA & 2.10 & 2.10 & 3.76 & 3.75 & 10.84 & 10.82 & 7.41 & 7.42 & 2.54 & 2.60 \\
\hline $\mathrm{SOV}$ & 4.02 & 4.02 & 5.73 & 5.75 & 11.85 & 11.80 & 2.77 & 2.76 & 0.82 & 0.84 \\
\hline GBR & 8.33 & 8.34 & 8.84 & 8.83 & 10.94 & 10.99 & 6.78 & 6.82 & 2.69 & 2.76 \\
\hline
\end{tabular}

Table A14: Calibration Targets: Consumption and Expenditure (Continued) 


\begin{tabular}{|c|c|c|c|c|c|c|c|c|c|c|}
\hline & \multicolumn{2}{|c|}{$\begin{array}{l}\text { Corporate Income } \\
\text { Tax Revenue } \\
(\% \text { of GDP })\end{array}$} & \multicolumn{2}{|c|}{$\begin{array}{c}\text { Natural } \\
\text { Resource Rents } \\
(\% \text { of GDP) }\end{array}$} & \multicolumn{2}{|c|}{$\begin{array}{c}\text { Contributions to } \\
\text { Pension System } \\
\text { (\% of GDP) }\end{array}$} & \multicolumn{2}{|c|}{$\begin{array}{l}\text { Income Tax } \\
\text { Revenue } \\
(\% \text { of GDP })\end{array}$} & \multicolumn{2}{|c|}{$\begin{array}{c}\text { Consump. Tax } \\
\text { Revenue } \\
(\% \text { of GDP })\end{array}$} \\
\hline & Target & Model & Target & Model & Target & Model & Target & Model & Target & Model \\
\hline USA & 1.98 & 1.98 & 0.20 & 0.20 & 6.68 & 6.67 & 17.95 & 21.15 & 5.21 & 6.12 \\
\hline WEU & 3.65 & 3.66 & 0.10 & 0.10 & 13.61 & 13.61 & 14.06 & 14.37 & 12.99 & 13.26 \\
\hline JSHK & 6.34 & 6.35 & 0.00 & 0.00 & 10.37 & 10.35 & 8.89 & 9.25 & 7.90 & 8.21 \\
\hline CHI & 5.51 & 5.52 & 1.20 & 1.20 & 5.20 & 5.18 & 3.41 & 3.82 & 12.49 & 13.97 \\
\hline IND & 3.30 & 3.31 & 1.60 & 1.60 & 1.90 & 1.90 & 2.50 & 3.63 & 5.60 & 8.01 \\
\hline RUS & 4.11 & 4.13 & 7.30 & 7.29 & 7.04 & 7.05 & 5.62 & 5.83 & 11.74 & 12.18 \\
\hline CAN & 6.12 & 6.13 & 0.50 & 0.50 & 2.37 & 2.37 & 20.23 & 20.04 & 8.09 & 8.01 \\
\hline EEU & 3.40 & 3.42 & 0.10 & 0.10 & 8.16 & 8.14 & 7.23 & 6.87 & 20.69 & 19.60 \\
\hline SAP & 4.59 & 4.60 & 1.20 & 1.19 & 0.31 & 0.31 & 1.81 & 1.93 & 8.36 & 8.91 \\
\hline BRA & 3.98 & 3.99 & 1.40 & 1.39 & 10.85 & 10.86 & 7.19 & 8.00 & 16.55 & 18.06 \\
\hline MEX & 4.29 & 4.30 & 2.80 & 2.74 & 2.22 & 2.22 & 5.32 & 6.10 & 7.12 & 8.13 \\
\hline $\mathrm{SAF}$ & 6.92 & 6.94 & 1.60 & 1.60 & 0.56 & 0.56 & 14.27 & 15.60 & 13.80 & 15.05 \\
\hline MENA & 1.76 & 1.76 & 9.60 & 9.73 & 4.36 & 4.35 & 2.78 & 3.35 & 10.71 & 12.90 \\
\hline SLA & 3.90 & 3.91 & 0.80 & 0.80 & 3.11 & 3.12 & 5.52 & 7.32 & 10.93 & 14.50 \\
\hline SSA & 3.09 & 3.11 & 2.80 & 2.80 & 2.20 & 2.20 & 4.45 & 6.02 & 9.16 & 12.38 \\
\hline SOV & 3.96 & 3.97 & 6.80 & 6.81 & 1.85 & 1.84 & 3.20 & 3.34 & 8.23 & 8.59 \\
\hline GBR & 3.90 & 3.91 & 1.00 & 1.06 & 7.79 & 7.79 & 13.67 & 14.63 & 12.07 & 12.89 \\
\hline
\end{tabular}

Table A15: Calibration Targets: Revenue ${ }^{36}$

\footnotetext{
${ }^{36}$ Note that income and consumption tax revenue are set to balance the budget and therefore may deviate from each region's reported revenue level.
} 


\section{A Calibration Details}

We first consider the Cobb-Douglas coefficients of the production function. In each region, we define skill groups such that $\beta_{t, k}=\left(1-\alpha_{t}\right) / 3, k \in(1,2,3)$, i.e., that each skill group, in 2017, collects a third of of total labor income. In the absence of automation, $\alpha$ s and $\beta$ s are fixed through time. The population share of each group is estimated with the World Inequality Database (Alvaredo et al., 2020) by interpolating country-specific income shares by population quintile (or decile, if data is available). Shares are summarized in table A16.

\begin{tabular}{|c|c|c|c|c|c|c|c|c|c|c|c|c|c|c|c|c|c|c|}
\hline & USA & WEU & JNII & CHI & IND & RUS & CAN & EEU & SAP & BRA & ME & & & MENA & SL & & SSA & SOV GBR \\
\hline \multicolumn{19}{|c|}{ Capital Income Share } \\
\hline & 0.341 & 0.368 & 0.487 & 0.383 & 0.267 & 0.405 & 0.388 & 0.416 & 0.326 & 0.288 & 0.36 & & & 0.335 & 0.26 & & 0.281 & $0.356 \quad 0.335$ \\
\hline \multicolumn{19}{|c|}{ No Automation Labor Income Share Per Skill Group } \\
\hline & 0.220 & 0.211 & 0.171 & 0.206 & 0.244 & 0.198 & 0.204 & 0.195 & 0.225 & 0.237 & 0.21 & & & 0.222 & 0.24 & & 0.240 & $0.215 \quad 0.222$ \\
\hline \multicolumn{19}{|c|}{ Share of Population by Skill Group } \\
\hline High & 0.040 & 0.109 & 0.109 & 0.060 & 0.030 & 0.050 & 0.109 & 0.093 & 0.052 & 0.020 & 0.02 & & & 0.040 & 0.02 & & $0.04 \varepsilon_{-1}$ & $0.050 \quad 0.090$ \\
\hline Med & 0.200 & 0.255 & 0.255 & 0.210 & 0.170 & 0.230 & 0.255 & 0.226 & 0.193 & 0.180 & 0.18 & & & 0.166 & 0.18 & & 0.17 & $0.230 \quad 0.250$ \\
\hline Low & 0.760 & 0.636 & 0.636 & 0.730 & 0.800 & 0.720 & 0.636 & 0.681 & 0.755 & 0.800 & 0.80 & & & 0.795 & 0.80 & & 0.78 & $0.720 \quad 0.660$ \\
\hline
\end{tabular}

Table A16: Input Shares by Region and Population Shares by Skill Group and Region

Capital income shares are calibrated such that, in 2017, each region's capital demand matches its capital stock as calculated from the IMF Investment and Capital Stock Database (ICSD; IMF 2019a). To achieve this, we scale the overall model so that one unit of model output is equal to 100 billion real U.S. dollars in 2017 value. The total global stock of capital is set such that the amount of global capital in a given period is equal to the period's global supply of net private assets (i.e. assets net of private debt), less total global non-capital assets. These are the sum of world-wide government debt and the present value of non-government owned fossil fuel rent flows, each of which have the same rate of return as other assets. The depreciation rate in each region is calibrated to the average difference between its net capital accumulation rate, from 2012 to 2017, and gross domestic investment rate for the same period. Both estimates are obtained from ICSD data; we assume that depreciation rates are fixed through time.

The total factor productivity term, $\phi_{t}$, is used to calibrate output in each region. We calibrate $\phi_{t}$ in 2017 to each region's GDP in the same year, adjusting the overall scaling factor to express the model's output in real dollar units. The path of $\phi_{t}$ is calibrated to long-term economic growth projections from Müller et al. (2019). The authors use a Bayesian model to provide two sets of estimations for GDPs through 2100, one estimating growth paths of countries jointly in a multivariate approach, and the other estimating each country individually. In the no automation case, we adopt a simple average of the two output paths as the calibration target, and adjust $\phi_{t}$ in 2100 to match output in each region. ${ }^{37} \phi_{t}$ is assumed to growth linearly between 2017 and 2100 . After 2100, TFP in all regions grow at a fixed rate of 1 percent per year. TFP values by region in 2017, 2050, and 2100 are summarized in table A17.

\footnotetext{
${ }^{37}$ While we assume 1 percent long-term technological growth in the model, individual regions are allowed to grow at a rate of less than 1 percent in the short run if required to match projections.
} 


\begin{tabular}{l|ccccc}
\hline & 2017 & $\begin{array}{c}2050 \text { W/O 1 Pct } \\
\text { Tech. Growth }\end{array}$ & $\begin{array}{c}2100 \text { W/O 1 Pct } \\
\text { Tech. Growth }\end{array}$ & $\begin{array}{c}\text { 2050 With 1 Pct } \\
\text { Tech. Growth }\end{array}$ & $\begin{array}{c}\text { 2100 With 1 Pct } \\
\text { Tech. Growth }\end{array}$ \\
\hline \hline USA & 1.00 & 1.15 & 1.37 & 1.60 & 3.13 \\
WEU & 0.69 & 0.83 & 1.05 & 1.15 & 2.40 \\
JSHK & 0.62 & 0.84 & 1.16 & 1.17 & 2.65 \\
CHI & 0.34 & 0.60 & 1.00 & 0.83 & 2.28 \\
IND & 0.29 & 0.43 & 0.65 & 0.60 & 1.48 \\
RUS & 0.47 & 0.53 & 0.61 & 0.74 & 1.39 \\
\hline CAN & 0.68 & 0.78 & 0.92 & 1.08 & 2.10 \\
EEU & 0.34 & 0.49 & 0.72 & 0.68 & 1.64 \\
SAP & 0.31 & 0.42 & 0.59 & 0.58 & 1.64 \\
BRA & 0.46 & 0.56 & 0.72 & 0.78 & 1.67 \\
MEX & 0.61 & 0.66 & 0.73 & 0.92 & 1.05 \\
SAF & 0.44 & 0.45 & 0.46 & 0.62 & 1.23 \\
\hline MENA & 0.43 & 0.48 & 0.54 & 0.67 & 0.41 \\
SLA & 0.49 & 0.58 & 0.72 & 0.81 & 1.76 \\
SSA & 0.18 & 0.18 & 0.18 & 0.74 & 2.40 \\
SOV & 0.37 & 0.53 & 0.77 & 1.21 & \\
GBR & 0.76 & 0.87 & 1.05 & & \\
\hline
\end{tabular}

Table A17: Calibrated TFP By Region and Year

The initial age- and skill-distribution of assets is calibrated to the distribution of total household assets in the 2016 Survey of Consumer Finances (SCF; Bricker et al. 2017). For the age profile, the age-asset distribution is spline smoothed and weighted so that, depending on the region-specific age of labor force entry, agents in their first working year own zero assets. For the skill-group profile, we sort SCF households by annual wage income and calculate the fraction of assets owned by each bin corresponding to the population shares of the U.S's skill groups. Because of the lack of largesample household-level data for non-U.S. regions, we apply the U.S's age-skill-group asset profile to all regions. ${ }^{38}$

The total amount of initial assets in each region is calibrated such that the model's net foreign asset stock, as a fraction of GDP, matches data from the International Investment Position (IIP) Database (IMF, 2019b). We measure a region's net foreign asset position as the difference between its net national wealth and its stock of capital. The total stock of global assets in 2017 is set to generate an initial world interest rate of approximately 6 percent.

Government consumption, taxes, and expenditures are calibrated to IMF macro-fiscal data. We set the rate of the (proportional) corporate income tax to raise, as a percentage of GDP, the amount of corporate income tax revenue in each region. We set the rate of the payroll tax to raise the share of pension benefits financed by payroll taxes. Calibrated tax rates are presented in Table A18. Income and consumption taxes adjust endogenously to balance the budget with the ratio between the two revenue sources calibrated to IMF data. We do not directly incorporate any other tax types in our model. Hence, we assume that non-tax government revenue (e.g. user fees and permit sales) is raised from our three main types of taxes - income, consumption, and corporate income - proportionate to their revenue and increase the revenue-to-GDP ratio targets accordingly.

\footnotetext{
${ }^{38}$ Non-U.S. regions are assumed to take the U.S profile, but scaled to their specific age of labor force entry, i.e. workers in regions where labor force entry occurs at age 18 have zero assets at age 18.
} 


\begin{tabular}{l|cccc}
\hline & $\begin{array}{c}\text { Consumption } \\
\text { Tax }\end{array}$ & $\begin{array}{c}\text { Income } \\
\text { Tax }\end{array}$ & $\begin{array}{c}\text { Payroll } \\
\text { Tax }\end{array}$ & $\begin{array}{c}\text { Corporate } \\
\text { Income Tax }\end{array}$ \\
\hline \hline USA & 9.0 & 24.4 & 13.5 & 9.8 \\
WEU & 24.8 & 17.5 & 23.9 & 18.6 \\
JSHK & 15.4 & 11.8 & 22.4 & 24.2 \\
CHI & 35.8 & 4.6 & 10.7 & 22.9 \\
IND & 13.6 & 3.9 & 3.6 & 18.5 \\
RUS & 22.9 & 7.4 & 17.2 & 17.3 \\
\hline CAN & 14.0 & 24.8 & 4.3 & 26.5 \\
EEU & 29.2 & 8.9 & 16.1 & 16.0 \\
SAP & 15.1 & 2.3 & 0.6 & 23.2 \\
BRA & 28.2 & 8.4 & 21.9 & 19.8 \\
MEX & 12.4 & 7.5 & 5.1 & 19.5 \\
SAF & 25.3 & 17.4 & 1.1 & 32.6 \\
\hline MENA & 23.3 & 4.3 & 10.4 & 12.7 \\
SLA & 21.7 & 8.6 & 6.1 & 27.0 \\
SSA & 17.6 & 7.0 & 4.3 & 18.7 \\
SOV & 15.0 & 4.6 & 4.1 & 23.5 \\
GBR & 20.0 & 18.1 & 13.8 & 23.7 \\
\hline
\end{tabular}

Table A18: Average 2017 Tax Rates By Region

On the expenditure side, we calibrate spending levels on five different categories: healthcare, education, general welfare expenditures, pensions, and other general public purchases of goods and services ("miscellaneous" expenditures, e.g. expenditure on military and federal administration). We treat miscellaneous expenditures as government consumption. The share of healthcare and education expenditure that is not government consumption is rebated to households according to equation (16). We set each region's initial debt-to-GDP ratio to match the model's net interest payments on debt with 2017 data. With the exception of the UBI scenarios, which involve some debt financing, we assume that debt is fixed as a share of GDP.

We calibrate fossil fuel rent flows to World Bank (2021) data and match rents as a share of GDP in the initial year. The share of this flow owned by the government is calibrated to the share of natural resource revenue that accrues to the government. We estimate the region-specific exhaustion date using data on the average rate of extraction and proven reserves. If a region's fossil fuel stock is projected to last beyond 2150, we exhaust the flow at the end of 2150 .

We interpret leisure in our model as a measure of labor force participation (LFP). The intratemporal ELS, $\rho$, is calibrated to roughly match the ratio of LFP between 21-year-old and 60-year-old Americans in 2017, which is estimated to be approximately $1.17{ }^{39}$ We adjust the leisure preference parameter, $\varepsilon_{t, k}$, to match the LFP of each skill group in each region. These targets are derived by combining a non-region-specific distribution target of relative LFP by skill-group and a region-specific target of the average LFP. ${ }^{40}$ The ratios of relative leisure taken by skill groups in a given region are estimated by calculating the fraction of non-participants of the labor force among low-, middle- and

\footnotetext{
${ }^{39}$ Age 21 is chosen as the year that Americans enter the labor force. Age 60 is chosen to represent an age when LFP declines, but is still sufficiently far away from age 66 when the model assumes that all Americans retire. Since the actual LFP-age curve does not exhibit a kink at 66 , it is difficult to match leisure taken by individuals in the years immediately prior to turning 66. LFP by age is estimated from 2016 Survey of Consumer Finance data.

${ }^{40}$ Specifically, all regions share the same ratio of LFPs between skill-group as estimated by SCF data, but each region's average LFP across skill-groups, which we draw from ILO data, is region-specific. In other words, SCF data determines the (non-region-specific) shape of the LFP profile by income, and ILO data determines the overall, region-specific level of participation. Leisure preferences coefficients are larger for agents with higher income. This is because LFP does not vary substantially across skill groups. Hence, high-skilled individuals must have a stronger preference for leisure. Otherwise they would spend a much larger than observed amount of their time endowment on leisure.
} 
high-skilled American households - defined (as above) as those in the bottom 76, middle 20, and top 4 percent by wage income - in SCF 2016. In each region, the target for the weighted average level of leisure taken across all skill groups is estimated with ILO data (ILOStat, 2020). ${ }^{41}$ Table A19 summarize leisure targets by skill-group and region.

\begin{tabular}{l|ccc}
\hline & High-skilled & middle-skilled & Low-skilled \\
\hline \hline USA & 11.7 & 8.5 & 17.1 \\
WEU & 14.9 & 10.9 & 21.8 \\
JSHK & 15.0 & 10.9 & 21.9 \\
CHI & 17.1 & 12.5 & 25.0 \\
IND & 28.2 & 20.6 & 41.2 \\
RUS & 8.2 & 6.0 & 12.0 \\
\hline CAN & 7.3 & 5.3 & 10.7 \\
EEU & 24.0 & 17.5 & 35.1 \\
SAP & 11.9 & 8.7 & 17.4 \\
BRA & 17.5 & 12.8 & 25.6 \\
MEX & 20.8 & 15.1 & 30.3 \\
SAF & 23.0 & 16.8 & 33.6 \\
\hline MENA & 26.3 & 19.2 & 38.5 \\
SLA & 14.9 & 10.9 & 21.8 \\
SSA & 9.1 & 6.6 & 13.3 \\
SOV & 20.3 & 14.8 & 29.7 \\
GBR & 8.3 & 6.1 & 12.1 \\
\hline
\end{tabular}

Table A19: Leisure Targets As Percent of Time Endowment (\%)

We calibrate the income tax system by using $\xi_{t}$, the progressivity term, to adjust the ratio between the METR of the high-skilled group and the average tax rate across all workers. The target for this ratio is the ratio between the METR of the top 4 percent of households by labor earning (i.e. high-skilled households) and the average effective tax rate of U.S. households as estimated by Altig et al. (2020) and Auerbach et al. (2016). This ratio, approximately 1.72, is set as the income tax progressivity target for all regions.

The region and skill-group specific pension replacement rate $\nu_{k}$ is calibrated to the progressivity of the Social Security Administration's payout schedule assuming maximum-taxable earnings since age 22 and withdrawal at age 66 in 2017. ${ }^{42}$ The pension system is highly redistributive, with high-skilled and middle-skilled U.S. workers only receiving 2.3 and 2.0 times the pension benefits of low-skilled workers, respectively. ${ }^{43}$ We set these ratios as the pension progressivity targets in all regions.

The contribution ceiling on payroll taxes is calibrated to the ratio between the 2017 Old Age, Survivor and Disability Tax (OASDI) tax contribution limit and the average 2017 U.S. wage rate of the model. ${ }^{44}$ This ratio, approximately 2.72 , is set as the target for all regions. Consequently, all high-skilled workers and some middle-skilled workers in the U.S. experience a marginal payroll tax of zero percent, but some high-skilled workers globally experience a non-zero marginal payroll tax depending on their age and the level of local wage inequality.

We additionally calibrate non-region-specific factor productivities for each type of labor and capital

\footnotetext{
${ }^{41}$ We aggregate ILO data using the same working age interval as the model's assumption. For example, in the U.S. we calibrate leisure to the fraction of non-participants among 21 to 65-year-old Americans.

${ }^{42}$ See https://www.ssa.gov/oact/cola/examplemax.html for benefit examples of workers with maximum-taxable earnings since 22. We translate the model's average wage rates for each skill group into Averaged Indexed Monthly Earnings (AIME).

${ }^{43}$ The average middle- and high-skilled worker's wage rates are 3.5 and 18 times that of the average low-skilled worker, respectively.

${ }^{44}$ The limit is set at $\$ 127,200$ following https://www.ssa.gov/oact/cola/cbb.html
} 
utilizing estimates of cost-saving productivity gains from automation Acemoglu et al. (2020). Details of this procedure are discussed in Section 3.4.

\section{B Autocalibration Details}

Our model has a large number of interrelated parameters to calibrate. To do so, we developed an autocalibration algorithm. To understand the algorithm, consider the parameterization of a model with $l$ parameters, $\mathrm{P}=\left\{\mathrm{p}_{1}, \ldots, \mathrm{p}_{l}\right\}$ that govern model outputs $\mathrm{T}=\left\{\mathrm{t}_{1}, \ldots, \mathrm{t}_{l}\right\}$. We seek a value for $\mathrm{P}$ such that the model outputs correspond to their target values, e.g. $\mathrm{T} \approx \mathrm{T}^{*}$ where $\mathrm{T}^{*}$ is a vector of targets drawn from macro-fiscal data (e.g. targets discussed in Appendix section A). Assume that the relationship between $\mathrm{T}$ and $\mathrm{P}$ can be linearly approximated in a small neighborhood around $\mathrm{T}^{*}$. Then calibration entails finding $\mathrm{M}$ such that

$$
\mathrm{T}=\mathrm{M} \cdot \mathrm{P}=\left(\begin{array}{ccc}
\mathrm{m}_{11} & \ldots & \mathrm{m}_{1 l} \\
\vdots & \ddots & \\
\mathrm{m}_{l 1} & & \mathrm{~m}_{l l}
\end{array}\right) \cdot \mathrm{P}
$$

where $\mathrm{m}_{i j}$ is the local gradient of $\mathrm{t}_{i}$ with respect to $\mathrm{p}_{j}$. Given $\mathrm{M}$, the model can be parameterized simply by solving (28) at $\mathrm{T}^{*}$.

This is difficult for two reasons. First, $\mathrm{M}$ depends on our choice of targets and must, therefore, be estimated on a relatively small interval - less than 50 percent of each output- $t$ value of absolute deviation - around $\mathrm{T}^{*}$. Hence, we need an iterative procedure to calculate M. Second, generating data for the estimation of parameters by running the model is, at 1 to 2 CPU-hours per run, costly. Were $l$ small, it one could estimate $\mathrm{M}$ by exhaustively searching over a grid of parameter values. But our model has 416 parameters that ex-ante may need to be jointly calibrated. Using Newton-Raphson is computationally infeasible since deriving requisite cross-partials would require running the model hundreds of thousands of times.

An alternate approach is to set $\mathrm{m}_{i j}=0$ for $i \neq j$, i.e. ignore off-diagonal elements in M. However, assuming that we update parameters simultaneously, this is feasible only if each target can be matched by adjusting exactly one parameter. If one or more of the off-diagonal, $\mathrm{m}_{i j}$, terms is large, guesses of $\mathrm{P}$ will persistently overshoot. This is the case for our model. Clusters of $t_{i}$ terms - pension expenditures in 2017 and 2050, for example, - are highly dependent on the same set of parameters. A third alternative is to ignore off-diagonal elements, but update only one parameter for each convergence of the model. The sequential updating of over 400 parameters is, however, no more feasible than comprehensively estimating M. ${ }^{45}$

Fortunately, most off-diagonal elements in $\mathrm{M}$ are essentially zero. For example, a given tax multiplier should have little effect on revenues from other taxes, let alone tax revenues in different regions. In other words, M can be approximated by a (relatively) sparse matrix. On-diagonal $\mathrm{m}_{i i}$ terms can't be zero - otherwise the system is under-identified. Therefore, before estimating off-diagonal elements, we establish a bijective correspondence between $\mathrm{T}$ and $\mathrm{P}$ by choosing on-diagonal elements that are most influential in determining $t_{i}$.

Our procedure involves four steps prior to actually applying our autocalibration algorithm. First, we generate a large number of permutations of parameters - approximately 10,000 - and run the

\footnotetext{
${ }^{45}$ Even if we update every region simultaneously, adjusting 17 parameters at a time, fully updating the 24 sets of region-specific parameters requires 24 runs of the model.
} 
model for each permutation. Permutations are generated by random draws over uniform distributions symmetric over an initial guess of parameters. As draws are made, the distributions' supports are gradually increased until the model fails to converge. This process guarantees sufficient distributional coverage of each iteratively calibrated parameter. It also provides a rough estimate of the range of each parameter within which the model will successfully converge.

Second, using these results, we regress each output $t_{i}$ against the entire set of parameters $\mathrm{P}$,

$$
\mathbf{t}_{i}=\mathrm{B}_{i} \cdot \mathbf{P}
$$

where $\mathbf{t}_{i}=\left\{\mathrm{t}_{i}^{1}, \ldots\right\}$ is a vector of model outputs of $i$ generated by permuting $\mathrm{P}$, and $\mathbf{P}=\left\{\mathrm{P}^{1}, \ldots\right\}$ is the corresponding matrix of permutations of parameters. Specifically, we non-parametrically bootstrap over draws of $\mathbf{t}_{i}$ using a LASSO regression (Tibshirani, 1996). L1 regularization is particularly useful for our purposes as it penalizes most coefficients in $\mathrm{B}_{i}$ to exactly zero. Because of computational constraints, we set a highly aggressive, $t_{i}$-specific shrinkage parameter so that nearly all coefficients are penalized to zero. For most targets, the shrinkage parameter is increased until less than 5 coefficients are consistently nonzero.

Third, for each $t_{i}$ we identify the parameter that corresponds to the coefficient in $\mathrm{B}_{i}$ with the largest number of non-zero estimates (our definition of most influential), and set it as $\mathrm{p}_{i}$. We address ties by gradually increasing the number of bootstrap runs until we observe a clear ranking. If two outputs share a top-ranking parameter, we prioritize production-side targets over consumption-side (e.g. saving and labor-leisure decisions) targets and consumption-side targets over fiscal targets. ${ }^{46}$

Fourth, after sorting $\mathrm{P}$, the off-diagonal $\mathrm{b}_{i j}$ coefficients, $l^{2}-l$ in total, are sorted by the fraction of bootstrap coefficient values that are non-zero. ${ }^{47}$ Next, we identify the most important off-diagonal element $\mathrm{b}_{i j}$ as determined in this step, and identify its corresponding target, $\mathrm{t}_{i}$, and parameter, $\mathrm{p}_{j}$. As described momentarily, we explicitly update $b_{i j}$ by establishing two equations and two unknowns, with the second target having parameter $j$ as its diagonal element. Although we're considering the example of solving for two parameters with two equations, our algorithm works for solving $n$ parameters with $n$ equations. Having established the first two-by-two partition by considering the most important off-diagonal coefficient, we follow the same procedure to establish the next two-by-two (or $n$-by- $n$ ) partition) by determining the second most important off-diagonal coefficient. The number of jointly updated parameters and the size of $n$ depend on the desired calibration precision. ${ }^{48}$

Having determined our partitioning equations and unknowns, we apply our autocalibration algorithm, which has three steps. We start with a guess of $\mathrm{P}$ and a given set of $\mathrm{m}_{i j}$ (and therefore $\mathrm{m}_{j i}$ ) elements that are explicitly estimated. First, a number of initializing runs of the model are made, incrementing $\mathrm{P}$ linearly proportional to each $\mathrm{b}_{i i}$, the diagonal coefficient, to match targets to a rough

\footnotetext{
${ }^{46}$ We tiebreak within each of these groups by prioritizing the target that is, conceptually, more clearly linked to the parameter. For example, GDP and private consumption are both strongly influenced by TFP, but TFP is clearly the primary determining factor of economic output. It is possible that a parameter's coefficient is penalized to zero for all bootstrap runs of all targets. In this case, the model is under-identified, and one target must be replaced with an alternative that is directly influenced by this parameter.

${ }^{47}$ We don't rank parameters by the size of their corresponding $b_{i}$ coefficients. This is because some parameters can take on a much larger range of values relative to others. Hence, even if the absolute value of $\mathrm{b}_{i j}$ is extremely $\mathrm{small} \mathrm{m}_{i j}$ can still be important for calibrating the model, so long as we can reject the null hypothesis, e.g. $\mathrm{m}_{i j}=0$, with a high level of confidence. The non-parametric bootstrap is equivalent to a null hypothesis test against $\mathrm{m}_{i j}$ being precisely zero, where the fraction of non-zero values of each coefficient is an estimate of the confidence that the null can be rejected.

${ }^{48}$ This is achieved by running a number of candidates of the algorithm, as described below, with progressively larger numbers of estimated off-diagonal $\mathrm{m}_{i j}$ elements, until the model is calibrated to the desired precision.
} 
level of precision. ${ }^{49}$ Specifically, we use 50 runs for versions of the algorithm with clusters of up to two jointly updated parameters. ${ }^{50}$ In each new run, each parameter is incremented by 2 percent of $\hat{\mathrm{p}}_{i}-\mathrm{p}_{i}$, where $\mathrm{p}_{i}$ is the starting guess, and $\hat{\mathrm{p}}_{i}=\mathrm{t}_{i}^{*} / \mathrm{b}_{i i}$ is a rough guess of the parameter that calibrates target $i$ based on $\mathrm{b}_{i i}$. All parameters are updated simultaneously.

Second, using the 50 sets of parameters and model outputs, we estimate each non-zero element in M. For parameter $i$, if $\mathrm{m}_{i j}=0 \forall j \neq i$, then no other parameter needs to be jointly updated with $i$. Therefore, new guesses of $\mathrm{p}_{i}$ can be proposed with a simple, univariate Newton-Raphson approach where $\mathrm{m}_{i i}$ is updated as $\mathrm{t}_{i}$ converges to $\mathrm{t}_{i}^{*}$. If $\mathrm{m}_{i j} \neq 0$ for some $j \neq i$, then $\mathrm{p}_{i}$ and $\mathrm{p}_{j}$ must be updated jointly. The sequences of $t_{i}$ 's and $t_{j}$ 's from step one are individually regressed on both parameters, with parameters being weighted inversely to the order in which the run is performed. ${ }^{51}$ This allows us to grid search over combinations of $\mathrm{p}_{i}$ and $\mathrm{p}_{j}$ to propose a joint update that minimizes the sum of predicted squared deviations of $\mathrm{t}_{i}$ and $\mathrm{t}_{j}$ with respect to $\mathrm{t}_{i}^{*}$ and $\mathrm{t}_{j}^{*} .{ }^{52}$ In the case of three jointly updated parameters, each target is regressed on all three parameters.

We re-run the model with the proposed parameters and check for precision. If the model is not yet sufficiently calibrated, a third step is required. We add the latest, $51^{\text {st }}$ run's output and parameters to the data, discard the observation of the first run - keeping the number of observations at 50 - and re-estimate each of the regressions in step two. Because of the inversely proportional weighting of the observations, new parameter guesses proposed with joint updating receive the largest weights. Early runs, where $\left|\mathrm{T}-\mathrm{T}^{*}\right|$ values are relatively large, are gradually eliminated from the estimation process. We continue to perform additional runs, adding their output to the moving window of observations, until all targets are matched to within 2 percent (or 2 percentage points for targets that can take on negative or positive values). ${ }^{53}$

By repeating steps one through three, the model can be recalibrated at the same level of precision to any alternate $\mathrm{T}^{*}$. Higher levels of precision - below 1 percent for all targets - can be reached by allowing for more complex interactions involving sets of three output-parameter pairs. However, this comes at substantial computation cost. With respect to the 2 percent target, we find that, at a minimum, three pairs of parameters must be jointly updated for each region. First, TFP and the saving preference rate are jointly updated to match GDP and private consumption as a share of GDP. Second, the wage multiplier of current retirees and the pension replacement rate are jointly updated to match pension expenditures in 2017 and 2050. Third, the corporate tax rate and the capital share are jointly updated to match corporate tax revenue as a share of GDP and the ratio of capital stock to GDP. Additionally, the global asset multiplier is jointly updated with each region's asset multiplier to match our 6 percent global interest target and region-specific net foreign asset positions. ${ }^{54}$

The algorithm requires no manual adjustment for re-parameterizations of the model - Appendix section C provides one such example - and can run in parallel to precisely calibrate the model to many sets of targets simultaneously. Major revisions - alternate production functions or additional sectors, for example - can be calibrate with a relatively small amount of human intervention. ${ }^{55}$ Reducing the

\footnotetext{
${ }^{49}$ Approximately $25-50$ percent of the target's absolute value depending on the target.

${ }^{50}$ We use 200 runs for versions with three jointly updated variables.

${ }^{51} \mathrm{~A}$ number of candidate regressions are utilized. We select for best fit among linear and log transformations of the independent and response variables, with and without an intercept, and with and without quadratic terms. Data points are weighted by the inverse of their location among the 50 runs, i.e. output set to 1 is weighted at $1 / 50=0.02$ and output set 50, from the most recent converged run of the model, is weighted at 1 .

${ }^{52}$ For two jointly updated variables, we use a grid size of 1,000 . The grid is centered on the current guesses of the parameters. The size of the grid is set to 25 percent of the range of each variable, as estimated in step one of the setup process. A multi-stage grid search is used for updating groups of three variables.

${ }^{53}$ This usually requires 5 to 20 convergences of the model in addition to the 50 initializing runs.

${ }^{54}$ In this case, we average over the proposed global asset multiplier from each region-specific estimating equation.

${ }^{55}$ This is mostly related to tiebreaking when one parameter appears to be equally important in adjusting multiple
} 
human factor in parameterizing large-scale OLG models introduces numerous research possibilities. Our ongoing work aims to comprehensively quantify the sensitivity of such models to the uncertainty of macro-fiscal data and projections of global economic growth.

\section{Sensitivity Analysis: Alternate Labor Productivity Calibration}

As a sensitivity analysis, we simulate a version of the model identical to that of section 4.1 with one major exception. Specifically, we calibrate the model such that $\chi_{2}=\chi_{3}=0.3$ in equations (21) and (22), i.e. a unit share shift toward either middle- or high-skilled labor, at the cost of low-skilled labor, induces the same GDP change as a unit share shift toward capital. Hence, all else equal, a one percentage point increase to the share of high- or middle-skilled labor, accompanied by an equalsized decline to low-skilled's share, causes a 0.3 percent increase to GDP. The automation scenario is otherwise identical to the baseline, entailing a new, region-specific frontier production function with the same shares as that of section 4.2. Henceforth, the "original calibration" refers to the version of the model with the original labor factor productivities as calibrated in section 4.1; "alternate calibration" refers to the version of the model as calibrated in this subsection.

Conceptually, this alternate calibration assumes that the marginal output gain from substituting labor with capital is identical to that of substituting low-skilled labor with high-skilled (or middleskilled) labor. This implies, naturally, that high- and middle-skilled workers are more productive than in our original calibration. Factor productivities are summarized in table A20. Relative to the calibration of 4.1, productivities of low-, middle-, and high-skilled workers are 16.9 percent lower, 11.1 percent higher, and 10.6 percent higher.

\begin{tabular}{l|cc|c}
\hline & $\begin{array}{c}\text { Original } \\
\text { Calibration }\end{array}$ & $\begin{array}{c}\text { Alternate } \\
\text { Calibration }\end{array}$ & \% Diff \\
\hline \hline Capital & 0.074 & 0.075 & 0.9 \\
Low-Skilled Labor & 0.964 & 0.801 & -16.9 \\
middle-skilled Labor & 3.374 & 3.750 & 11.1 \\
High-Skilled Labor & 17.501 & 19.351 & 10.6 \\
\hline
\end{tabular}

Table A20: Calibrated Factor Productivity Coefficients

In this scenario, skill-biased technological change is more attractive relative to the original calibration. Regions' new automation choices are displayed in figure A17. Regions that delay automation automate sooner in the alternate scenario. China, which automates in 2027 under the original calibration, now automates immediately. The two other regions that delay automation, former Soviet states (SOV) and Southeast Asia, both adopt the new technology roughly 20 years before doing so in the original calibration. However, with one exception - South Africa - regions that never automate with the original factor productivities also never automate with the alternates. This is in large part because less developed regions that use less capital also tend to have fewer high-skilled (and more lowskilled) workers, lowering the marginal benefit to output of an increase to high-skilled productivity. ${ }^{56}$ Therefore, the frontier technology remains inefficient in these regions.

South Africa, which doesn't automate in the original model, automates in 2059, reverts to the legacy technology in 2074, and automates again, permanently, in 2102. However, their overall gain is

outputs. Additionally, some "hyperparameters" of the algorithm - the choice of utilizing 50 initializing runs to estimate M, for example - are specific to our model, and may need to be adjusted for a different setup.

${ }^{56}$ This can be seen from equation (22). 


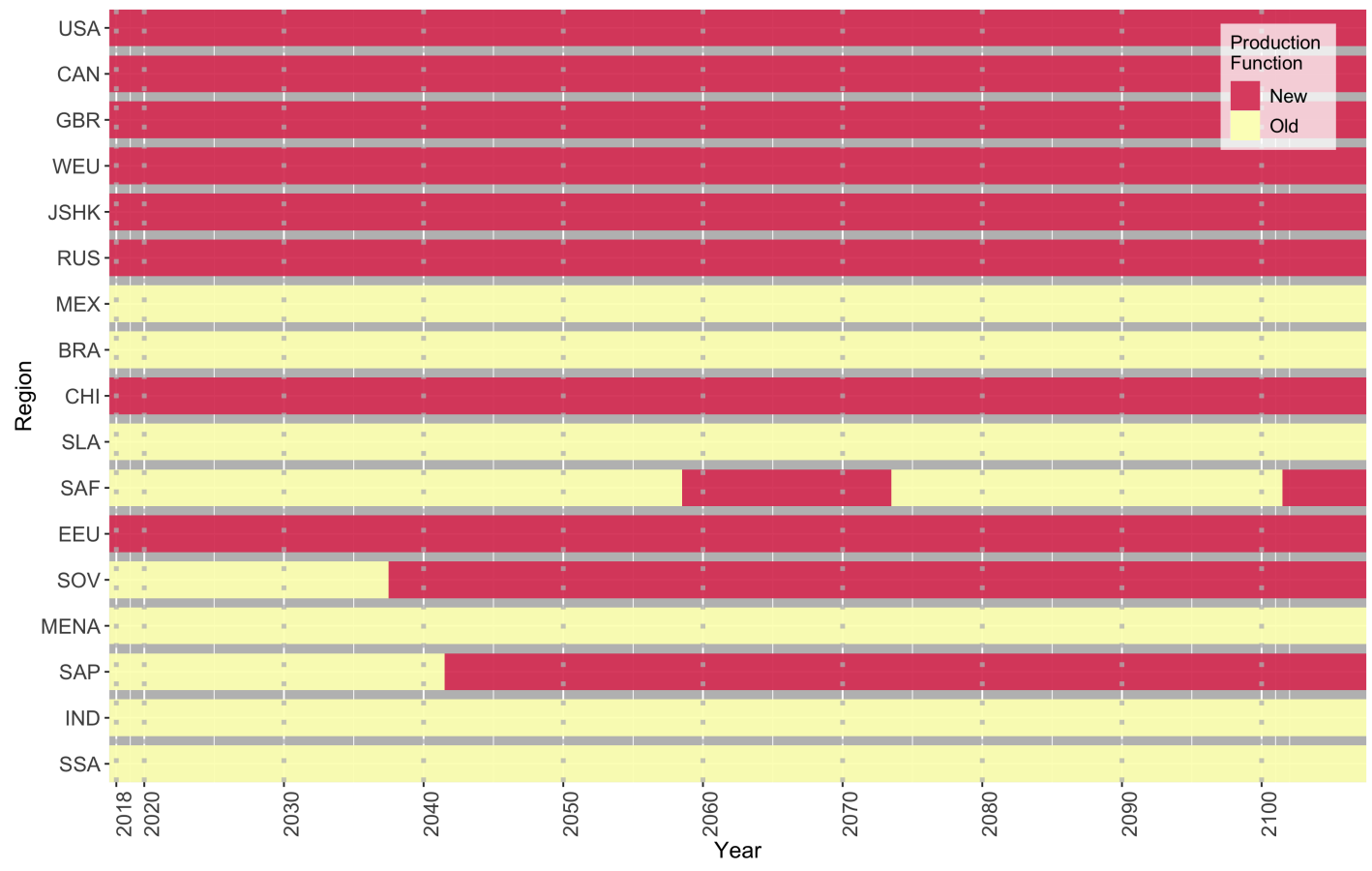

Figure A17: Choice of Production Function by Region, Alternate Labor Productivity Calibration

small - at 0.1 to 1.5 percent of GDP between 2059 and 2073 relative to no automation - in the new calibration. Relative to other regions that never automate in the original calibration (e.g. Brazil, Mexico), South Africa has a larger share of workers that are high-skilled. This difference, alongside South Africa's relatively high TFP, means that the automating technology is marginally beneficial with the new calibration.

Interest rates increase with the alternate calibration, driven by higher capital demand and countries' decision to automate sooner, but only very slightly. Paths of the world interest rate are contrasted in figure A18. In 2050, the world interest rate is 3.3 percent with baseline automation under the original calibration, and 3.4 percent with baseline automation under the alternate. In 2100, these rates are, respective, 2.1 and 2.2 percent.

Regions that automate benefit slightly more, in terms of GDP, with the alternate labor productivity calibration. Figure A19 contrasts GDP percent changes, relative to no automation, of the U.S. and the world average. ${ }^{57}$ Relative to no automation and by 2050, the U.S's GDP gain increases from the original model's 5.2 percent to 6.5 percent. By 2100, U.S. GDP is 10.1 percent higher than no automation, 2 percentage points higher than in the original calibration. Regions that automate sooner with the new calibration experience larger gains to output. In 2050, China's GDP is 3.6 percent higher with the original calibration, and 5.3 percent higher with the alternate.

\footnotetext{
${ }^{57}$ Note that the no automation scenario is slightly different across calibrations. However, this difference is very small because the no-automation scenario's GDP in both 2017 and 2100 are calibrated to a target. In 2050, U.S. GDP is 0.2 percent higher, assuming no automation, in the alternative calibration relative to the original.
} 


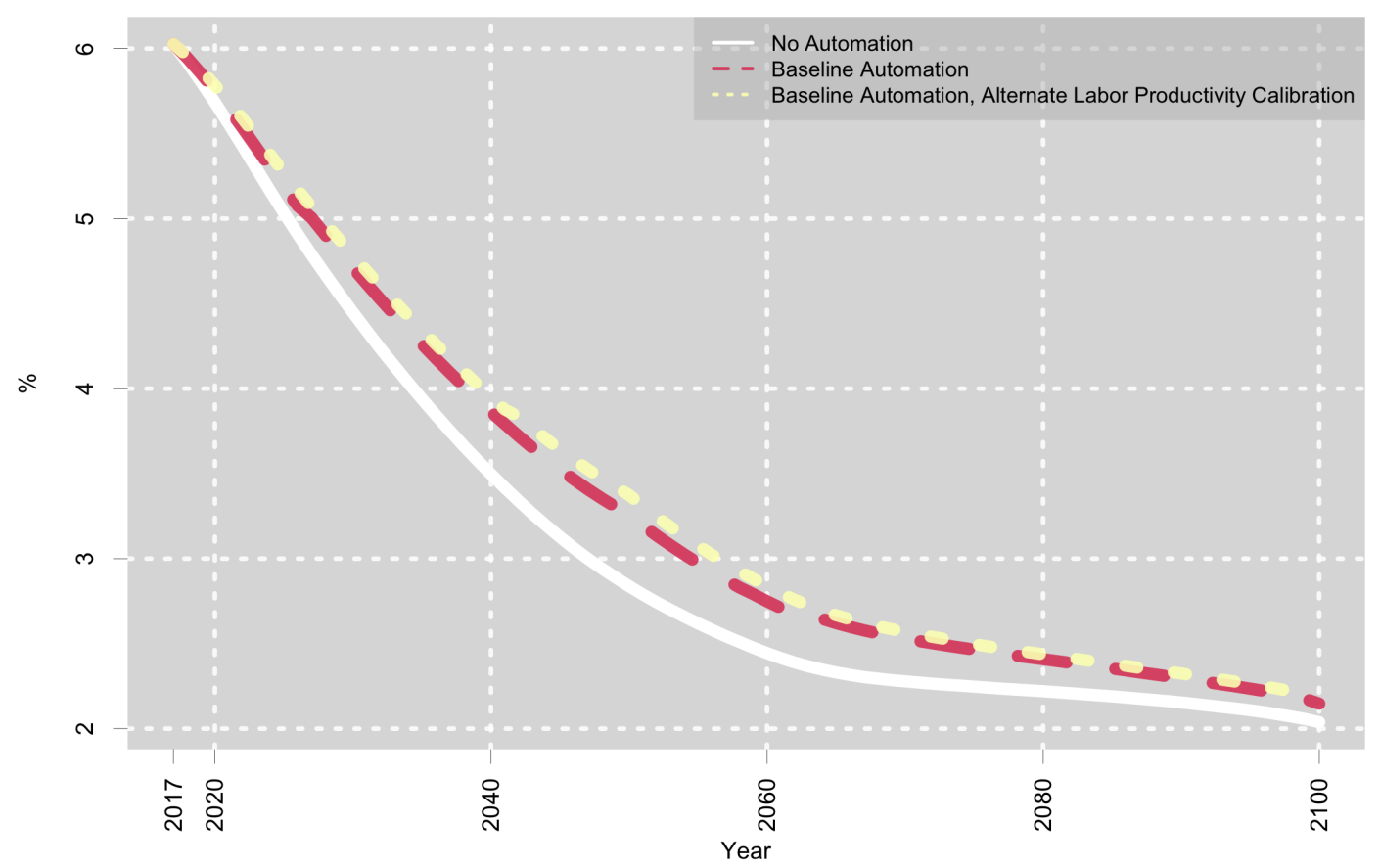

Figure A18: Comparison of Global Post-Corporate Tax Rate of Return
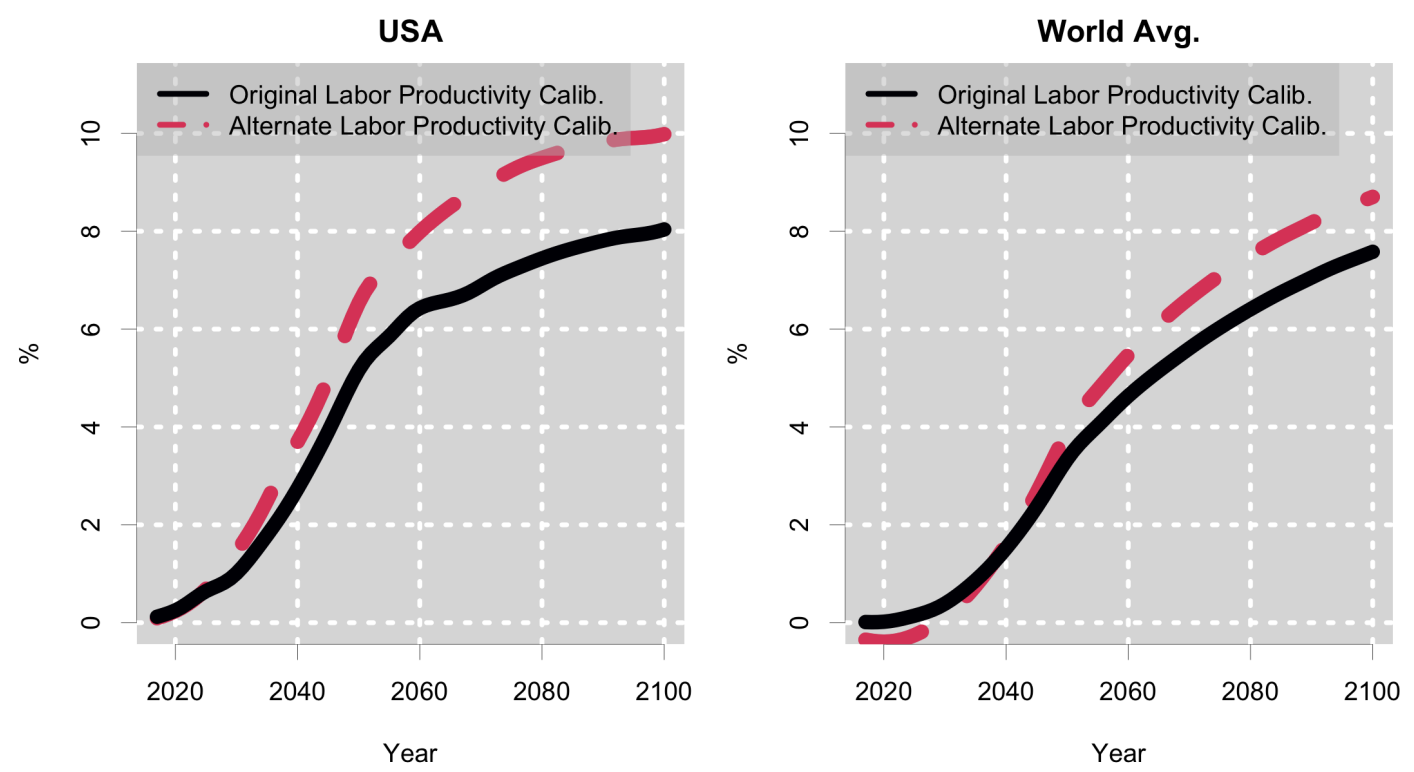

Figure A19: GDP Percent Change in Baseline Relative to ‘No Automation’ Scenario

It is not possible to precisely compare compensating-differential welfare changes across different calibrations of the model. This is because in order to match each region's consumption and labor force participation at different labor factor productivities, the parameters of the agents' utility functions must also be different. Hence, even relative welfare changes - those presented in figure 6 , for example - are denominated in slightly different units. With this caveat in mind, we contrast relative welfare changes from automation with the two calibrations. In regions that choose to automate, the alternate calibration results in a slight increase to workers' welfare relative to the original calibration. In the 
U.S. and relative to no-automation, low-, middle- and high-skilled workers born in 2000 are made 9.8 percent worse, 2.5 percent better, and 18.7 percent better off with baseline automation with the alternative calibration. In contrast, the same cohorts are made, respective, 11 percent worse, 0.8 percent better, and 16.8 percent better off with the original calibration. Other results regarding wage and welfare inequality are also broadly comparable to those of section 4.2. The average global worker alive in 2050 is 0.8 percent worse off, in terms of lifetime utility, and the average worker alive in 2100, is 0.5 percent worse off. ${ }^{58}$

\footnotetext{
${ }^{58}$ This is to be contrasted with 0.9 percent and 1.1 percent, respectively, in the original calibration.
} 